\title{
The effect of adding multiple triangular vortex generators on the leading edge of a wing
}

Francisco Adolfo Pino Romainville

West Virginia University

Follow this and additional works at: https://researchrepository.wvu.edu/etd

\section{Recommended Citation}

Pino Romainville, Francisco Adolfo, "The effect of adding multiple triangular vortex generators on the leading edge of a wing" (2005). Graduate Theses, Dissertations, and Problem Reports. 4185.

https://researchrepository.wvu.edu/etd/4185

This Thesis is protected by copyright and/or related rights. It has been brought to you by the The Research Repository @ WVU with permission from the rights-holder(s). You are free to use this Thesis in any way that is permitted by the copyright and related rights legislation that applies to your use. For other uses you must obtain permission from the rights-holder(s) directly, unless additional rights are indicated by a Creative Commons license in the record and/ or on the work itself. This Thesis has been accepted for inclusion in WVU Graduate Theses, Dissertations, and Problem Reports collection by an authorized administrator of The Research Repository @ WVU. For more information, please contact researchrepository@mail.wvu.edu. 


\title{
THE EFFECT OF ADDING MULTIPLE TRIANGULAR VORTEX GENERATORS ON THE LEADING EDGE OF A WING
}

\author{
Francisco Adolfo Pino Romainville
}
Thesis submitted to the College of Engineering and Mineral Resources at West Virginia University in partial fulfillment of the requirements for the degree of Master of Science in Aerospace Engineering John L. Loth, Ph.D., Chair Wade W. Huebsch, Ph.D. John M. Kuhlman, Ph.D.

Department of Mechanical and Aerospace Engineering Morgantown, West Virginia 2005

Keywords: Wing Stall, Delay Flow Separation, Improving Stall Characteristics, Free Shear Layer, Vortex Generators. 


\author{
ABSTRACT \\ THE EFFECT OF ADDING MULTIPLE TRIANGULAR VORTEX \\ GENERATORS ON THE LEADING EDGE OF A WING
}

\title{
Francisco Adolfo Pino Romainville
}

The goal of this research was to investigate preliminary test data obtained by Professor Robert E. Bond at the University of Tennessee in the year 2001. Dr. Bond added triangular horizontal flat plates (vortex generators) to the leading edge of a wing, to delay flow separation at high angles of attack. The present approach was both experimental and computational. The experimental method was used to determine, with the aid of smoke, the angle of attack at which the wing stalled. For this qualitative method a wing (airfoil NACA 0015) was used. It had a 32 inch span and attached to its leading edge were eight equilateral triangular flat plates measuring three inches on each side. The computational method involved the use of the CFD Fluent software. The results obtained with the experimental method showed that, when the vortex generators had a 1 inch space in between each other, the flow remained attached to 16 degrees, but stalled at 18 degrees. Using different spacings, an increase in stall angle from two to five degrees was observed, as compared to a wing without vortex generators. Increasing the distance between the vortex generators affected the stall angle. The computational method gave trends that were similar to the experimental results. Each wing leading edge mounted triangular vortex generator produced a pair of counter rotating trailing vortices trailing in the direction of $\mathrm{V}_{\infty}$. When these vortices passed over the wing upper surface, they energized the boundary layer, thereby delaying the wing stall. 


\section{ACKNOWLEDGEMENTS}

Primarily, thanks to my parents Jose and Luz who always supported me with their love, exemplarity, and resources and who inspire me for trying to be better each day. Without them, I would have never started this investigation, and I would have surely not completed it.

To my committee: thanks to Dr. John Loth for introducing me to the aerospace world, teaching me how to use many tools in the machine shop, and for all his patience and dedication put into this investigation. Thanks also to Dr. John Kuhlman for inspiring me every class with his exemplarity and dedication, and Dr. Wade Huebsch for all his patience, dedication, and good pieces of advice in the CFD simulation. I am very grateful to work with such outstanding engineers and consequently have formed valuable friendship with them.

Finally, thanks to all these people that directly or indirectly helped me out in different ways: to Dr. Gary Morris, for solving my problems and doubts when I got lost in some aspects of this research; to Dr. Robert Bond, for providing his preliminary test data; to Raquel Alo, for her love, patience, and for the correction of my English; to Julio Noriega, for showing me out how to use Pro-Engineering for my drawing; to Patrick Browning, who helped me construct the smoke generator for the subsonic wind tunnel; to Cliff Judy, who built the supports for the wing; to Gary La Ruta, for conducting the experiment and taking data once; to Raphael Alwin, for supplying pieces of information from the Profili software for the different Reynolds numbers; to Manoharan Thiagarajan teaching some tricks in Microsoft Word; and finally to others, who I did not list, for their support, and encouragement. 


\section{TABLE OF CONTENTS}

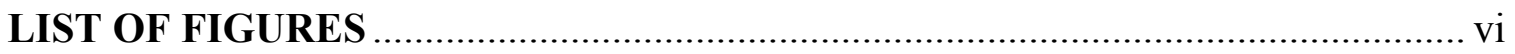

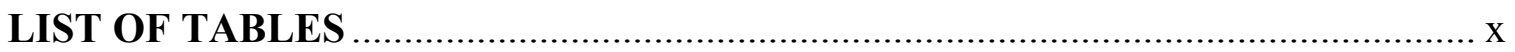

APPENDIX A: TABLES ...................................................................................

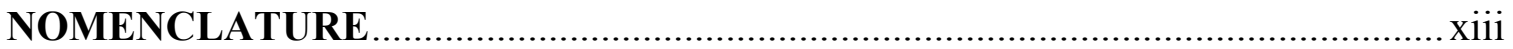

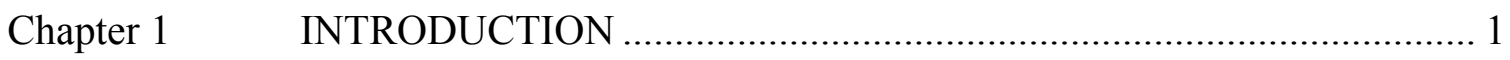

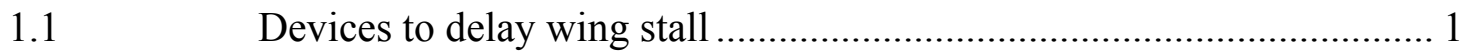

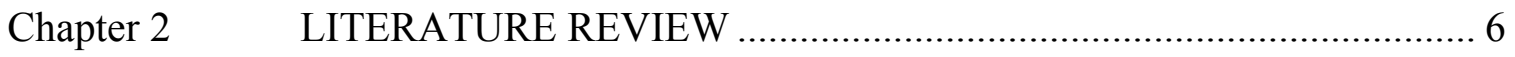

Chapter $3 \quad$ METHODS OF APPROACH.............................................................. 20

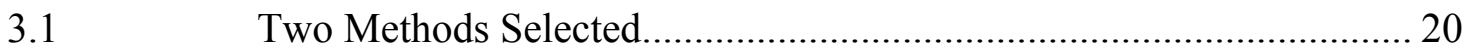

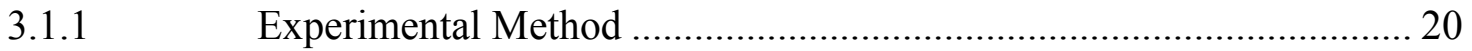

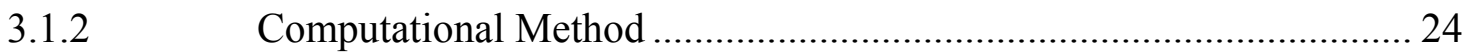

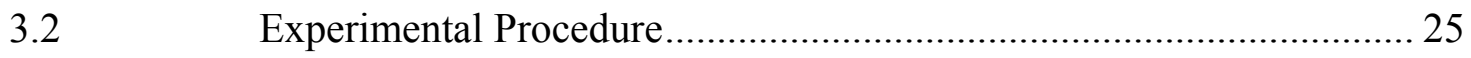

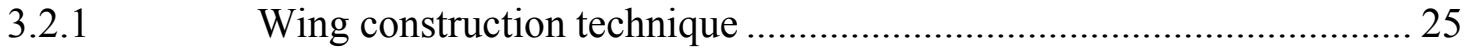

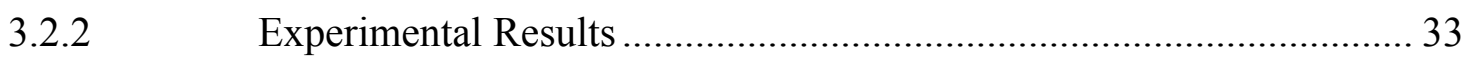

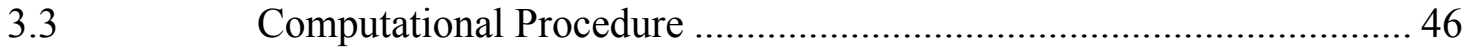

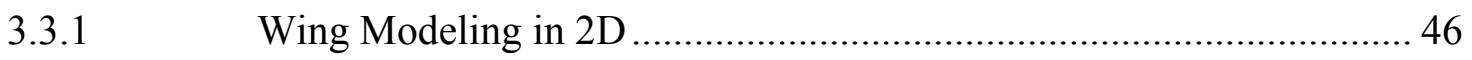

3.3.2 Boundary conditions and mesh design in 2D ..................................... 46

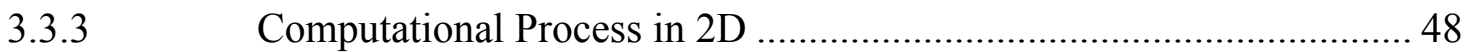

3.3.4 Results with Profili Software ........................................................... 49

3.3.5 Computational 2D Results with Fluent Software: ............................... 51

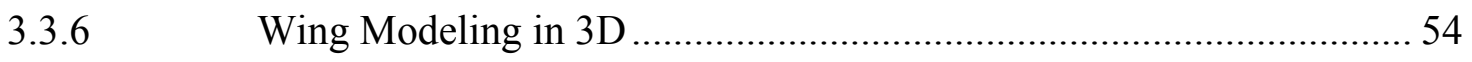


3.3.7 Boundary conditions and mesh design in $3 \mathrm{D}$...............................5 55

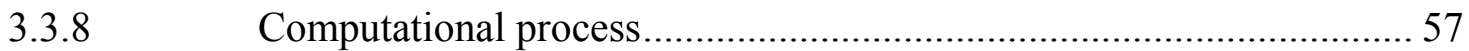

3.3.9 Computational 3D Results with Fluent Software: ........................... 58

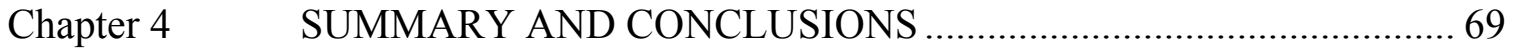

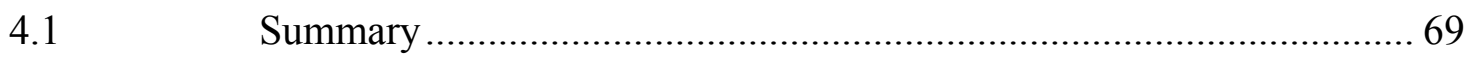

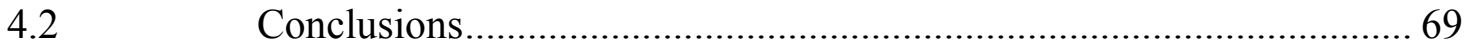

Chapter 5 RECOMENDATIONS ............................................................. 72

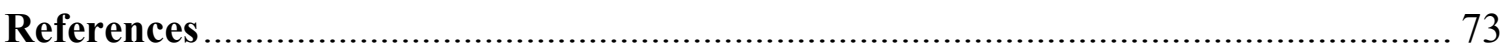




\section{LIST OF FIGURES}

Page

Figure 1-1: Schematic of the subsonic flow field over the top of a triangular vortex generator at high angle of attack (Anderson, 2001) ............................ 2

Figure 1-2: Wing characteristics of Bond's preliminary investigation............................... 3

Figure 1-3: Bond's results for lift coefficient vs. angle of attack with and without (clean) delta flaps type vortex generators.................................................... 4

Figure 1-4: Bond's results for drag coefficient vs. angle of attack with and without (clean) delta flap type vortex generators

Figure 3-1: Single-return wind tunnel (Pope, 1966) ……………………………….... 21

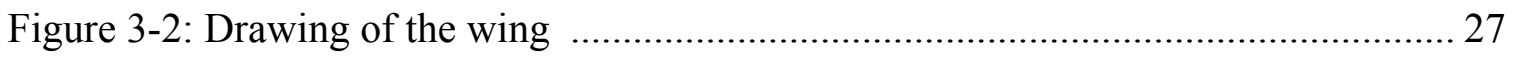

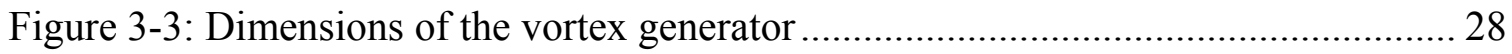

Figure 3-4: Detail of the screw and pipe attached to the wing side................................. 30

Figure 3-5: Acrylic window located on the bottom wall of the test section of the

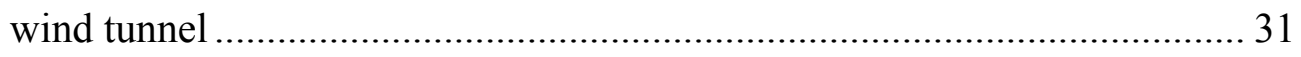

Figure 3-6: Localization of the tufts on the wing ………………................................ 32

Figure 3-7: Lift Coefficient vs. Angle of Attack for 2D NACA 0015 (Miley, 1982)

Figure 3-8: Airflow around the wing close to stall $\left(\alpha=10^{\circ}\right)$ at $\operatorname{Re}=2.5 \times 10^{4}$ 35

Figure 3-9: Post stall airflow around the wing $\left(\alpha=12^{\circ}\right)$ at $\operatorname{Re}=2.5 \times 10^{4}$ 36

Figure 3-10: Airfoil around the wing at increased Reynolds number $\left(\operatorname{Re}=1.5 \times 10^{4}\right)$, delayed stall to about $\alpha=16^{\circ}$ 39 
Figure 3-11: Airflow around wing with vortex generators to delay the stall to $\alpha=18^{\circ}$, at $\operatorname{Re}=1.5 \times 10^{4}$

Figure 3-12: Airflow around the wing at increased Reynolds number $\left(\operatorname{Re}=6 \times 10^{4}\right)$, delayed stall to about $\alpha=16^{\circ}$

Figure 3-13: Airflow around wing with vortex generators to delay stall to $\alpha=18^{\circ}$, at $\operatorname{Re}=6 \times 10^{4}$ 43

Figure 3-14: Airflow around the wing at increased Reynolds number $\left(\operatorname{Re}=9.2 \times 10^{4}\right)$, delayed stall close to about $\alpha=16^{\circ}$ 44

Figure 3-15: Airflow around wing with vortex generators to delay stall to $\alpha=18^{\circ}$, at $\operatorname{Re}=9.2 \times 10^{4}$ 45

Figure 3-16: 2D Fluent boundary layer and mesh generation for airfoil NACA 0015 with up and downstream boundary location at ten chord length distance from the airfoil 47

Figure 3-17: Lift Coefficient vs. Angle of attack obtained from Profili software 50

Figure 3-18: Velocity vectors colored by velocity magnitude $(\mathrm{m} / \mathrm{s})$ for $2 \mathrm{D}$ NACA 0015 airfoil at $12^{\circ}$ angle of attack and $R e=6 \times 10^{4}$ 52

Figure 3-19: Contours of Static Pressure (Pa) for 2D NACA 0015 airfoil at $12^{\circ}$ angle of attack and $R e=6 \times 10^{4}$ 53

Figure 3-20: 2D comparison between computational (CFD and Profili) and experimental results (Miley, 1982) at $\mathrm{Re}=4.8 \times 10^{4}$. 54

Figure 3-21: 3D Fluent boundary layer and mesh generation for airfoil NACA 0015 with vortex generators with up and downstream boundary location at 12.5 chord length distance from the airfoil 56 
Figure 3-22: Development and location of tip vortices on low aspect ratios wings (Hoerner, 1985)

Figure 3-23: CFD Fluent results between a clean wing vs. a wing with 2 vortex generators attached with $\mathrm{AR}=0.7$ at $\mathrm{Re}=6 \times 10^{4}$ 60

Figure 3-24: Velocity vectors colored by velocity magnitude $(\mathrm{m} / \mathrm{s})$ for $3 \mathrm{D}$ simulation with $4 \mathrm{VG}$ at $16^{\circ}$ angle of attack at the symmetry plane for $\operatorname{Re}=6 \times 10^{4}$

Figure 3-25: Velocity vectors colored by velocity magnitude $(\mathrm{m} / \mathrm{s})$ for 3D simulation with $4 \mathrm{VG}$ at $16^{\circ}$ angle of attack and at 0.75 inches off the symmetry plane for $\mathrm{Re}=6 \times 10^{4}$.

Figure 3-26: Velocity vectors colored by velocity magnitude $(\mathrm{m} / \mathrm{s})$ for 3D simulation with $4 \mathrm{VG}$ at $16^{\circ}$ angle of attack at 1.5 inches off the symmetry plane for $\mathrm{Re}=6 \times 10^{4}$ 63

Figure 3-27: Velocity vectors colored by velocity magnitude $(\mathrm{m} / \mathrm{s})$ for 3D simulation with $4 \mathrm{VG}$ at $16^{\circ}$ angle of attack at 2 inches off the symmetry plane for $\mathrm{Re}=6 \times 10^{4}$ 64

Figure 3-28: Contours of Static Pressure (Pa) for 3D simulation with $4 \mathrm{VG}$ at $16^{\circ}$ angle of attack at the symmetry plane for $\mathrm{Re}=6 \times 10^{4}$ 65

Figure 3-29:Contours of Static Pressure $(\mathrm{Pa})$ for $3 \mathrm{D}$ simulation with $4 \mathrm{VG}$ at $16^{\circ}$ angle of attack at 0.75 inches off the symmetry plane for $\mathrm{Re}=6 \times 10^{4}$. 65

Figure 3-30: Contours of Static Pressure $(\mathrm{Pa})$ for $3 \mathrm{D}$ simulation with $4 \mathrm{VG}$ at $16^{\circ}$ angle of attack at 1.5 inches off the symmetry plane for $\mathrm{Re}=6 \times 10^{4}$ 66 
Figure 3-31: Contours of Static Pressure (Pa) for 3D simulation with 4 VG at $16^{\circ}$ angle of attack at 2 inches off the symmetry plane for $\mathrm{Re}=6 \times 10^{4}$ 66

Figure 3-32: Comparison of the results obtained in the CFD simulation for a wing with $\mathrm{AR}=1.53$ at $\mathrm{Re}=6 \times 10^{4}$ 67 


\section{LIST OF TABLES}

Page

Table 2-1: Summary of the main characteristics of the experiments (Solignac et

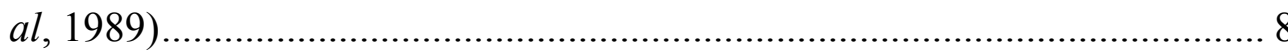

Table 2-2: Model setup in the test sections (Solignac et al, 1989) ................................. 9

Table 3-1: Wing measurements and model geometry dimensions ............................... 29

Table 3-2: Atmospheric conditions for the wing with no vortex generators and with different configurations of the vortex generators at $\operatorname{Re}=2.5 \times 10^{4} \ldots \ldots . .34$

Table 3-3: Recorded data of the wing with no vortex generators attached .................... 35

Table 3-4: Summary of the experimental results of different wing configurations.......... 37

Table 3-5: Atmospheric conditions for experiment with the lowest upstream

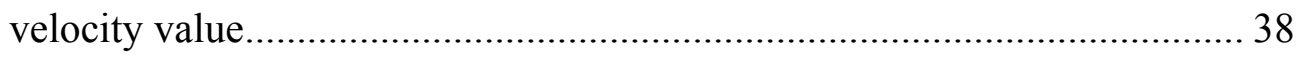

Table 3-6: Recorded data for the lowest freestream velocity value.............................. 38

Table 3-7: Atmospheric conditions for the closest to the average velocity value and the greatest velocity value

Table 3-8: Recorded data for the closest value to the average of the freestream velocity value

Table 3-9: Recorded data for the greatest freestream velocity value............................ 43

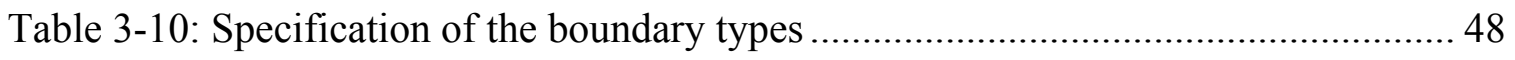

Table 3-11: New wing dimensions for the CFD Fluent simulation.............................. 61 


\section{APPENDIX A: TABLES}

Table A-1: Coordinates used for the construction of the airfoil with 9.5 inches of

chord

Table A-2: 2D Experimental results for the NACA 0015 airfoil at different

Reynolds numbers (Miley, 1982) 78

Table A-3: Computational Profili results for airfoil NACA 0015 with

$\operatorname{Re}=1.2 \times 10^{4}$

Table A-4: Computational Profili results for airfoil NACA 0015 with $\operatorname{Re}=4.8 \times 10^{4}$ 80

Table A-5: Computational Profili results for airfoil NACA 0015 with $\operatorname{Re}=7.4 \times 10^{4}$ 81

Table A-6: 2D CFD Fluent results for the NACA 0015 airfoil at $\mathrm{Re}=4.8 \times 10^{4}$ 82

Table A-7: 2D calculated results for the NACA 0015 airfoil at $\mathrm{Re}=4.8 \times 10^{4}$

Table A-8: 3D CFD Fluent results for a wing with $\mathrm{AR}=0.76$ for the NACA 0015 airfoil

Table A-9: 3D calculated results for a wing with $\mathrm{AR}=0.76$ for the NACA 0015 airfoil 84

Table A-10: 3D CFD Fluent results for a wing with $A R=0.76$ for the NACA 0015 airfoil with two vortex generators attached 84

Table A-11: 3D calculated results for a wing with $\mathrm{AR}=0.76$ for the NACA 0015 airfoil with two vortex generators attached 85

Table A-12: 3D CFD Fluent results for a wing with $A R=1.53$ for the NACA 0015 airfoil 85 
Table A-13: 3D calculated results for a wing with $\mathrm{AR}=1.53$ for the NACA 0015

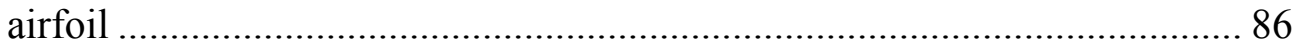




\section{NOMENCLATURE}

Variables

a

A

AR

b

c

$\mathrm{C}_{1}$

$\mathrm{C}_{\mathrm{L}}$

$\mathrm{h}_{\mathrm{T}}$

L

M

P

$\operatorname{Re}$

$\mathrm{Re}_{\text {calc }}$

$\mathrm{Re}_{\text {effec }}$

$\mathrm{q}_{\infty}$

S

$\mathrm{T}$

V

$\mathrm{V}_{\text {true }}$
Definition

Speed sound

Area

Aspect Ratio

Wing span

Wing chord

Lift coefficient in 2D

Lift coefficient in 3D

Gage Pressure

Lift

Mach number

Absolute Pressure

Reynolds number

Calculated Reynolds number

Effective Reynolds number

Dynamic pressure

Wing area

Temperature

Velocity

True airspeed in the tunnel 


\begin{tabular}{ll} 
Greek & Angle of attack \\
$\alpha$ & Stalled angle of attack \\
$\alpha_{\text {stall }}$ & Ratio of density and sea level density \\
$\sigma$ & Sweep angle \\
$\Lambda$ & Tip vortex circulation \\
$\Gamma$ & Density \\
$\rho$ & Air sea-level density \\
$\rho_{\mathrm{SL}}$ & Ratio of Specific Rates \\
$\gamma$ & Viscosity \\
$\mu$ & Air sea-level viscosity \\
$\mu_{\mathrm{SL}}$ & Vorticity \\
$\omega$ & Maximum Vorticity \\
$\omega_{\max }$ & Boundary Layer Thickness \\
\hline$\delta$ &
\end{tabular}




\section{Chapter 1 INTRODUCTION}

\subsection{Devices to delay wing stall}

Ever since men succeeded in flying, they have tried to improve wing performance. Since wing performance determines the obtainable glide angle and the fuel efficiency of motorized flight, it deserves the most attention. Other components, such as engines, fuselage, etc, are also required to make flying faster, higher, safer, cheaper, and more reliable. Consequently, many investigators continue to research on improving wing characteristics. Some of these investigations concentrated on devices to delay the stall during landing, take off and in icy conditions. According to Watts and Fish (2002), such devices can be classified in four general categories: slats, drooped leading edges, strakes, and vortex generators. The first type, slats, is either fixed or deployable free standing airfoils positioned ahead of the leading edge. They take over some of the wing load, thereby reducing the suction peak on the wing itself. Such slats significantly increase wing drag, manufacturing, and maintenance costs. Drooped leading edges, such as the Kruger flaps, are widely used on most commercial jet aircrafts, and are very effective in increasing the wing leading edge radius, resulting in an increased stall angle and maximum lift coefficient. Strakes are found on fighter planes operating at very high angles of attack. Vortex generators are small protrusions that are generally placed upstream of likely areas of flow separation. They are mainly used to eliminate flow separation problems on engines cowlings, wing flaps, and ailerons.

In this research vortex generators in the form of equilateral triangular flat plates have been mounted on the wing leading edge. Their purpose is to increase wing stall 
angle by shedding multiple leading edge vortices over the wing upper surface. The vorticity shed by these leading edge devices energizes the wing boundary layer to help maintain the attached flow. The leading edge vortices shed by such triangular flat plates attached to the wing are shown schematically in Figure 1-1.

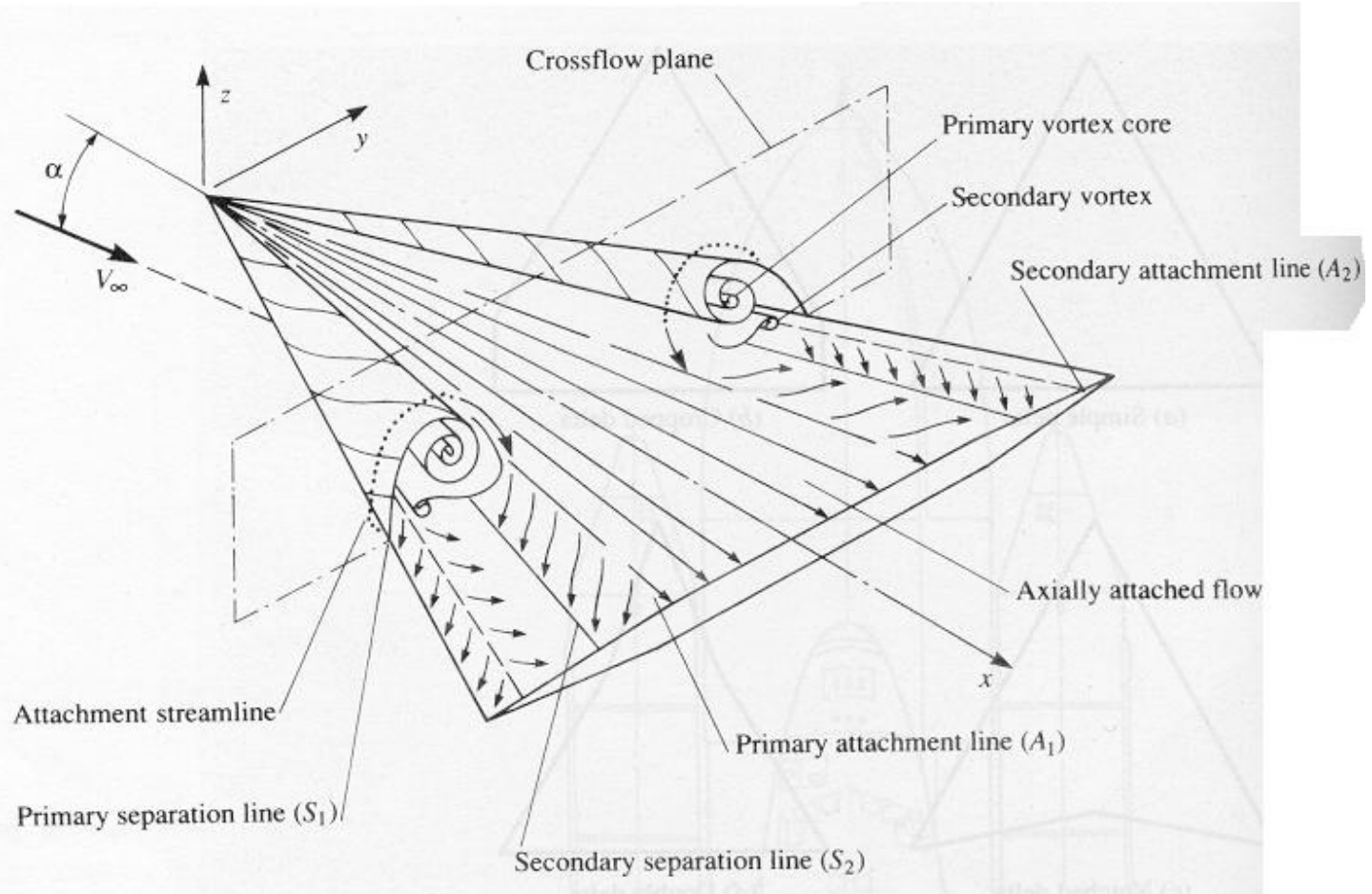

Figure 1-1: Schematic of the subsonic flow field over the top of a triangular vortex generator at high angle of attack (Anderson, 2001)

Multiple triangular horizontal flat plates on leading edge can delay wing stall. If also electrically heated along their leading edge they can double up as de-icers.

In 2001, Professor Robert E. Bond at the University of Tennessee performed a flow visualization wind tunnel test using a small span wing, with multiple triangular surfaces mounted on its leading edge. This 10 inches span wing had attached equilateral 
triangular vortex generators with $20 \%$ of the chord size, each the size of one eighth of the wing span as shown in Figure 1-2. They were bolted to the wing lower leading edge surface. As the angle of attack increased, each triangle shed stronger leading edge vortices. When the wing is positioned at a positive angle of attack in the wind tunnel, the effectiveness of these five leading edge vortex generators becomes evident.

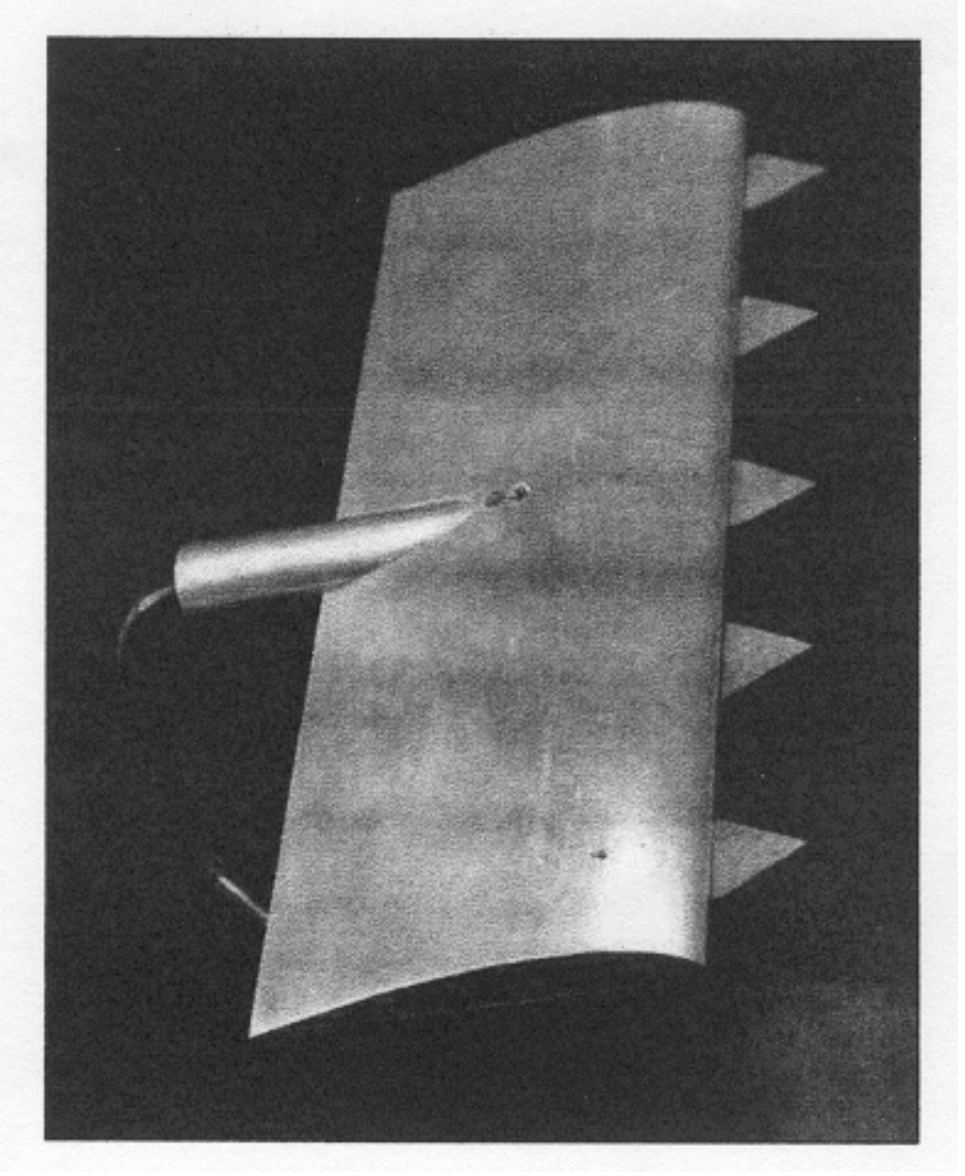

Figure 1-2: Wing characteristics of Bond's preliminary investigation

The preliminary results obtained in his experiment are shown below. Figure 1-3 shows a comparison between the results obtained with and without the vortex generators 
attached. Dr. Bond observed a delay in the stall angle without a significant drop in lift coefficient, from 16 to 30 degrees.

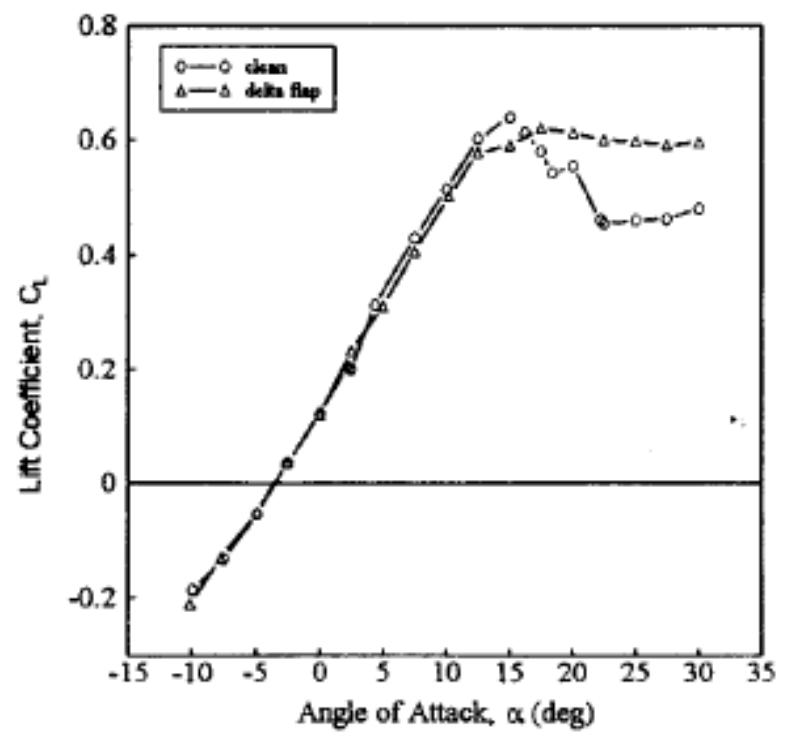

Figure 1-3: Bond's results for lift coefficient vs. angle of attack with and without (clean) delta flaps type vortex generators.

Likewise, figure 1-4 shows a comparison between the results obtained with and without delta flap vortex generators for the drag coefficient vs. the angle of attack. The drag coefficient increases somewhat when the delta flaps have been added to the leading edge. 


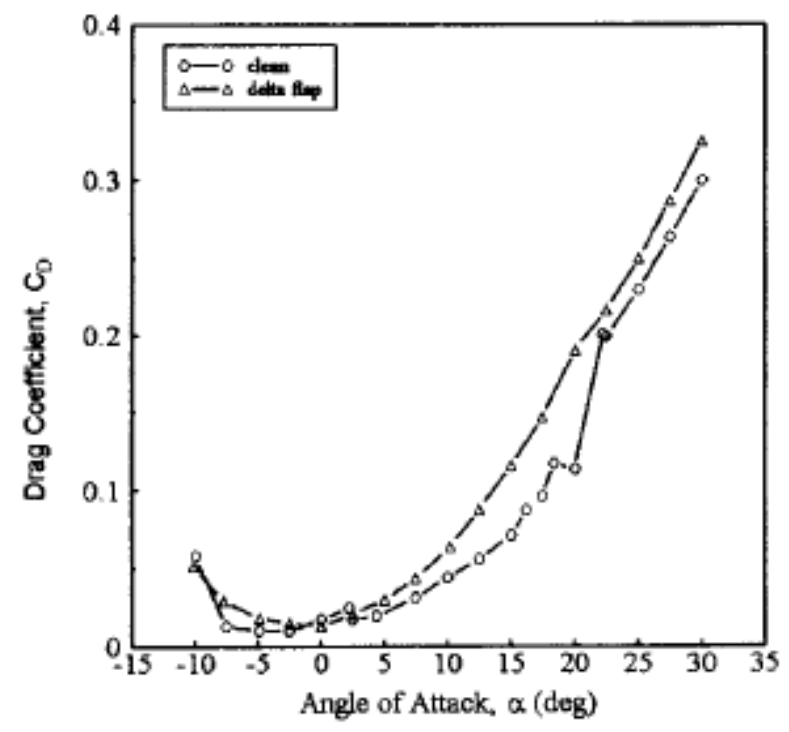

Figure 1-4: Bond's results for drag coefficient vs. angle of attack with and without (clean) delta flap type vortex generators.

Encouraged by Bond's results, the objective of this research is to repeat such tests with a much larger model using a NACA 0015 airfoil, and to compare the CFD predicted stall limits with the observed wind tunnel experimental results. 


\section{Chapter 2 LITERATURE REVIEW}

During the past century, researchers have attempted to improve wing stall characteristics by delaying both leading edge and trailing edge flow separation. This review is limited to a description of vortex breakdown (disorganization of vortex) that occurs on delta wings.

Gursul (2004) described recent developments in delta wing aerodynamics. According to studies described by this author, for slender delta wings $\left(\Lambda \geq 65^{\circ}\right)$, as the separated shear layer rolls up, a very strong axial flow is developed in the core of the leading edge vortex. The maximum speed in the core of the leading edge can be four or five times greater than the free stream velocity and the time-average axial velocity is axisymmetric. Over the delta wing, the separated shear layer rolls up forming vortical structures, and small secondary vortices are formed around the primary vortex. Near the axis of the time-averaged vortex, the maximum swirl velocity is reached; depending on the angle of attack, such velocity can exceed the free stream velocity. The swirl level and the external pressure gradient outside the vortex core determine whether the vortex will breakdown, as well as the location of such breakdown. For the leading-edge vortices, the swirl level and the external pressure gradient depend on characteristics of the wing geometry, such as the incidence and the sweep angle. The vortices of slender delta wings (as opposed to nonslender delta wings, $\Lambda \leq 55^{\circ}$ ) are formed close to the surface of the wing. As a consequence, the vortex-boundary layer is very important at low Reynolds numbers; that is, the Reynolds number has a crucial effect on the structure of the vortical flows. Increases in Reynolds numbers produce a delay of the breakdown of the leading edge vortex, and inboard vortices are formed at low Reynolds numbers. Furthermore, 
because of the splitting of the primary vortex, dual vortex structures (secondary vortices) are observed, and the vortex breakdown decreases the axial velocity. Nevertheless, a similarity between nonslender and slender delta wings is found at a relatively high angle of attack $\left(\alpha=15^{\circ}\right)$ : in both cases, the breakdown is not abrupt. The slender wing vortex structure breaks down and the conical region of stagnant flow can be visualized at an angle of attack of $20^{\circ}$. These vortex interactions are generic for both wings. The most dominant sources of buffeting are vortex breakdown and shedding, and shear reattachment; however, unsteady flow phenomena might also yield buffeting of wings and fins. Finally, in the experiments, a lift enhancement was generated by the use of a flexible delta wing.

Pagan and Solignac (1986) conducted an experimental study of the breakdown of a vortex generated on delta wings. To measure such a vortex, the authors used laser sheet visualizations, multi-holed probes, and 3D laser Doppler velocimetry. The experiment was conducted in a wind tunnel with a test section of one meter of diameter, and the wing had $75^{\circ}$ of sweep angle, and $560 \mathrm{~mm}$ of chord. The velocity recorded was $14.5 \mathrm{~m} / \mathrm{s}$. The results showed that the adverse pressure gradient placed in the stagnation point on the axis caused the vortex breakdown at an angle of attack of $19.3^{\circ}$. Therefore, the velocity of the rotational components decreased as a result of the breakdown. Moreover, large fluctuations were recorded at the starting point of the recirculation bubble. In this region, the variance for the fluctuating velocities was very high as a consequence of largeamplitude and the low-frequency longitudinal oscillations.

Solignac, Pagan, and Molton (1989) conducted an experimental study in order to investigate the basic properties of the organization of the vortex for an incompressible 
flow over the upper surface of the delta wing with $75^{\circ}$ sweep angle, as well as to correlate reference data to the predictions of numerical codes. To generate results at different Reynolds numbers, three wind tunnels were used. A summary of the main characteristics of the experiments are presented in table 2-1.

Table 2-1: Summary of the main characteristics of the experiments (Solignac et al, 1989)

\begin{tabular}{|c|c|c|c|c|c|c|c|}
\hline \multirow{2}{*}{$\begin{array}{l}\text { Wind } \\
\text { tunnel }\end{array}$} & \multirow{2}{*}{ Chord (m) } & \multirow{2}{*}{$\mathrm{U}_{\mathrm{o}}(\mathrm{m} / \mathrm{s})$} & \multirow{2}{*}{$\operatorname{Re}_{c} / 10^{6}$} & \multicolumn{2}{|c|}{ Wall measurements } & \multicolumn{2}{|c|}{ Field measurements } \\
\hline & & & & Pressure & Visual & Probe & LDA \\
\hline S2L & 0.5 & 20 & 0.7 & $\mathrm{x}$ & $\mathrm{x}$ & $\mathrm{x}$ & 3-D \\
\hline $\mathrm{F} 2$ & 1.45 & 24 & 2.3 & $\mathrm{x}$ & $\mathrm{x}$ & - & $2-\mathrm{D}$ \\
\hline F2 & 1.45 & 40 & 3.9 & $\mathrm{x}$ & $\mathrm{x}$ & - & $2-\mathrm{D}$ \\
\hline F1 & 1.45 & 20 & 2.5 & $\mathrm{x}$ & - & $\mathrm{x}$ & - \\
\hline F1 & 1.45 & 40 & 4.1 and $8.3(*)$ & $\mathrm{x}$ & - & $\mathrm{x}$ & - \\
\hline F1 & 1.45 & 80 & & $\mathrm{x}$ & - & $\mathrm{x}$ & - \\
\hline
\end{tabular}

(*) Reynolds number obtained with a stagnation pressure of $2 \mathrm{e} 5 \mathrm{~Pa}$

Wind tunnel dimensions for the different experiments performed by Solignac et al (1989) and the instrument used to collect data are shown in Table 2-2. 


\section{Table 2-2: Model setup in the test sections (Solignac et al, 1989)}

\begin{tabular}{|c|c|c|c|}
\hline Wind & $\begin{array}{c}\text { Test } \\
\text { section } \\
\text { tunnel }\end{array}$ & $\begin{array}{c}\text { Angle of } \\
\text { attack }\end{array}$ & Probes \\
& $(\mathrm{m})$ & (degrees) & \\
\hline F1 & $4.5 \times 3.5$ & 20 & five-hole probe \\
F2 & $1.4 \times 1.8$ & 20 & - \\
S2L Ch & D=1 & 20 & five-hole probe \\
\hline
\end{tabular}

The results showed similar data obtained in wind tunnels F1 and F2. The most common similarity in the experimental results was a conical shape of the main vortex, starting at the apex and the effect of pressure distribution on the surface of the model. The structure of the flow near to the leading edge depended on the nature of the boundary layer (laminar or turbulent). Comparing two types of flow, secondary separation occupied more space when laminar than when the flow was turbulent. In turbulent flow, the separation line and the secondary separation both were located happened further away from the leading edge. The wing dimensions were an important factor effecting the pressure distributions in both tunnels (F1 and F2).

Ol and Gharib (2003) investigated the leading-edge vortex structure of nonslender delta wings at low Reynolds numbers. The experiment was conducted for a swept delta wing focusing mainly in the apex region. The data was obtained using a version of stereoscopic digital particle imaging velocimetry in a water tunnel of $45 \times 60 \mathrm{~cm}$ of width and height, respectively. Flow visualization was also another method used to corroborate the results obtained. Moreover, low angles of attack ranging from 5 to $20 \mathrm{deg}$ were used 
in the experiment and the delta wing models had sweep angles of 50 and $65 \mathrm{deg}$. This investigation was conducted at two very low Reynolds numbers of $6 \times 10^{3}$ and $15 \times 10^{3}$. The results showed weak secondary leading-edge vortices that allowed a greater degree of stagnant flow outboard at a higher angle of attack in the primary leading-edge vortices. Otherwise, the results obtained for delta wing with sweep angle of 65 deg replicated the results found for slender delta wings. For a delta wing with sweep angle of $50 \mathrm{deg}$, unexpected strong primarily leading-edge vortices were observed at low angles of attack with a conical velocity field. On the other hand, the vortex breakdown showed an upward sequence of extensive regions of airstream undulation at higher angles of attack. Additionally, in the breakdown region in crossflow planes, the leading-edge shear-layer rollup was observed. However, the paired vortical structures generated by the delta wing were increased inside the shear layer as a function of the angle of attack. Therefore, the flow had the tendency to remain the same or even turn backward to the streamwise direction at higher angles of attack.

Hasegawa, Yoshikawa, and Matsuuchi (2005) studied the effect of vortex generator jets with different aspect ratios on boundary layer control. An adaptive control allowed changing the jet speed to different flow situations for the vortex generator jets. The wing model used had three different types of rectangular orifices with different aspect ratios ( $\mathrm{AR}=0.16,1$ (square), and 6.4). In the first wing model, the rectangle orifice was located with the long side of the orifice in the streamwise direction, and the rectangle orifice with $\mathrm{AR}=6.4$ was placed with the long side turned to the spanwise direction. The vortices became stronger for the latter case, mixing the boundary layer and making the control separation effective. 
Kerho, Hutcherson, Blackwelder, and Liebeck (1993) studied the effect of various forms of vortex generators on the laminar separation bubbles of two-dimensional low Reynolds number flow for a Liebeck LA2573A airfoil. Initially, the investigators tried to reduce or eliminate the separation bubble using vortex generators; therefore, reducing the drag. While the separation bubble had little effect on the lift, it significantly increased the airfoil drag. The drag effects of the vortex generators were caused by using different generator sizes and spacings. Among the generator types used were wishbone vortex generators and a ramped cone generators. The vortex generators were small enough to fit completely within the boundary layer. The experiment was carried out using these different generator configurations at angles of attack less than the stall angle with different Reynolds numbers (range from $2 \times 10^{5}$ to $6 \times 10^{5}$ ). The results showed that for the lower Reynolds numbers, the vortex generators decreased the airfoil drag. The airfoil drag decreased $38 \%$ at a lift coefficient $C_{1}=0.572$ with the submerged vortex generators at Reynolds number of $2.35 \times 10^{5}$.

Littell and Eaton (1991) investigated the unsteady flowfield behind a vortex generator rapidly pitched to angle of attack. The experiment was conducted in an open circuit design wind tunnel of $61 \times 13 \mathrm{~cm}$ of width and height respectively. The vortex generator was located at $54 \mathrm{~cm}$ of the contraction exit and was at an angle of attack of 22 deg. This vortex generator consisted in a half-delta wing with dimensions of $10 \mathrm{~cm}$ chord and $4 \mathrm{~cm}$ height. Since the half-delta vortex generator was partially in the turbulent boundary layer (angle of attack ranging from 0 to $18 \mathrm{deg}$ ), so a cross-wire anemometer was located behind the wing in four stations in order to capture the data. The reduced frequency was 0.25 and the airspeed in the tunnel was $12.5 \mathrm{~m} / \mathrm{s}$. In the experiment, 
circulation, peak vorticity, and vortex core location of the flow were calculated and studied as a function of time for the formation and relaxation of the vortex. The results showed some unsteadiness mainly attributed to the effective angle of attack of the moving vortex generator and the fluid motion shed by the leading edge of the wing.

Wang and Zaman (2002) investigated the aerodynamics of a jet in the vortex wake of a wing. The experiment was carried out in a suction-type low-speed wind tunnel of $51 \mathrm{~cm}$ of width and $76 \mathrm{~cm}$ of height. The freestream air speed in the tunnel was 6.1 $\mathrm{m} / \mathrm{s}$. The wing model had sweepback of $75 \mathrm{deg}$, a span of $127 \mathrm{~mm}$ at the leading edge, and a thickness of $1.6 \mathrm{~mm}$. Vortex-wake strength and exit velocity data were taken using the hot-wire anemometry for the three dimensions. The results showed that by changing the jet-to-freestream velocity ratio and vortex-wake strength, the vortices shed from airframe components behaved differently from an isolated coflowing jet. The interaction between the jet and the wing vortices generated secondary vortical structures especially during takeoff, landing, and maneuvering of the vehicle.

Watts and Fish (2002) studied a scalloped wing leading edge. This new wing with the scalloped leading edge apparatus was compared then to similar wings with straight leading edges to determine the increase in the efficiency of the lift over drag ratio. The apparatus was composed by many protrusions spaced laterally along the leading edge facing the upstream direction. Also, the protrusions connected smoothly to the wing. The advantage of this feature was that the protrusions generated lateral air flow along the leading edge of the streamlined body. Therefore, the protrusions limited the creation of stagnation points of high static pressure and introduced vortices which were consistent with the stream on the leading edge. The tip vortex strength and the related induced drag 
were also lowered. Additionally, the lift was increased and the drag was reduced at angles of attack up to $10^{\circ}$. However, at angles of attack close to $0^{\circ}$ the lift showed no increase and no drag penalty. In general, this invention proved to have an equal or higher lift over drag ratio, and the wing performance was not modified. The flow separation was delayed to higher angles of attack, so the scalloped wing improved wing characteristics.

Bragg and Gregorek (1987) investigated airfoil performance with vortex generators. Using the canard airfoil from the Voyager aircraft, the test was conducted in a subsonic wind tunnel at speed of $70 \mathrm{mph}$ and standard atmospheric conditions. This highly optimized laminar flow section generated good clean airfoil performance; however, problems were encountered in lift and drag ratio concerning early boundarylayer transitions. Usually the canard airfoils contaminated the leading edge producing losses of the overall lift in airplanes. Therefore, vortex generators were used to prevent or delay flow separation suffering small drag penalties and incrementing the lift. Deltashaped vortex generators were designed and tested in order to improve the tripped (5\% chord location) airfoil performance and to produce a clean airfoil effect. The experiment was carried out using pressure taps along the wing and unfinished portions of the airfoil which were not sanded (rough) to simulate the rain and insect debris on the airfoil. This created a turbulent boundary-layer region in which a drag rise was observed and evaluated. Vortex generators also improved the performance of the airfoil under these conditions.

To examine the effectiveness of a wing leading-edge vortex flap, DiCarlo, Brown, and Hallissy (1992) used a modified F-106B research airplane. Specifically, the investigators established a database using their invention to ascertain the validity of the 
analysis methods and designs regarding the vortical flow-control concept. The experiment included the refinements of the design codes for vortex flaps, entries to aid verifying design codes, and determining basic characteristics of aerodynamics. The design and fabrication of the flaps, the structural modifications to the wing tip and leading edges for the aircraft, the development and installation of the instrumentation system in the aircraft (wing and flap surface pressure measurements), the ground-based simulation assess flying qualities, and the flight testing determined the aerodynamic characteristics. It was possible to deflect the vortex flap between $20^{\circ}$ to $50^{\circ}$, with increments of $10^{\circ}$. Repetitive testings of variations of the angle of attack were conducted, which allowed correlating the results for the flow field. A range of Mach numbers from 0.6 and 0.9 were used in the flight testing, emphasizing transonic test conditions to be applied to future high-speed civil transportation aircraft.

Szumowsky and Wojciechowski (2005) used vortex generators to control internal supersonic flow separation in a transonic wind tunnel, using an asymmetric twodimensional convergent-divergent channel with a planar surface at one side and a bump having a cylindrical contour with a diameter of $500 \mathrm{~mm}$. To change the boundary layer in the divergent section, obstacles (V-shaped half-cylinders) and swirling jets were used. The results indicated delay of the flow separation for a turbulent flow close to the wall, as a function of the Laval nozzle. Furthermore, the obstacles produced a shock wave and the next expansion waves formed wavy lines in the spanwise direction. Because of the changes of the flow, the secondary flow appeared downstream from the obstacles in the plane normal to the wall. The shock-expansion waves, which were wavy in design, were injected by the flowing jets. In this specific case, the secondary flow in the spanwise 
direction produced the stationary vortices. As opposed to the obstacle generator, the swirling jets-type generator did not increase the drag on the wall. Consequently, manipulations on the strength of the jets controlled the delay of the flow separation only to some degree.

To study the effects of fin and jet vortex generators on the crossflow, Wetzel and Simpson (1998) used a subsonic, continuous, closed-return wind tunnel with an interchangeable test section of $1.8 \times 1.8 \mathrm{~m}$ square. The model, which was similar to a submarine body with $229 \mathrm{~cm}$ long and $21 \mathrm{~cm}$ of maximum diameter, was made with fiberglass skin mated to an aluminum skeleton. Half of the vortex generators used were fins and jets were added around the model, at different configurations. In order to improve the turning performance, the vortex generators were placed on the top and bottom centerline of the body from bow to stern; such vortex generators were made of an aluminum sheet, and were $25.4 \mathrm{~mm}$ long, $12.7 \mathrm{~mm}$ high, and $1.6 \mathrm{~mm}$ thick. Changing the crossflow separation and the resultant hydrodynamic forces altered the turning performance. Velocities of 30-60 m/s and sideslip angles of 0-15 deg were used in the experiment. Visualization of the behavior of the flow was accomplished by the use of oilflow; for the diagnostics, the investigators used the force and moment measures. The results indicated that while jets avoided flow separation until 30 deg, fins delayed such separation until 37 deg; i.e., fins were more effective than jets in delaying the flow separation. Additionally, the importance of the exact location of the vortex generators near to the bow was indicated by the oil flows. Also, the low-aspect ratio appendage of the vortex generators was of major importance as regards the near-body fluid dynamics. 
Zaman and Foss (1996) studied the effects of vortex generators on a jet in a cross flow in an open-circuit induction type low-speed wind tunnel with a test section of $76 \mathrm{x}$ $51 \mathrm{~cm}$. To produce the vortex generators effect, the investigators used tabs to study their effect on the penetration and spreading of a jet. The results indicated that, on the one hand, tabs located on the leeward side had negligible effects. Additionally, substantially low pressures on this side were revealed by the static pressure measures. As a result of that, a "pressure hill" on the side of the tap in the streamwise vorticity of the flow field was not produced enough in magnitude. On the other hand, tabs located on the windward side had important effects on the flow field. Specifically, the bound vortex pair and the vorticity were opposite; consequently, the bound vortex pair was weak and the jet penetration was diminished.

To study the separation control on low-pressure turbine airfoils, Volino (2003) used synthetic vortex generator jets. Control of the boundary layer separation on the lowpressure turbine airfoil was effectively accomplished by the use of such oscillating jets, when low Reynolds numbers were used $\left(\operatorname{Re}=2.5 \times 10^{4}\right)$. Next, passive flow control was reduced, and the separation bubble was eliminated. To promote momentum transport and to prevent flow separation, Volino used turbulent mixing and increased the fluid momentum from the vortex generator jets. Such jets produced disturbances, which were related to the turbulent spot or a wake induced turbulent strip. This disturbance did not induce the reattachment immediately appearing initially in the outer part of the boundary layer. Next, reattachment happened as a result of the disturbance spreading near to the wall region. 
Wendt (2004) conducted a parametric study of vortices shed from airfoil vortex generators. The goal was to determine, using an Internal Fluid Mechanics Facility, the dependence of initial vortex circulation and the peak vorticity on elements of airfoil geometry (angle of attack, chord length, span, and boundary layer thickness) and impinging-flow conditions. The test section of the subsonic facility was a straight circular pipe measuring $20.4 \mathrm{~cm}$ in diameter, and the vortex generators were symmetric airfoils of cross section NACA 0012, mounted on the surface of the straight pipe. A seven-hole probe one chord length downstream of the airfoil trailing-edge location determined the circulation and the peak-vorticity. The results showed that the tip-vortex circulation $(\Gamma)$ was proportional to Mach number, angle of attack, and the ratio of airfoil span over boundary-layer thickness at vortex-generator location $(\mathrm{h} / \delta)$. When these parameters were kept constant and the aspect ratio was varied, the peak streamwise vorticity $\left(\omega_{\max }\right)$ was also proportional to the Mach number, to the angle of attack, and to the ratio $h / \delta$. On the other hand, increments of the peak streamwise vorticity were observed every time aspect ratio increased before falling off at higher values. It was concluded that Prandtl's relationship between finite airfoil circulation and airfoil geometry may be an accurate method to model the tip-vortex circulation expression. That is, it would be possible to model the behavior of the peak vorticity from a conservation relationship that equates the moment at the airfoil tip to the rate of angular momentum production of the shed vortex (Lamb vortex).

Jirasek (2004) investigated a new vortex generator model and its applications to flow control, using a model denoted JBAY which consists in an efficient method for simulating CFD. The JBAY model was based on the lifting force theory of Bender, 
Anderson, and Yagle (1999). Jirasek's procedure, however, included a new technique to define the model control points and thus simplify its use, improve performance, and increase the accuracy. The investigation consisted of experimental and computaional part. The experimental part was carried out in different scenarios: a vortex generator on a flat plate and two flow control cases ("S duct" air intake and a high lift wing configurations). In the computational part, the Edge CFD code consisted of a finite volume Navier-Stokes solver and used unstructured meshes. The model was configured for the two equation k- $\omega$ model combined with the Wallin \& Johansson EARSM model with compressible corrections. Since all cases were stable, no under-relaxation was necessary. The results in the first scenario indicated that a single vortex generator of a flat plate captured the induced vorticity. The vortex generator was $7 \mathrm{~mm}$ high and $49 \mathrm{~mm}$ long, and it was mounted where the boundary layer was $45 \mathrm{~mm}$ thick. The angle of attack and the flow speed measured $23^{\circ}$ and $34 \mathrm{~m} / \mathrm{s}$, respectively. In the second case, using RAE M2129 Sduct, the goal was to find out if the extent of the model was independent of the value of the vortex model constant $\left(\mathrm{C}_{\mathrm{VG}}\right)$ and demonstrated the effectiveness of the vortex generator model for the study of vortex generator installation. In the third case, the goal of this scenario was to reduce flap chord length and simultaneously increase the main airfoil chord length, keeping the same lift. Then, a multi-element high-lift airfoil with vortex generators on the flap looked for the validation of the experimental data. In summary, the results showed excellent agreement with the experimental data and very good accuracy. The computational results depended on the grid analysis made previously in which only one model of the constant $\mathrm{C}_{\mathrm{VG}}$ was used and showed that the vortex generators arrays worked for internal and external flows. 
In summary, the devices described (as well as combinations of them) have been studied for more than a century. Thus, it may be concluded that the control of the flow has been an issue to which great importance has been given. The goal of the present investigation is to contribute to that research. Specifically, vortex generators were used as an alternative way to delay the flow separation, and the distance between such vortices that would be best in terms of delaying the flow separation was investigated. 


\section{Chapter 3 METHODS OF APPROACH}

\subsection{Two Methods Selected}

The preferred experimental method used to calculate section the lift coefficient generated involves using pressure taps along the wing chord. Since the wing varied in configuration in the spanwise direction, determining the wing lift coefficient with pressure taps would require pressure taps in both chordwise and spanwise direction, an impossible task. Therefore, in the present study only a smoke generator was used to visualize the onset of flow field separation on the wind tunnel model. A second method was needed to correlate the flow visualization performance of the wing. Thus a computational method was selected using Fluent CFD software.

\subsubsection{Experimental Method}

The behavior of the airflow on a wing spanning between the upper and lower wall of a wind tunnel was observed at different angles of attack, and at different Reynolds numbers. This method permitted determination of the angle of attack which produces visual wing stall. 


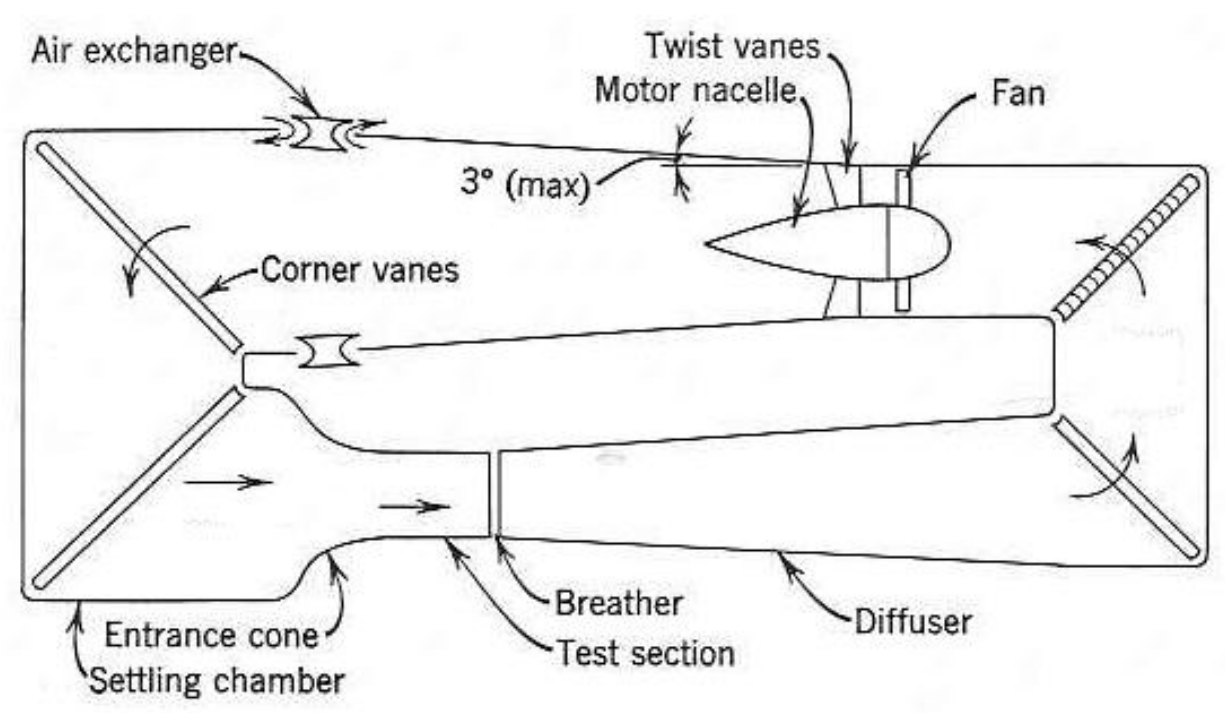

Figure 3-1: Single-return wind tunnel (Pope, 1966)

The wind tunnel used was of the single-return (Figure 3-1) type. At this point, it was necessary to determine the correction factor of the wind tunnel so that the calculations could be performed as accurately as possible. The test section was required to allow the wing, with its required characteristics, to fit in the wind tunnel.

Once measured the test section, it allowed knowing the maximum wingspan, thus the chord size was the $10 \%$ of the wingspan. Therefore, the thickness distributions for the NACA four-digit sections were calculated using the following equation given by Abbott and Von Doenhoff (1959):

$$
\pm y_{t}=\frac{t}{0.20}\left(0.296990 \sqrt{x}-0.12600 x-0.35160 x^{2}+0.28430 x^{3}-0.10150 x^{4}\right),
$$

where $t$ is the maximum thickness expressed as a fraction of the chord. Then, the leading edge radius was calculated using the relation shown below. 


$$
r_{t}=1.1019 t^{2}
$$

The height of the vortex generators would be $25 \%$ of the chord size. Using these formulas mentioned before, some basic relations permitted calculations such as areas and the wing's aspect ratio.

The remaining measurements correspond to the apparatus used in the laboratory before the experiment was carried out. Determining the ambient conditions was the first step to collect the information using the different apparatus. Assuming that the air is an ideal gas and knowing the values of ambient pressure and the temperature, the density was obtained according to the equation of ideal gases:

$$
\rho=\frac{P}{R T}
$$

The sigma $(\sigma)$ value corresponded to the ratio of densities between the value previously obtained with the equation of ideal gases, and the sea level density:

$$
\sigma=\frac{\rho}{\rho_{S L}}
$$

Next, the velocity developed inside the wind tunnel was obtained by determining the relation of the gauge pressure measured during each experiment with the ratio of densities, multiplied by a calibration factor for the WVU low-speed wind tunnel factor:

$$
V_{\text {true }}\left[\frac{f t}{s}\right]=68.76 \frac{\sqrt{h_{T}[\text { in.of.water }]}}{\sqrt{\sigma}}
$$


Knowing all parameters mentioned above, the Reynolds number was obtained for each different scenario, using the following equation:

$$
\operatorname{Re}_{\text {calc }}=\frac{\rho_{\infty} V_{\text {true }} x}{\mu_{\infty}}
$$

The Reynolds number obtained had to be multiplied by a correction factor as a result of the turbulence level in the wind tunnel, however, in order to obtain the effective Reynolds number used in the experiment.

$$
\operatorname{Re}_{\text {effec }}=1.31 \mathrm{Re}_{\text {calc }}
$$

Finally, to calculate the lift coefficient needed for the computational section, it was necessary to use the equations of the speed of sound and the Mach number: Speed of sound

$$
a=\sqrt{\gamma R T}
$$

The Mach number was calculated to verify if it would be necessary to use the energy equation in the simulation. If the resultant Mach number was greater than 0.3 , the energy equation would have to be considered.

$$
M=\frac{V_{\text {true }}}{a}
$$

During the experiment, a digital camera and a video recorder were used. A smoke generator allowed visualizing the streamlines over the wing over a wide range in angle of attack indicating where the flow separation occurred. 


\subsubsection{Computational Method}

The second method permitted a much more detailed quantitative simulation of the same phenomenon, at the same conditions described in the Experimental Methods section. The computational method involved the use of the same information described in the Experimental Methods section, as well as modeling using CFD Fluent software. It is important to notice, however, a difference regarding this model, as compared to the experiment in the wind tunnel: the software model did not include surface imperfections associated with attaching the vortex generators to the wing. The wing and the triangle flats were modeled as one piece.

The Fluent CFD code was able to calculate the lift generated by the wing, so using the relation shown below the lift coefficient could be obtained.

$$
C_{L}=\frac{L}{q_{\infty} S},
$$

where $\mathrm{q}_{\infty}$ is the dynamic pressure defined by the relation

$$
q_{\infty}=\frac{1}{2} \rho V_{\text {true }}^{2}
$$




\subsection{Experimental Procedure}

\subsubsection{Wing construction technique}

The NACA 0015 airfoil was chosen because it is a symmetric airfoil that not only simplifies the construction of the wing, but also avoids errors involved with the use of more imperfect shapes. Another reason justifying experimenting with a symmetric airfoil was similarity of the curves of the lift coefficient versus the angle of attack over a range of Reynolds numbers, which are comparable to other symmetric airfoils at low Reynolds numbers.

In order to build the wing with the proper shape, the Winfoil software was used to draw templates of the airfoil shape. The airfoil NACA 0015 was configured to have 9.5 inches of chord. The paper templates were printed and glued to aluminum sheets. Next, aluminum templates were made by cutting along the shape defined by the paper template. Subsequently, these two aluminum templates were attached to the sides of a slab of foam and cut to size with a hot wire. With the core of the wing cut to size, it was covered with a thin balsa wood skin. After the balsa wood had been applied, the chord length increased to 9.5 inches, whereas the span remained 31.5 inches. Next, the leading edge was replaced by a piece of wood to strengthen the leading edge. This piece of wood was sanded off until it duplicated the needed shape. A piece of wood $1 / 4$ inches thick was added to each end to make the wing stronger. Finally, tape was used on the trailing edge to make it sharper and to improve performance. At this point, the dimensions of the wingspan were 32 inches span and 9.5 inches chord (see Figure 3-2).

To be able to use the metal screws to attach the vortex generators, a $1 / 2$ inches by $1 / 2$ inches aluminum bar was inserted just behind to the leading edge. This bar had holes 
tapped at 1 inch spacing as needed to attach the vortex generators. After the bar was inserted, the wing was refinished with wood filler. 


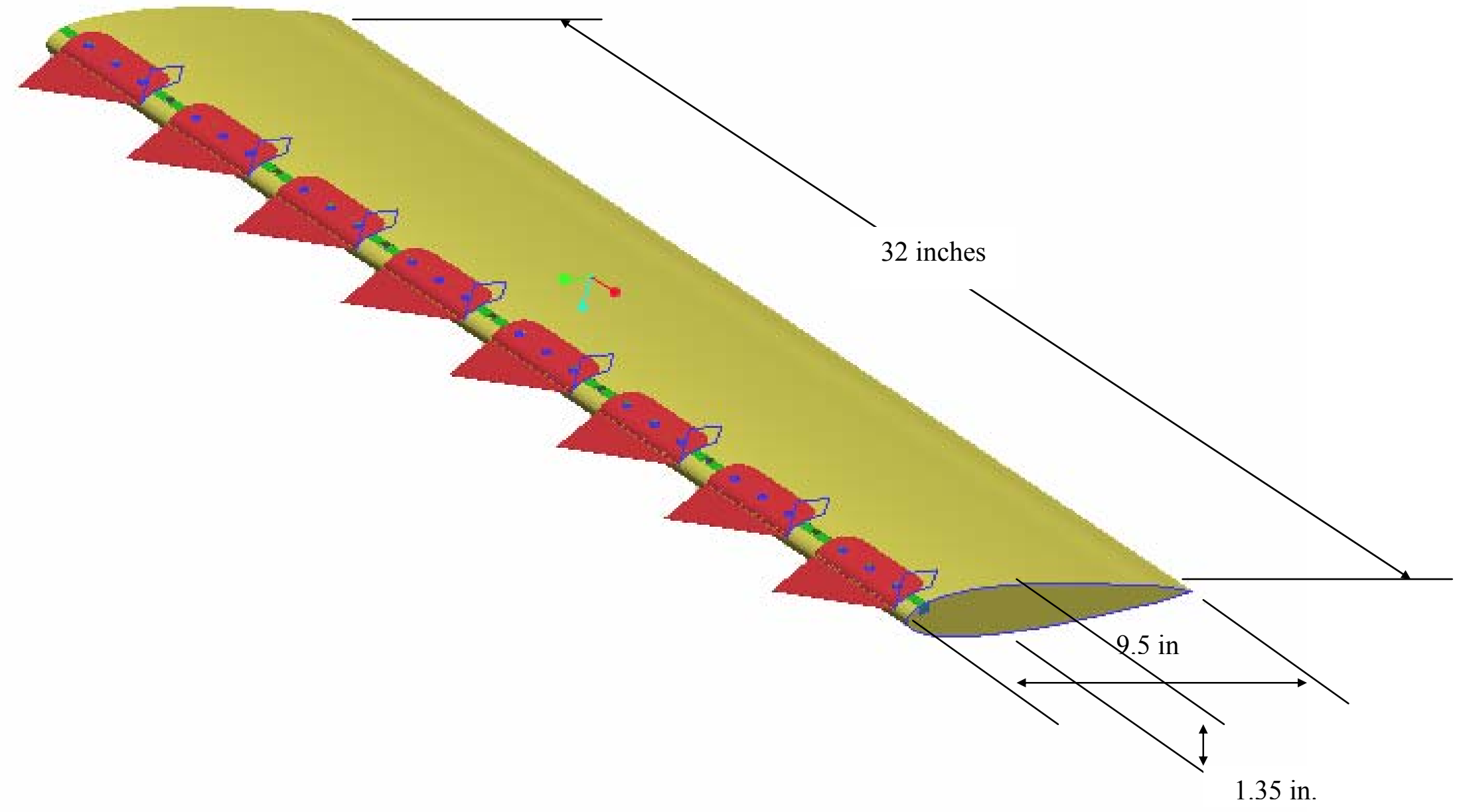

Figure 3-2: Drawing of the wing 
The vortex generators, which consisted of equilateral triangles, were made of 0.015 " thick aluminum sheets, with 3 inches per side (Figure 3.3). This size of the vortex generators was chosen because it facilitated the visualization of the vortices formed on the upper surface of the wing. These equilateral triangles also had an extension of 1 inch along the base for attachment to the wing. This extension was bent to follow the contour of the wing. The extension had three holes to screw the triangles to the wing. Unused holes were covered with tape to minimize surface irregularities.

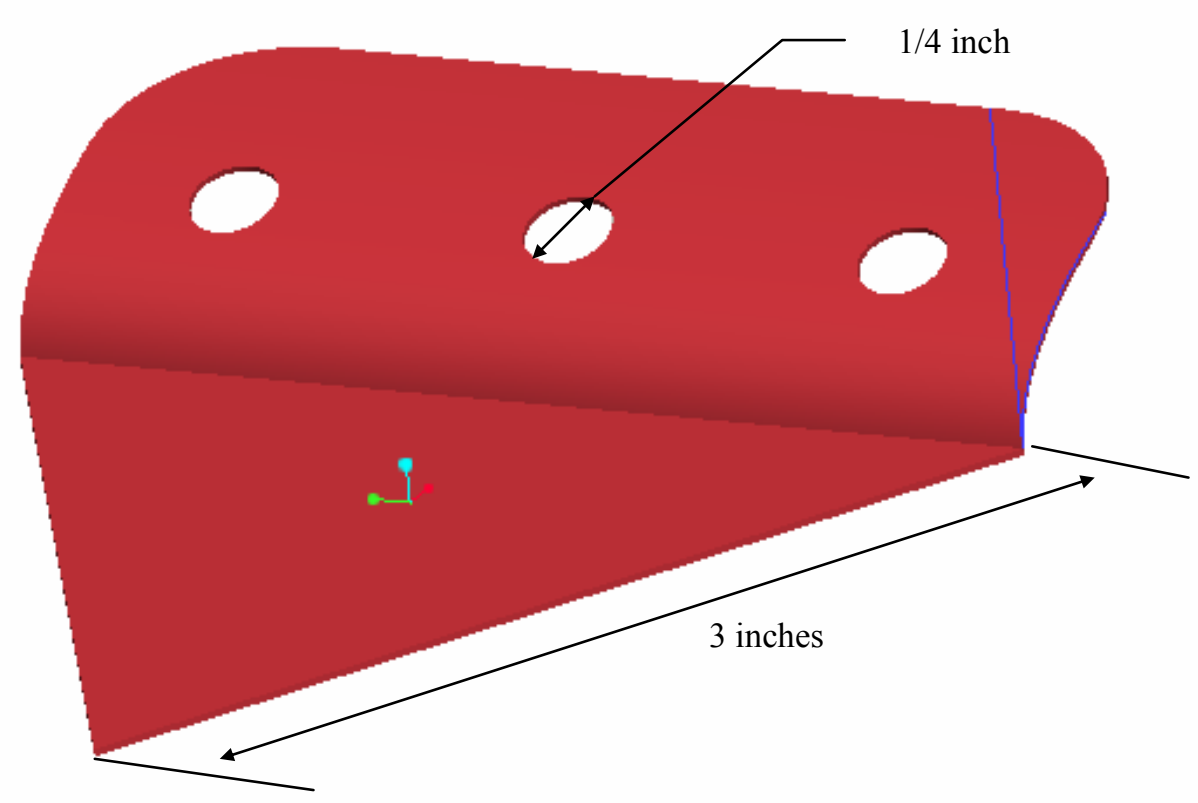

Figure 3-3: Dimensions of the vortex generator

Table 3-1 shows the summary of the wing dimensions and some basic calculations, such as the area of the wing. This table also shows some useful aerodynamic definitions, such as the wing span, chord length and dimensions of the vortex generators. 
Table 3-1: Wing measurements and model geometry dimensions

\begin{tabular}{|l|c|c|}
\cline { 2 - 3 } \multicolumn{1}{c|}{} & Value & Units \\
\hline Max. wing thickness & 1.425 & in \\
Wingspan (b) & 32 & in \\
Chord (c) & 9.5 & in \\
Base flat plate & 3 & in \\
Height flat plate & 2.6 & in \\
Vortex generators area & 3.9 & in \\
Wing area w/ no VG & 304 & in $^{2}$ \\
Area wing (S) & 335.2 & in $^{2}$ \\
\hline
\end{tabular}

To mount the wing in the wind tunnel, a circular pipe was inserted through the wing at the $1 / 4$ chord position, near its center of pressure. In addition, aluminum end plates and Teflon bearing sleeves were attached to the wing. Set screws inside the Teflon sleeves avoided undesired change in angle of attack during the experiment (Figure 3-4). Then, the wing was placed in the middle of the test section at twice the chord length from the inlet to the leading edge and from the trailing edge to the outlet. 


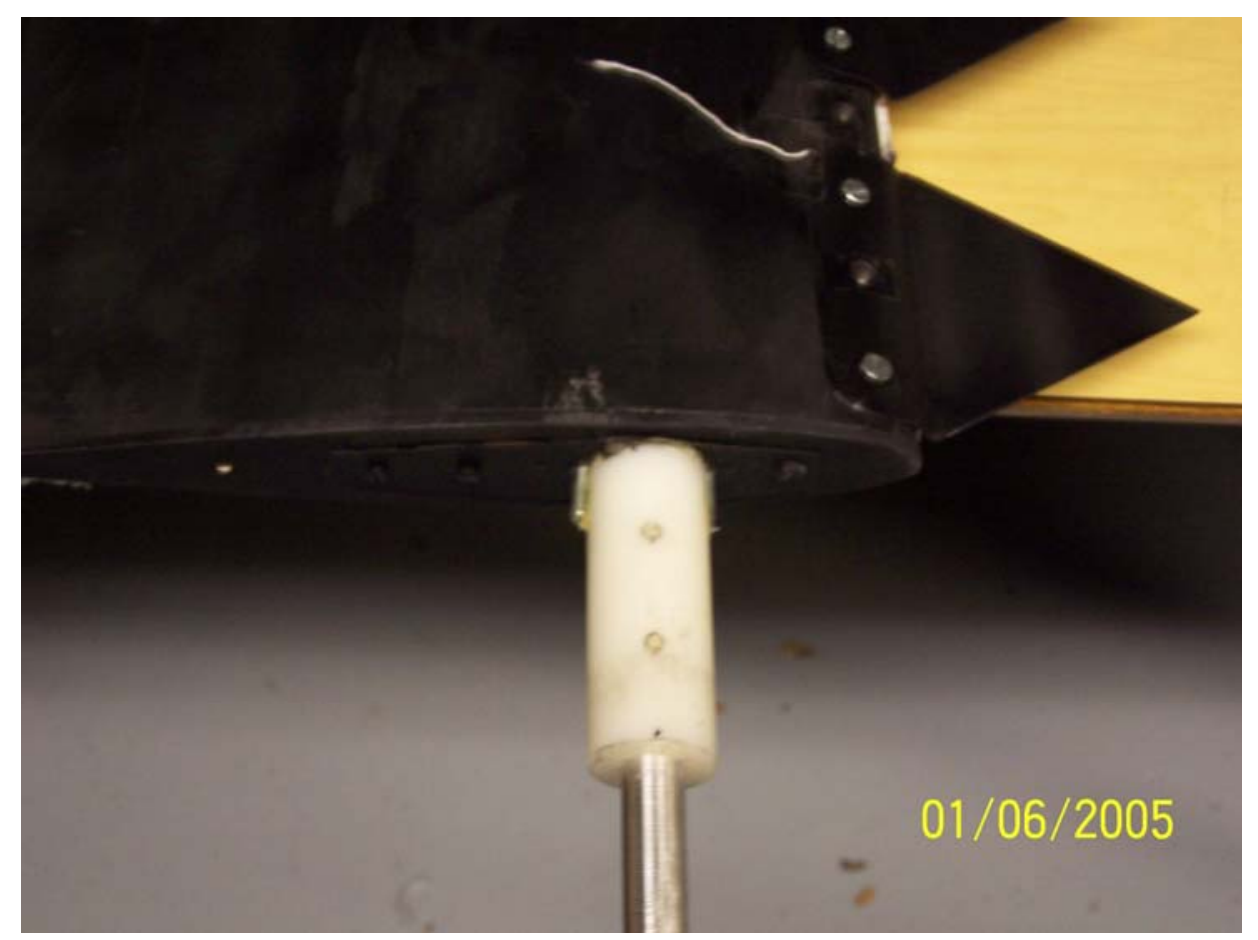

Figure 3-4: Detail of the screw and pipe attached to the wing side

Because preliminary tests revealed difficulties in viewing the smoke trails over the wing, it was necessary to add an acrylic window to the wind tunnel test section (Figure 3-5). Such a window, located in the test section floor, allowed visual inspection of the flow field around the wing. The wind tunnel side windows allowed observation of the upper wing surface using a video camera. 


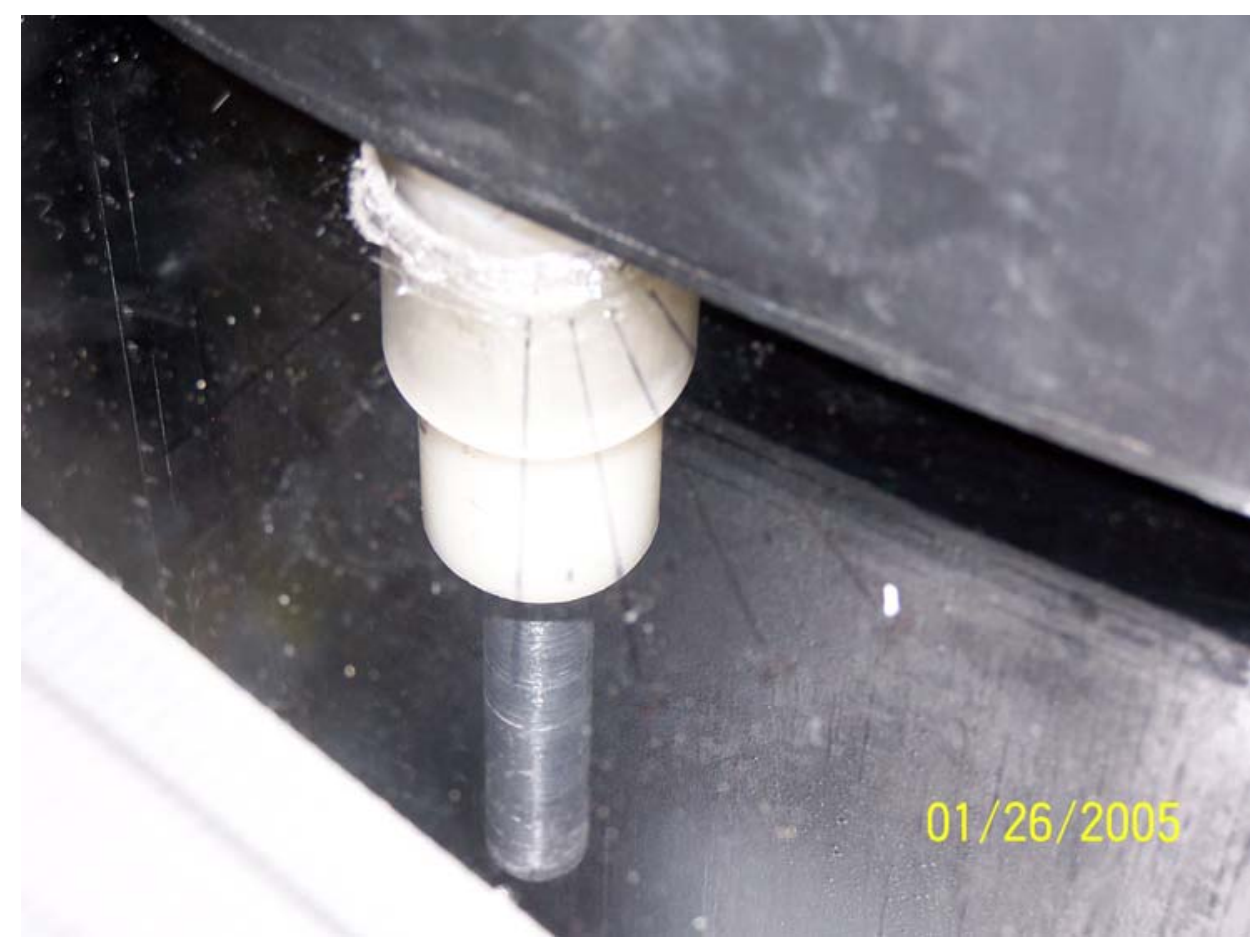

Figure 3-5: Acrylic window located on the bottom wall of the test section of the wind tunnel

The single loop, low speed wind tunnel, was used in the present experiment. It had a contraction section measuring 77 inches high and 109 inches wide. The test section was 44.5 inches wide and 32 inches in height. The experiment was repeated many times, at different wind velocities and angles of attack; however, only the most representative data have been included.

The visual observation of the flow from the bottom was not considered sufficient to detect wing stall; therefore, tufts were attached to the wing upper surface at different locations shown in figure 3-6, and 1.5 inch apart from each other. A smoke generator placed 11 inches from the wing leading edge allowed visualization of the flow streamlines. 


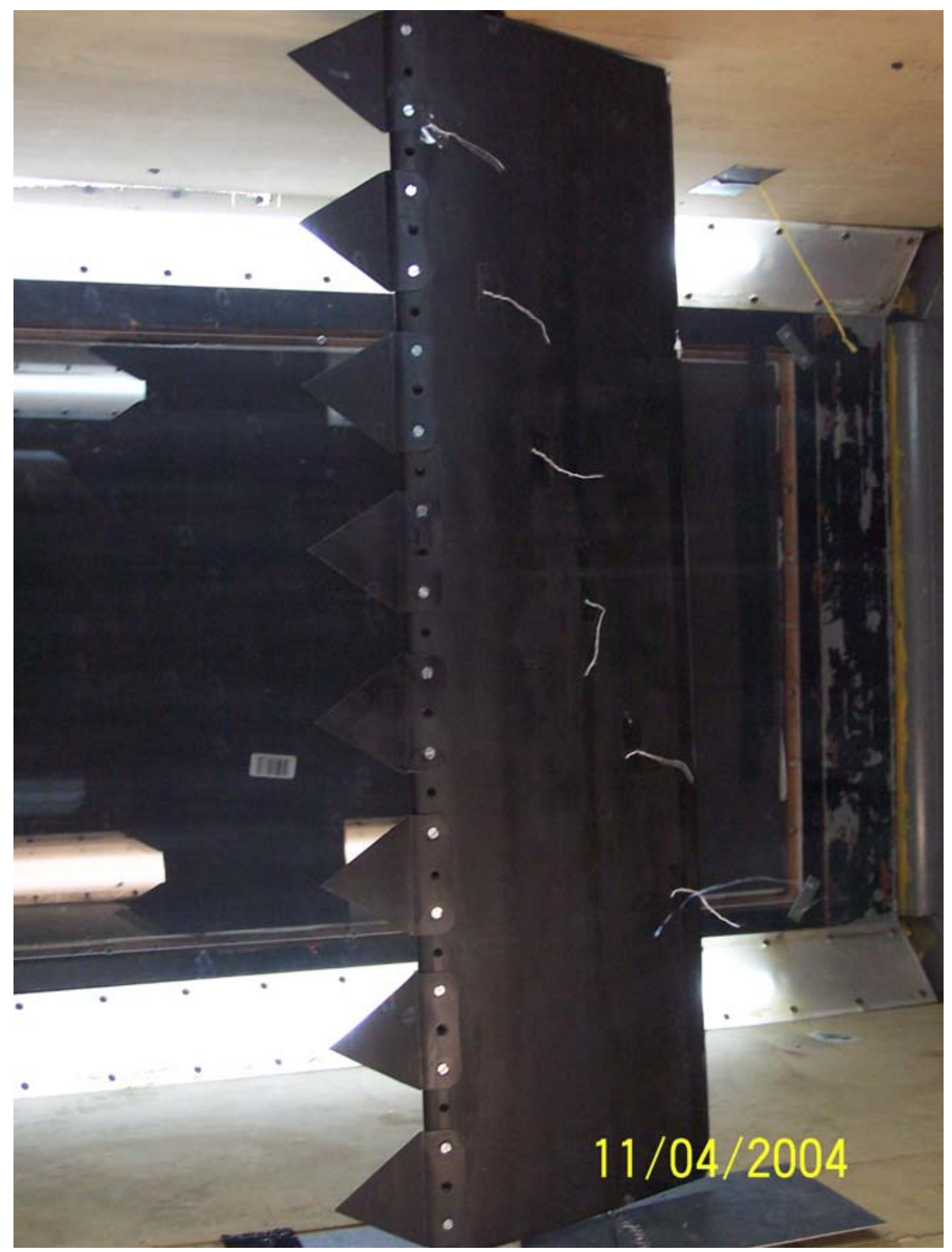

Figure 3-6: Localization of the tufts on the wing

Before testing, the manometer scale had to be adjusted at zero gage pressure to permit an accurate measurement of the gage pressure in the low-speed wind tunnel. Once this last detail was finished, the experiment was conducted at different angles of attack. According to Miley (1982), a regular airfoil NACA 0015 stalls between $11^{\circ}$ and $13^{\circ}$ at Reynolds number of $4.3 \times 10^{4}$ and $8.4 \times 10^{4}$, respectively (Figure 3-7). However, to 
corroborate the experimental results, it was necessary to compare them with the results of other experiments. Note, WVU wind tunnel test were conducted at Reynolds number close to $\mathrm{Re}=4.3 \times 10^{4}$.

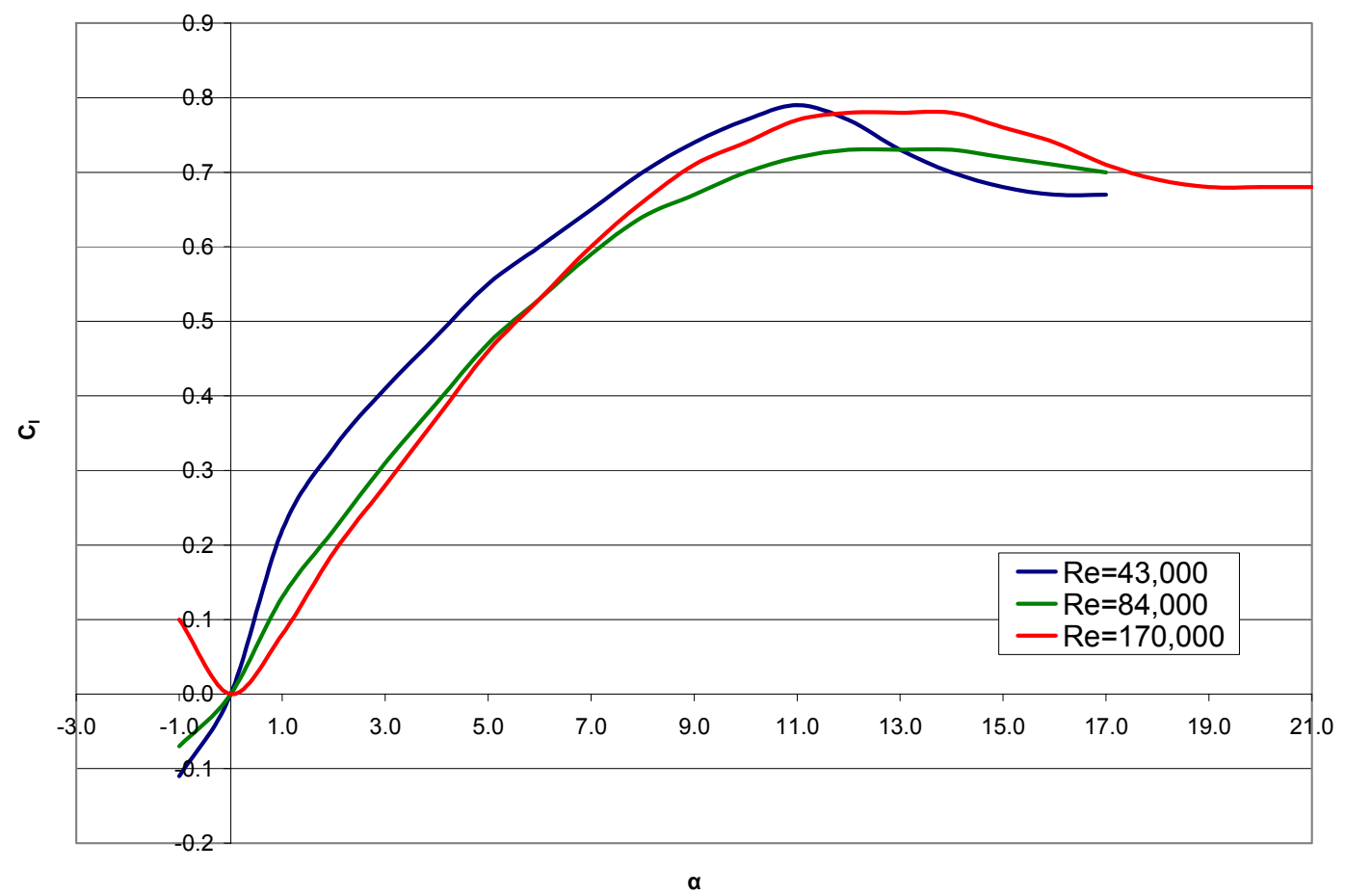

Figure 3-7: Lift Coefficient vs. Angle of Attack for 2D NACA 0015 (Miley, 1982)

\subsubsection{Experimental Results}

After conducting the experiment, some important data were taken in order to determine the atmospheric conditions (atmospheric pressure and temperature) in which the experiment was conducted. The data shown in table 3-2 was measured using the barometer and the thermometer in order to obtain the atmospheric conditions for each experiment. These parameters were measured initially with no vortex generators to verify the wing stall angle. 
Table 3-2: Atmospheric conditions for the wing with no vortex generators and with different configurations of the vortex generators at $\operatorname{Re}=2.5 \times 10^{4}$

\begin{tabular}{|c|c|c|}
\cline { 2 - 3 } \multicolumn{1}{c|}{} & Value & Units \\
\hline $\mathrm{P}_{\mathrm{atm}}$ & 28.64 & inches of $\mathrm{Hg}$ \\
$\mathrm{T}_{\mathrm{amb}}$ & 63.5 & ${ }^{\circ} \mathrm{F}$ \\
$\mathrm{R}$ & 53.3 & $\left(\mathrm{ft}^{\mathrm{l}}-\mathrm{lb}_{\mathrm{f}}\right) /\left(\mathrm{lb}_{\mathrm{m}}{ }^{\circ} \mathrm{R}\right)$ \\
$\mathrm{P}$ & 0.073 & $\mathrm{lb}_{\mathrm{m}} / \mathrm{ft}^{3}$ \\
$\rho_{\mathrm{SL}}$ & 0.0764 & $\mathrm{lb}_{\mathrm{m}} / \mathrm{ft}^{3}$ \\
$\sigma$ & 0.951 & \\
$\mu_{\mathrm{SL}}$ & $3.74 \mathrm{E}-07$ & $\mathrm{lb}_{\mathrm{f}}-\mathrm{s} / \mathrm{ft}^{2}$ \\
\hline
\end{tabular}

Before starting the wind tunnel, the manometer was refurbished at zero gage pressure in order to capture the pressure variation between the contraction cone and the test section. Once the wing was placed in the test section and aligned at $0^{\circ}$ of angle of attack, the wind tunnel was started. The smoke generator was also plugged in to obtain smoke as a result of the vaporization of the glycerin in the throat, which was coiled with a wire aligned with the stagnation line of the wing. This wire was connected to a power source. Subsequently, when the smoke was coming along the wing, eight pictures were taken continuously in order to visualize the behavior of the flow. This procedure was repeated at different angles of attack to determine the angle of attack at which the wing stalled.

Table 3-3 shows the summary of the experimental data measured for NACA 0015 with no vortex generators. 
Table 3-3: Recorded data of the wing with no vortex generators attached

\begin{tabular}{|c|c|c|}
\hline $\mathrm{P}_{1}-\mathrm{p}_{2}$ & 0.165 & in $\mathrm{H}_{2} \mathrm{O}$ \\
Freestream velocity & 28.6438 & $\mathrm{ft} / \mathrm{sec}$ \\
Mach number & 0.0254 & Subsonic flow \\
$\mathrm{Re}_{\text {calc }}$ & $1.9 \times 10^{4}$ & \\
$\operatorname{Re}_{\text {effect }}$ & 25463 & \\
\end{tabular}

Additionally, the images captured by the digital camera are shown in the next figures. Figures 3-8 shows the airflow around the wing just below to stall $\left(\alpha=10^{\circ}\right)$ and Figure 3-9 shows post-stall $\left(\alpha_{\text {STALL }}=12^{\circ}\right)$ at a freestream velocity of $28.64 \mathrm{ft} / \mathrm{s}$. This experiment shows flow stall starts at about $11^{\circ}$ just like the theory shown in Figure 3-7 predicted.

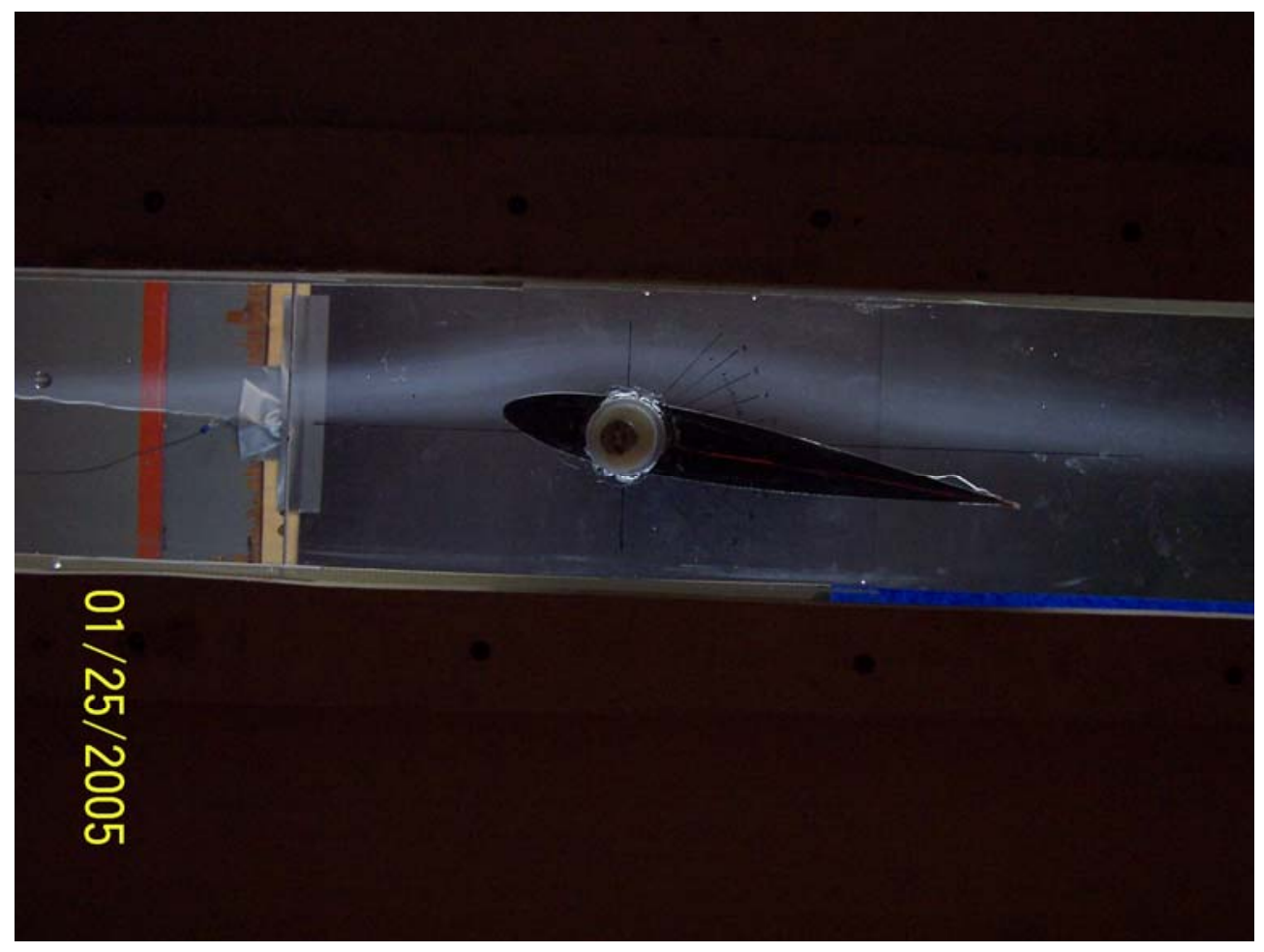

Figure 3-8: Airflow around the wing close to stall $\left(\alpha=10^{\circ}\right)$ at $\operatorname{Re}=2.5 \times 10^{4}$ 


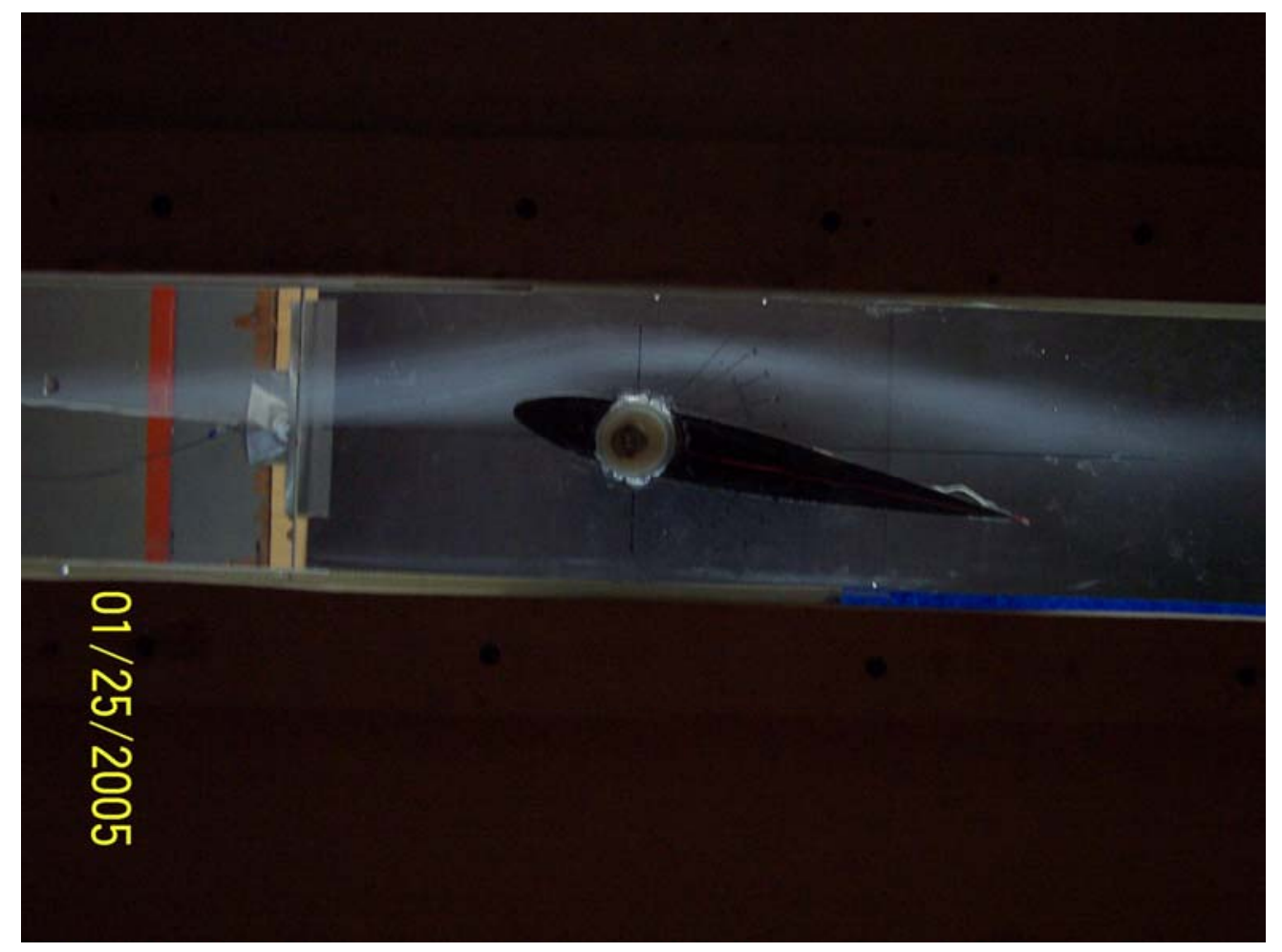

Figure 3-9: Post stall airflow around the wing $\left(\alpha=12^{\circ}\right)$ at $\operatorname{Re}=2.5 \times 10^{4}$

After to carry out the experiment with no vortex generators, the vortex generators were placed on the wing in order to achieve the best configuration that the attached bar allowed. Thus, the vortex generators were moved with increments of 1 inch per configuration to find the optimal distance. Therefore, the camcorder placed in the contraction cone played an important role because it allowed showing if the vortices generated by the vortex generators attenuated the effect. Once again, the tufts and visualization trough the windows permitted the corroboration of the flow separation. A summary of these experiments are shown in Table 3-4 at very low Reynolds number. 


\section{Table 3-4: Summary of the experimental results of different wing configurations}

\begin{tabular}{|c|c|c|}
\cline { 2 - 3 } \multicolumn{1}{c|}{} & \multicolumn{2}{c|}{ Angle of Attack } \\
\hline $\begin{array}{c}\text { Gap between each } \\
\text { vortex generator }\end{array}$ & $\begin{array}{c}\text { Near Stall } \\
{[\mathrm{deg}]}\end{array}$ & $\begin{array}{c}\text { Post Stall } \\
{[\mathrm{deg}]}\end{array}$ \\
\hline No delta flaps & 10 & 12 \\
0 inches & 14 & 16 \\
1 inch & 16 & 18 \\
2 inches & 16 & 18 \\
\hline
\end{tabular}

These results for the wing with no flaps were very similar to the past experiments. Also, when the delta flaps were attached at different locations, stall was delayed up to $6^{\circ}$, depending on the gap between adjacent vortex generators. When the distance between the vortex generators increased, the stall performance of the wing improved, by allowing the vortices to reattach on the upper surface of the wing which delays flow separation. However, since the bar that holds the vortex generators had 1 inch of distance between each hole, choice of gap size was too limited to determine the optimal spacing. It could be a topic for a future investigation using vortex generators with $25 \%$ of the chord size.

Once the best configuration was found, the experiment was repeated several times at different Reynolds numbers using the same configuration of distance between each vortex generator. Then, the most representative data were shown in which the results showed similarity. However, before to carry out the experiments, the atmospheric conditions needed to be recorded in order to calculate the parameters (same procedure). In order to assure the results obtained, the experiment was conducted several times with variations of the freestream velocities. Therefore, the minimum, maximum, and the closet 
to the average between the minimum and maximum were presented. Since the experiments were conducted in different days, the ambient conditions changed. They were recorded and showed in the next tables.

Table 3-5: Atmospheric conditions for experiment with the lowest upstream velocity

\begin{tabular}{|c|c|c|}
\multicolumn{3}{c}{ value } \\
\cline { 2 - 3 } \multicolumn{1}{c|}{} & Value & Units \\
\hline $\mathrm{P}_{\text {atm }}$ & 29.17 & inches of Hg \\
$\mathrm{T}_{\mathrm{amb}}$ & 68 & ${ }^{\circ} \mathrm{F}$ \\
$\mathrm{R}$ & 53.3 & $\left(\mathrm{ft}-\mathrm{lb}_{\mathrm{f}}\right) /\left(\mathrm{lb}_{\mathrm{m}}{ }^{\circ} \mathrm{R}\right)$ \\
$\rho$ & 0.073 & $1 \mathrm{~b}_{\mathrm{m}} / \mathrm{ft}^{3}$ \\
$\rho_{\mathrm{SL}}$ & 0.076 & $\mathrm{lb}_{\mathrm{m}} / \mathrm{ft}^{3}$ \\
$\sigma$ & 0.96 & \\
$\mu_{\mathrm{SL}}$ & $3.74 \mathrm{E}-07$ & $\mathrm{lb}_{\mathrm{f}}-\mathrm{s} / \mathrm{ft}^{2}$ \\
\hline
\end{tabular}

Table 3-6 shows the summary of the experimental data measured and calculated for NACA 0015 with vortex generators at the lowest freestream velocity in the wind tunnel.

Table 3-6: Recorded data for the lowest freestream velocity value

\begin{tabular}{|c|c|c|}
\hline $\mathrm{p}_{1}-\mathrm{p}_{2}$ & 0.036 & in $\mathrm{H}_{2} \mathrm{O}$ \\
Freestream velocity & 13.31 & $\mathrm{ft} / \mathrm{sec}$ \\
Mach number & 0.0118 & subsonic flow \\
$\mathrm{Re}_{\text {calc }}$ & $1.14 \times 10^{4}$ & \\
$\mathrm{Re}_{\text {effect }}$ & 14940 & \\
\hline
\end{tabular}


Figures 3-10 shows the airflow around the wing just below stall $\left(\alpha=16^{\circ}\right)$ and Figure 3-11 shows the airflow at post-stall $\left(\alpha_{\text {STALL }}=18^{\circ}\right)$ with a freestream velocity of $13.31 \mathrm{ft} / \mathrm{s}$. In the latter figure, the flow separation is clear on the upper surface of the airfoil and the tufts verify this separation on the side view.

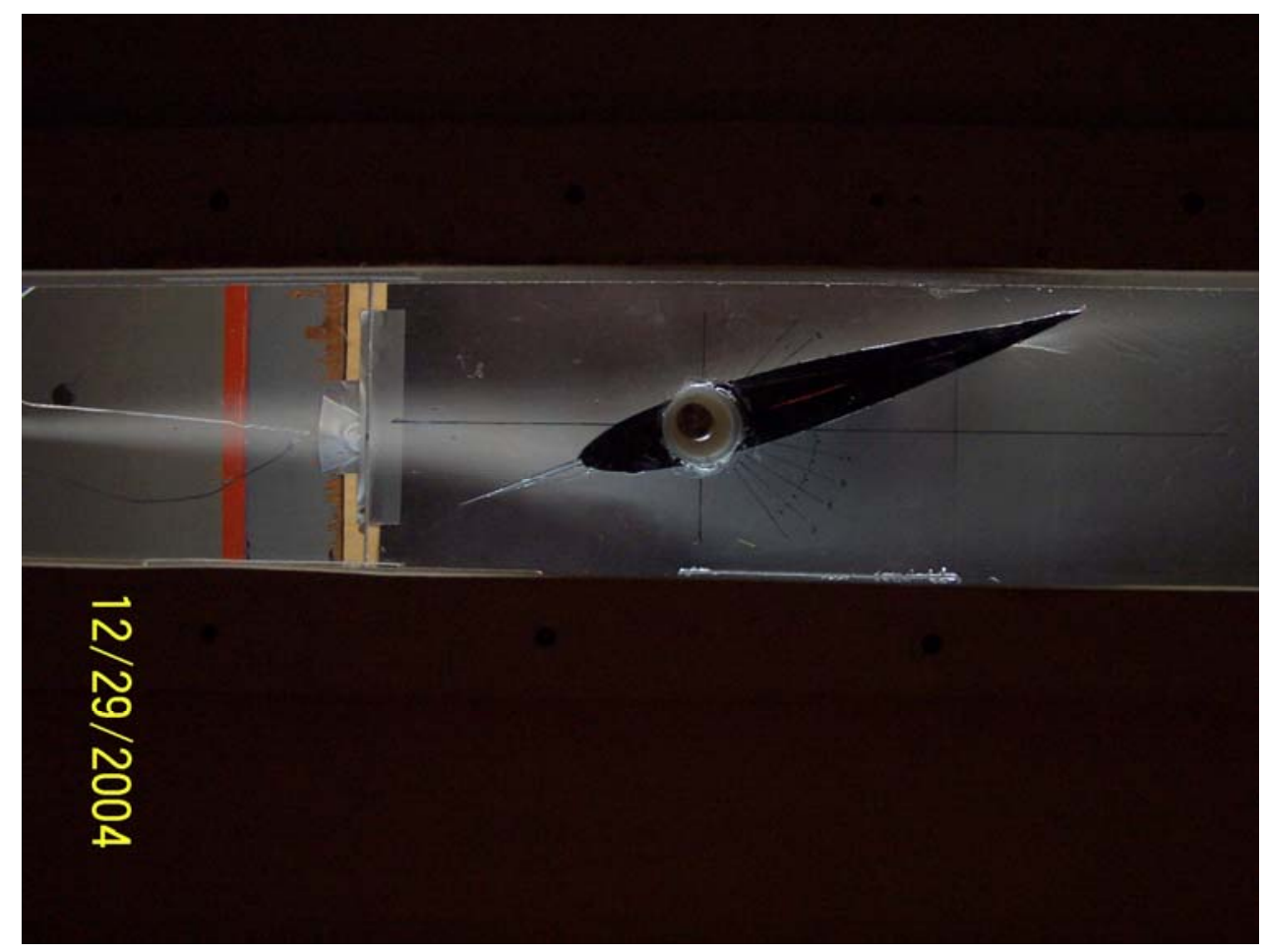

Figure 3-10: Airfoil around the wing at increased $\operatorname{Reynolds}$ number $\left(\operatorname{Re}=1.5 \times 10^{4}\right)$, delayed stall to about $\alpha=16^{\circ}$ 


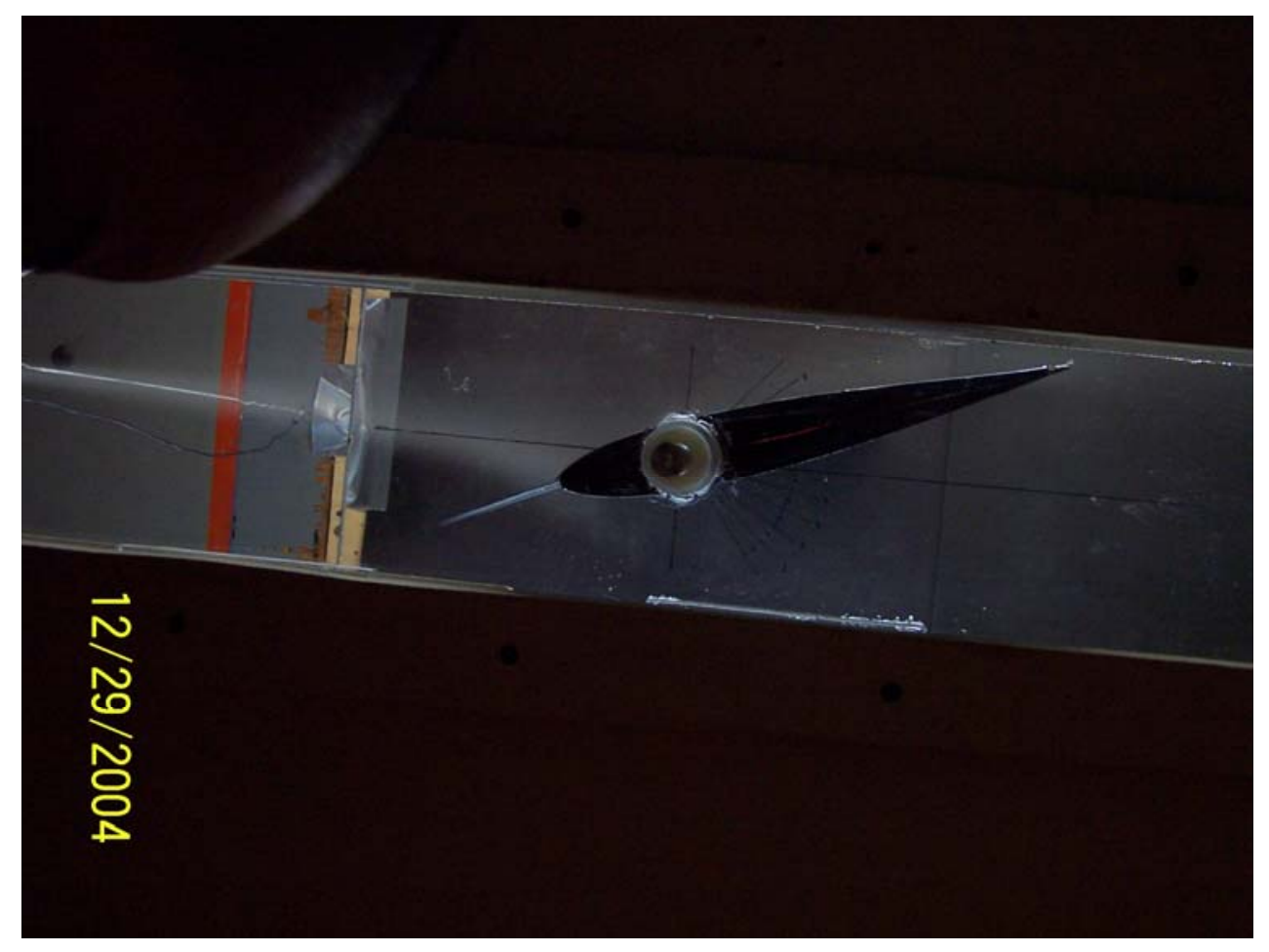

Figure 3-11: Airflow around wing with vortex generators to delay the stall to $\alpha=18^{\circ}$,

$$
\text { at } \operatorname{Re}=1.5 \times 10^{4}
$$

The data showed below correspond to an extension to verify the results obtained previously but a higher Reynolds numbers. As mentioned before, these experiments were conducted on different days to collect the data shown in Table 3-7. 
Table 3-7: Atmospheric conditions for the closest to the average velocity value and the greatest velocity value

\begin{tabular}{|c|c|c|}
\cline { 2 - 3 } \multicolumn{1}{c|}{} & Value & Units \\
\hline $\mathrm{P}_{\mathrm{atm}}$ & 31 & inches of $\mathrm{Hg}$ \\
$\mathrm{T}_{\mathrm{amb}}$ & 67 & ${ }^{\circ} \mathrm{F}$ \\
$\mathrm{R}$ & 53.3 & $\left(\mathrm{ft}-\mathrm{lb}_{\mathrm{f}}\right) /\left(\mathrm{lb}_{\mathrm{m}}{ }^{\circ} \mathrm{R}\right)$ \\
$\rho$ & 0.078 & $\mathrm{lb}_{\mathrm{m}} / \mathrm{ft}^{3}$ \\
$\rho_{\mathrm{SL}}$ & 0.076 & $\mathrm{lb}_{\mathrm{m}} / \mathrm{ft}^{3}$ \\
$\sigma$ & 1.022 & \\
$\mu_{\mathrm{SL}}$ & $3.74 \mathrm{E}-07$ & $\mathrm{lb}_{\mathrm{f}}-\mathrm{s} / \mathrm{ft}^{2}$ \\
\hline
\end{tabular}

Table 3-8 shows the summary of the experimental data measured and calculated for NACA 0015 with vortex generators at the closest value to the average of the upstream velocity value.

Table 3-8: Recorded data for the closest value to the average of the freestream velocity value

\begin{tabular}{|c|c|c|}
\hline $\mathrm{P}_{1}-\mathrm{p}_{2}$ & 0.537 & in $\mathrm{H}_{2} \mathrm{O}$ \\
Freestream velocity & 49.8345 & $\mathrm{ft} / \mathrm{sec}$ \\
Mach number & 0.0442 & subsonic flow \\
$\mathrm{Re}_{\text {calc }}$ & $4.55 \times 10^{4}$ & \\
$\operatorname{Re}_{\text {effect }}$ & 59540 & \\
\hline
\end{tabular}


Figures 3-12 and 3-13 show the airflow around the wing close to stall $\left(\alpha=16^{\circ}\right)$ and poststall $\left(\alpha_{\text {STALL }}=18^{\circ}\right)$ at freestream velocity of $49.83 \mathrm{ft} / \mathrm{s}$. Figure $3-13$ does not show clearly the flow separation because the smoke was very weak, but the tufts assure the onset of this phenomena.

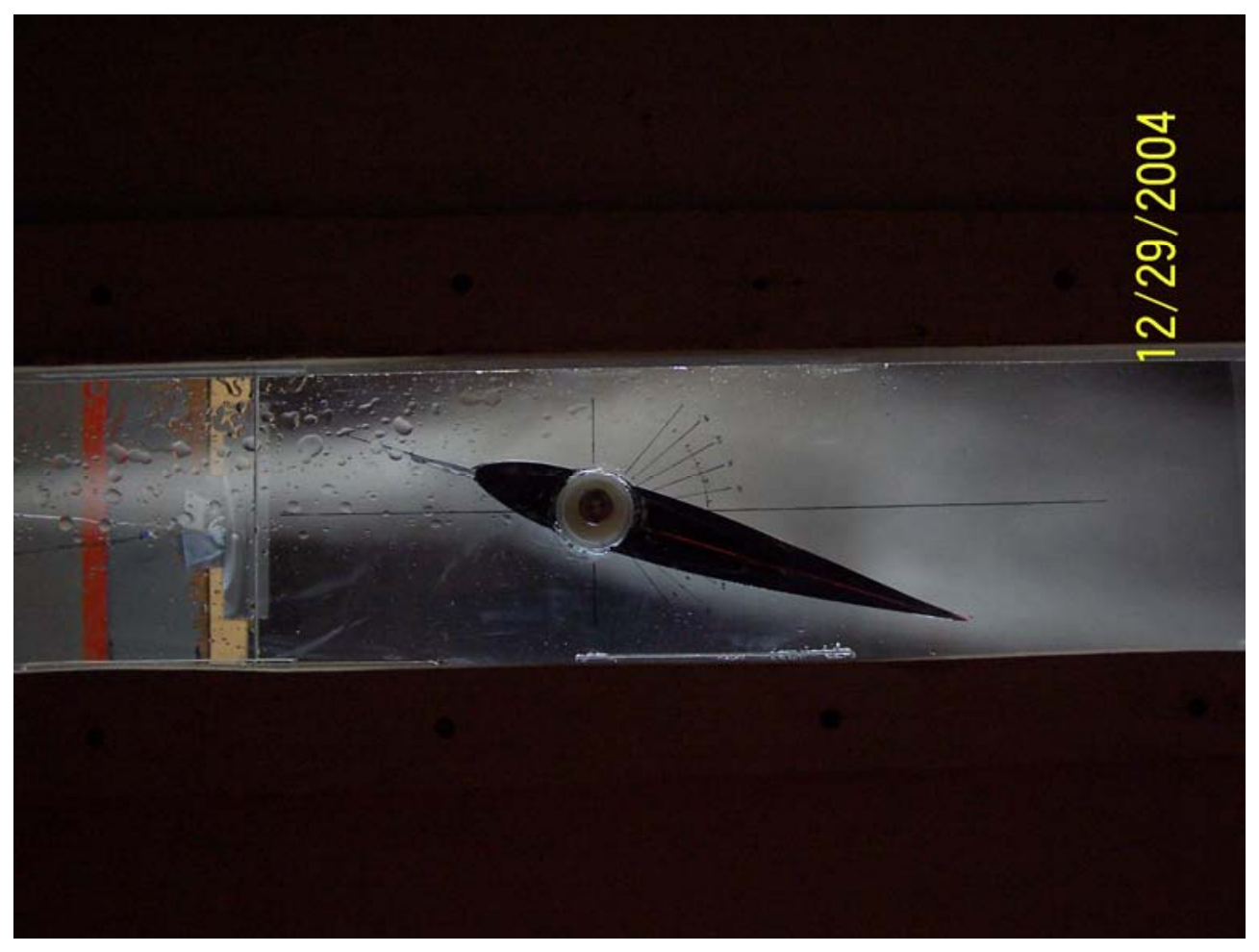

Figure 3-12: Airflow around the wing at increased Reynolds number $\left(\operatorname{Re}=6 \times 10^{4}\right)$, delayed stall to about $\alpha=16^{\circ}$ 


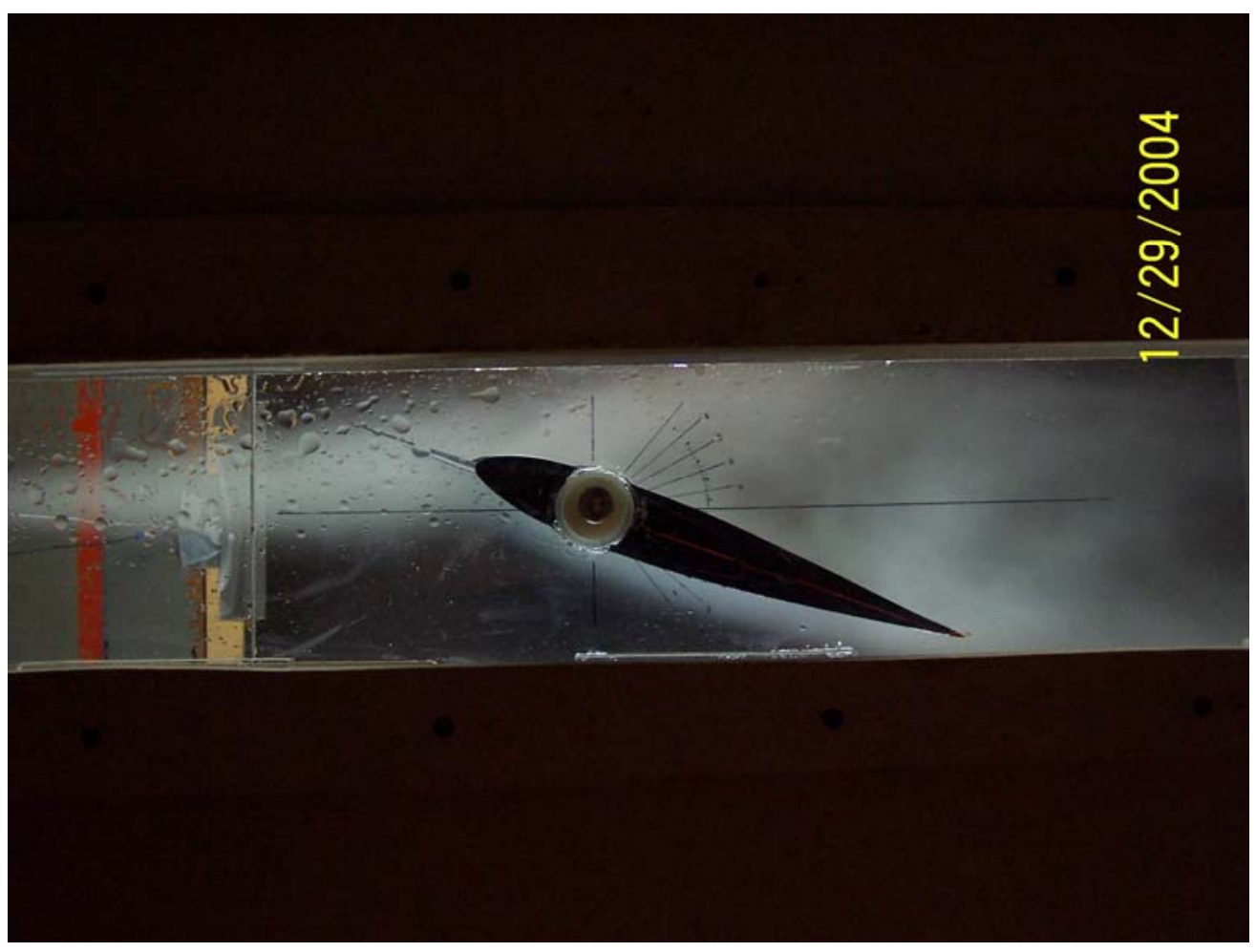

Figure 3-13: Airflow around wing with vortex generators to delay stall to $\alpha=18^{\circ}$, at

$$
\operatorname{Re}=6 \times 10^{4}
$$

Table 3-9 shows the summary of the experimental data measured and calculated for NACA 0015 with vortex generators at the greatest velocity value. The atmospheric conditions were the same than the last experiment conducted.

Table 3-9: Recorded data for the greatest freestream velocity value

\begin{tabular}{|c|c|c|}
\hline $\mathrm{p}_{1}-\mathrm{p}_{2}$ & 1.3 & in $\mathrm{H}_{2} \mathrm{O}$ \\
Freestream velocity & 77.5381 & $\mathrm{ft} / \mathrm{sec}$ \\
Mach number & 0.06873 & subsonic flow \\
$\mathrm{Re}_{\text {calc }}$ & $7.07 \times 10^{4}$ & \\
$\operatorname{Re}_{\text {effect }}$ & 92640 & \\
\hline
\end{tabular}


Figures 3-14 and 3-15 show the airflow around the wing close to stall $\left(\alpha=16^{\circ}\right)$ and poststall $\left(\alpha_{\text {STALL }}=18^{\circ}\right)$ at the highest freestream velocity of $77.54 \mathrm{ft} / \mathrm{s}$. Figure 3-15 show the bubble on the surface as a result of the flow separation for the highest speed tested.

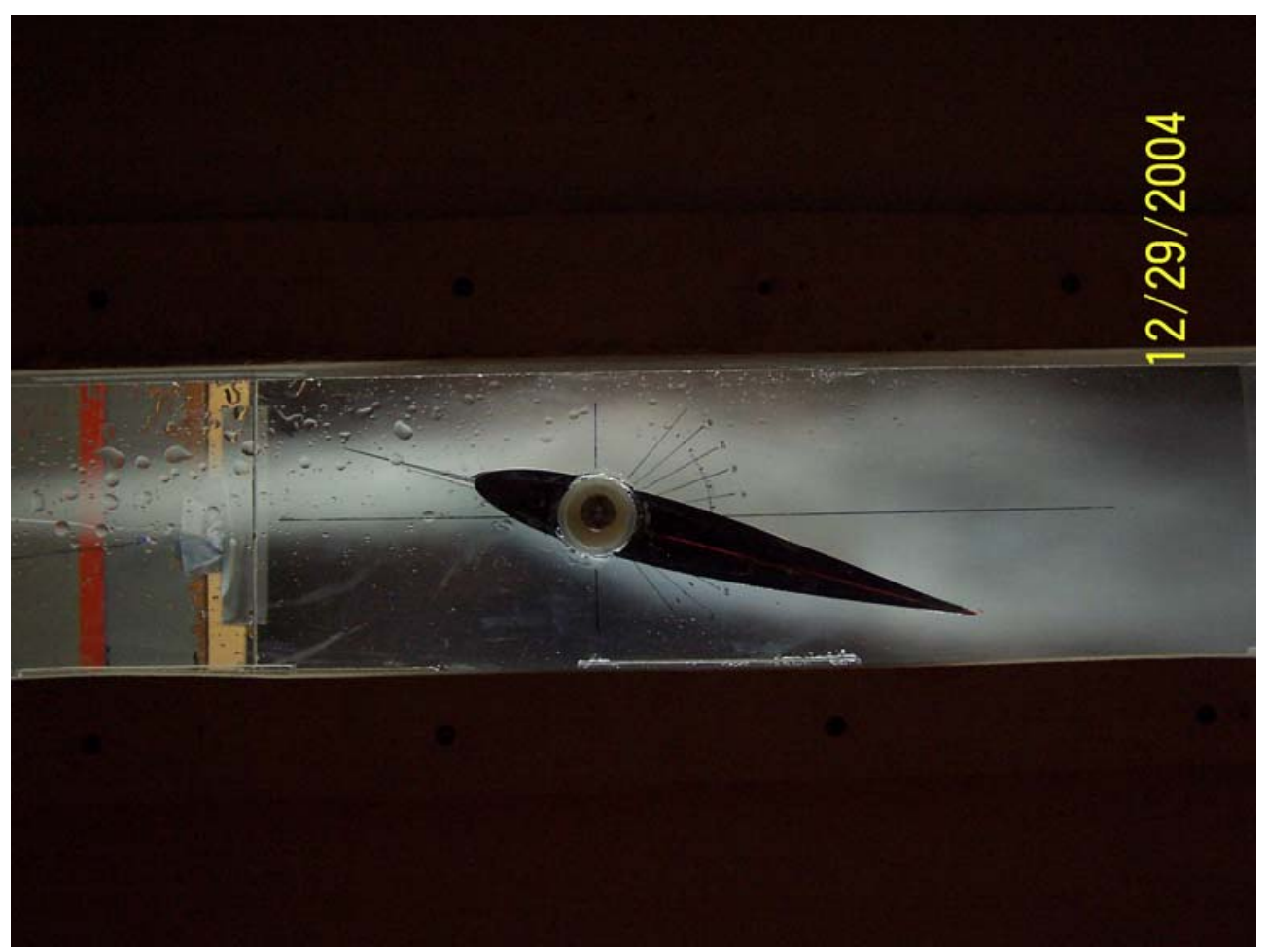

Figure 3-14: Airflow around the wing at increased Reynolds number $\left(\operatorname{Re}=9.2 \times 10^{4}\right)$, delayed stall close to about $\alpha=16^{\circ}$ 


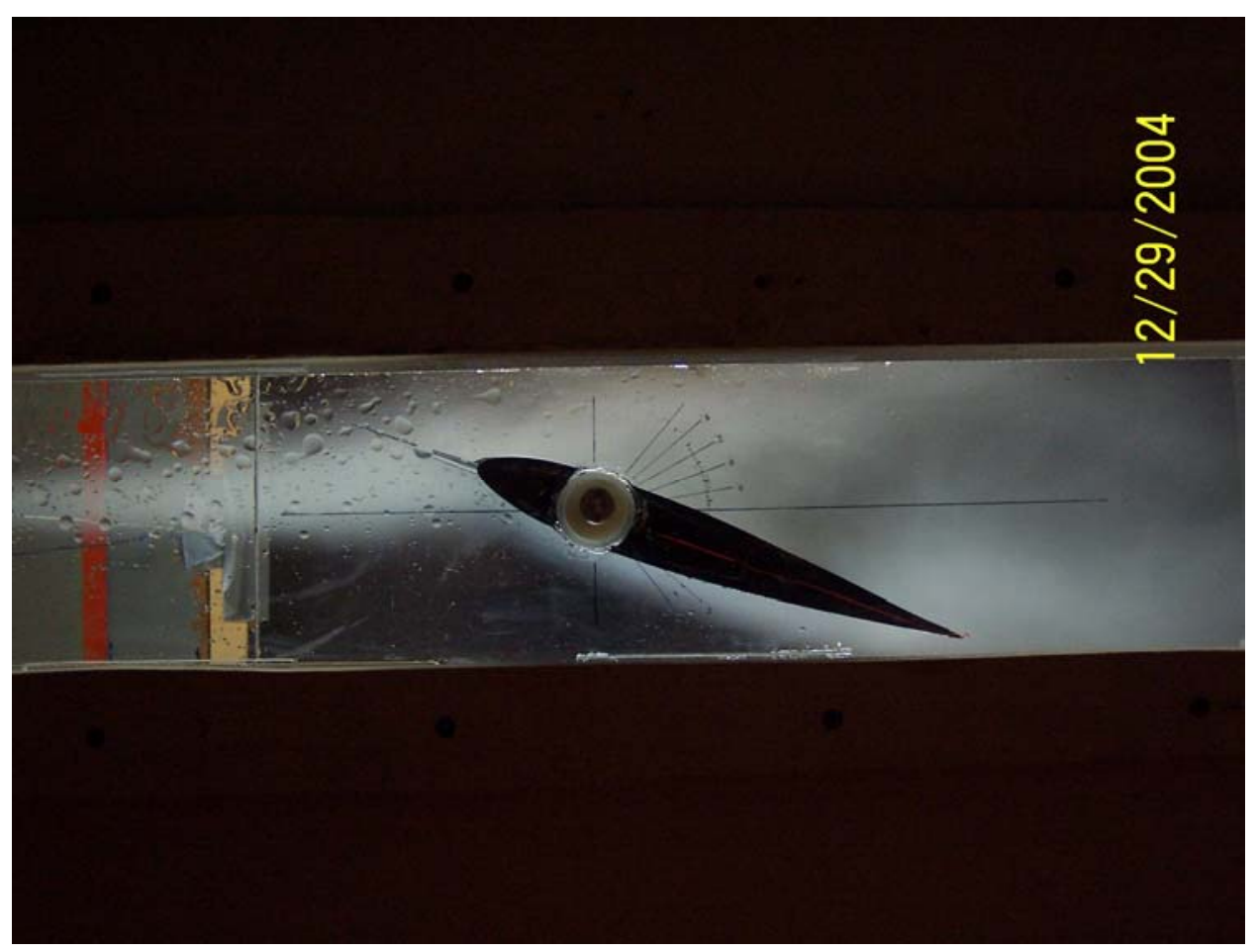

Figure 3-15: Airflow around wing with vortex generators to delay stall to $\alpha=18^{\circ}$, at

$$
\operatorname{Re}=9.2 \times 10^{4}
$$

Unfortunately, this method does not allow obtaining the lift coefficient quantitatively. Performing these experiments, only the angle of attack can be observed in which the flow separation occurs. 


\subsection{Computational Procedure}

\subsubsection{Wing Modeling in 2D}

The original coordinates for the NACA 0015 airfoil were taken to build and draw the airfoil for the experimental and the computational methods (not only for Gambit software, but also for Pro-Engineering software). As the wing was originally modeled with a chord of 9.5 inches, the values of the coordinates were multiplied by the same number in order to have the same size and effects during the experiment using the computational method.

The model was constructed in Gambit software introducing the points in Cartesian coordinates in two dimensions in order to build the airfoil. Then, these points were connected with the command "nurbs" obtaining the desired airfoil shape. Finally, the airfoil was ready to be defined the boundary conditions.

\subsubsection{Boundary conditions and mesh design in 2D}

The boundary conditions were defined according to the tutorial given by the Cornell University. The boundary layer was defined well away from the airfoil in order to have more accurate results. As long as the boundary layer was placed farther, it had less effect on the airfoil. However, a different upstream shape was chosen since unstructured grid was used. This created region corresponded to a square of 240x240 inches of size in which the airfoil was centered in the middle of this domain; see Figure 3-16. The relation given by this tutorial is $12.5 \mathrm{c}$, where $\mathrm{c}$ is the chord size. 
Next, the airfoil area had to be subtracted from the boundary layer in order to have only the flow volume outside the wing meshed. However, when the angles of attack were necessary to calculate, the airfoil had to be rotated first. Then, the subtraction procedure was repeated as mentioned before.

Figure 3-16 shows the created region that defines the boundary layer and the mesh generation.

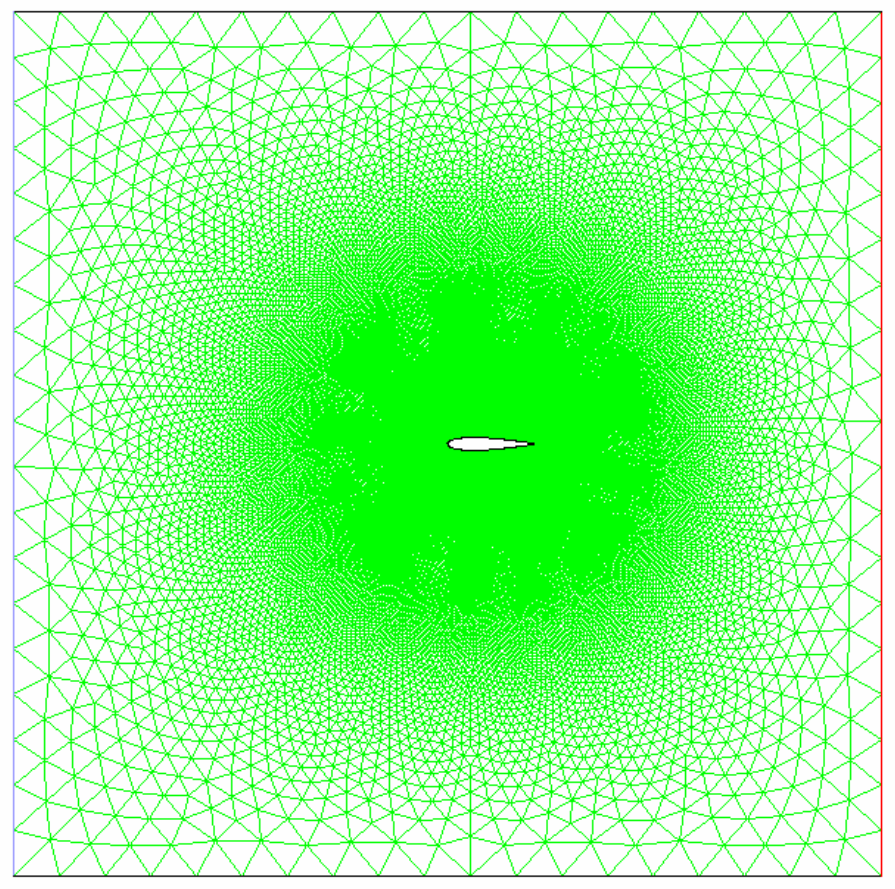

Figure 3-16: 2D Fluent boundary layer and mesh generation for airfoil NACA 0015 with up and downstream boundary location at ten chord length distance from the airfoil

In order to perform the mesh generation, the airfoil edges were selected and meshed with a specific value of 0.1 for interval size. The same way, the outer edges of the rectangular face were meshed with a specific value of 5 for interval size. Then, the rectangular face was meshed with Tri/Pave meshing scheme. In this way, the smallest 
grids were close to the airfoil and they grow as far as the airfoil was placed. The boundary layer was specifying by the type as shown in the following Table 3-10. Finally, the file was saved and exported in 2D.

Table 3-10: Specification of the boundary types

\begin{tabular}{|c|c|}
\hline Name & Type \\
\hline Airfoil & Wall \\
Upper boundary & Wall \\
Lower boundary & Wall \\
Right boundary & Pressure_outlet \\
Left boundary & Velocity_inlet \\
\hline
\end{tabular}

\subsubsection{Computational Process in 2D}

In the CFD Fluent software, the option in 2D had to be checked to start working. Next, the grid process included the reading of the file, the checking, and the scaling of the grid in English units. Under the model, the simulation was defined as segregated because for flows low-speed flow where the $\mathrm{V}<330 \mathrm{ft} / \mathrm{s}$, it is reasonable to assume $\rho$ as constant to simplify the analysis. This assumption of incompressible flow is an excellent approximation because the variation of the density is negligibly small (Anderson, 2000). Under the formulation, the implicit solver converged much faster than the explicit solver. Under the time, the steady option was chosen because the simulation was at steady flow or time average steady flow (i.e., not dynamic simulation). The other options were left by default. The heat transfer equation was kept off because for all the iterations, the Mach number was less than 0.3. Also, a laminar flow was chosen for the simulation. To assure 
this type of flow, the internal flow was examinated. Since the maximum velocity occurred in the core of the vortex generator, it could be four or five times greater than the freestream velocity (Gursul, 2004). Then, the maximum Reynolds number was $9.2 \times 10^{4}$ so this boundary layer the maximum internal Reynolds number in the core of each vortex generator would be $4.6 \times 10^{5}$. Therefore, this dimensionless value is less than the lower

limit in the range of laminar-turbulent transition Reynolds number, roughly between $10^{6}$ and $10^{7}$ (Schlichting, 2003). This analysis was made based in the boundary layer over the upper surface of the delta flap in which it had the greatest velocity value.

The air was selected under the Fluid Materials. Finally, the boundary conditions were defined by input each freestream velocities for the velocity inlet and zero to the pressure outlet. Finally, the residuals were kept at 0.001 and the software was initialized in order to be solved. Then, the iterations started until the program converged and the results were obtained.

\subsubsection{Results with Profili Software}

Since it was difficult to compare the experimental data obtained in the present study with results found in the literature, Profili professional version software was used to obtain the lift coefficient versus angle of attack plot at the different Reynolds numbers. This software was made in Visual $\mathrm{C}++6.0$ having approximately 50,000 code lines. It computational tool generated all the polars database. After choosing the airfoil desired and input the Reynolds numbers required, the Profili software obtained the values for angle of attack, lift coefficient, drag coefficient, moment coefficient, etc. These results 
could be exported in Excel worksheet in order to plot of lift coefficient versus the angle of attack in the velocity range used in the present experiments; see Figure 3-17.

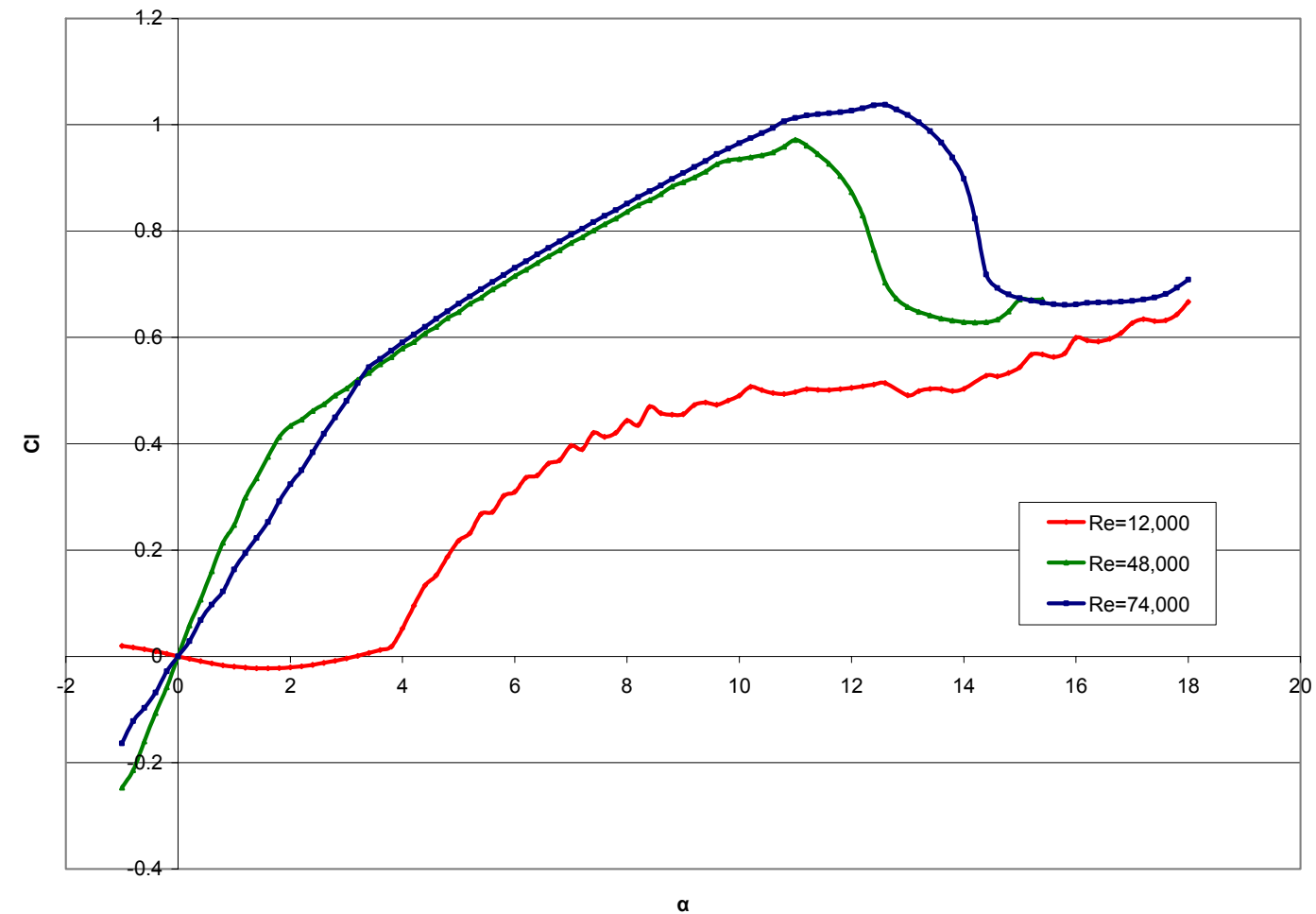

Figure 3-17: Lift Coefficient vs. Angle of attack obtained from Profili software

These results showed an irregularity at the lowest velocity value, with a Reynolds number of $1.2 \times 10^{4}$. According to this software, the airspeed developed at this Reynolds number was too low to create lift. This information was only referential to compare the experimental results and Miley's (1982). For the other Reynolds numbers, the lift coefficients shown were off compared with the experimental results, but the angles of attack approached well to those found by Miley. 


\subsubsection{Computational 2D Results with Fluent Software:}

The iterations allowed building several tables and graphs for comparison with the data from the experimental section. Among them, the most important were the velocity vectors and the static pressure distributions developed inside the boundary layer in the simulation. The CFD Fluent software determined the lift generated by the wing in the different configurations, and using the formulas afore mentioned, the lift coefficients were obtained. Then, the following plots show these pieces of information with their respective explanation.

Figure 3-18 shows the computed velocity vectors colored by the velocity magnitude in $\mathrm{m} / \mathrm{s}$ for 2D NACA 0015 at $12^{\circ}$ angle of attack (closest to stall) with a Reynolds number of $4.8 \times 10^{4}$. This figure shows that a small bubble formed on the upper surface on the airfoil as a consequence of the airfoil being close to stall. This figure also shows that the wake was large (flow separation) starting from half of the airfoil chord approximately. 


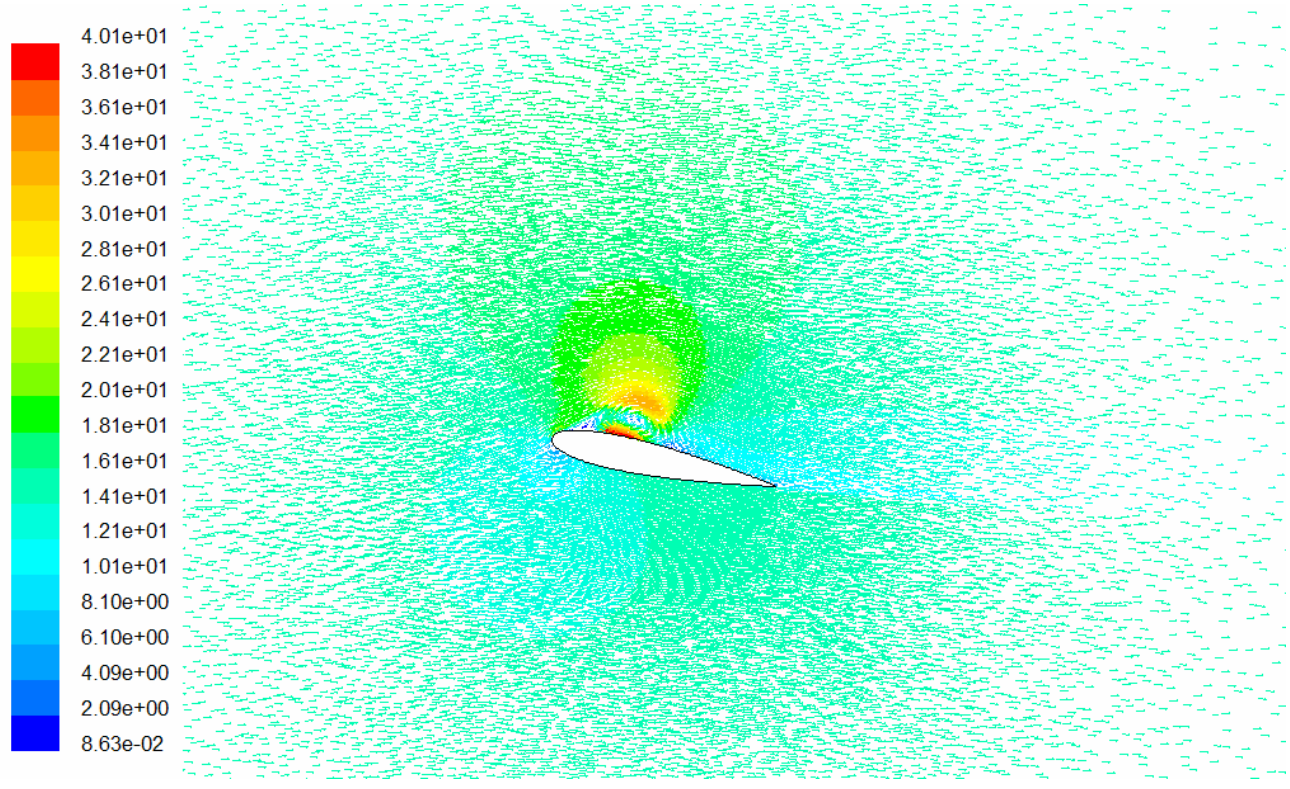

Figure 3-18: Velocity vectors colored by velocity magnitude (m/s) for 2D NACA

\section{5 airfoil at $12^{\circ}$ angle of attack and $\operatorname{Re}=6 \times 10^{4}$}

Figure 3-19 shows the computed contours of static pressure in Pascal for 2D NACA 0015 at $12^{\circ}$ angle of attack (closest to stall) with a Reynolds number of $4.8 \times 10^{4}$. The lower surface of the airfoil had bigger static pressures comparing with the upper surface. At approximately half of the airfoil chord, the airfoil has the lowest static pressure on the upper surface. 


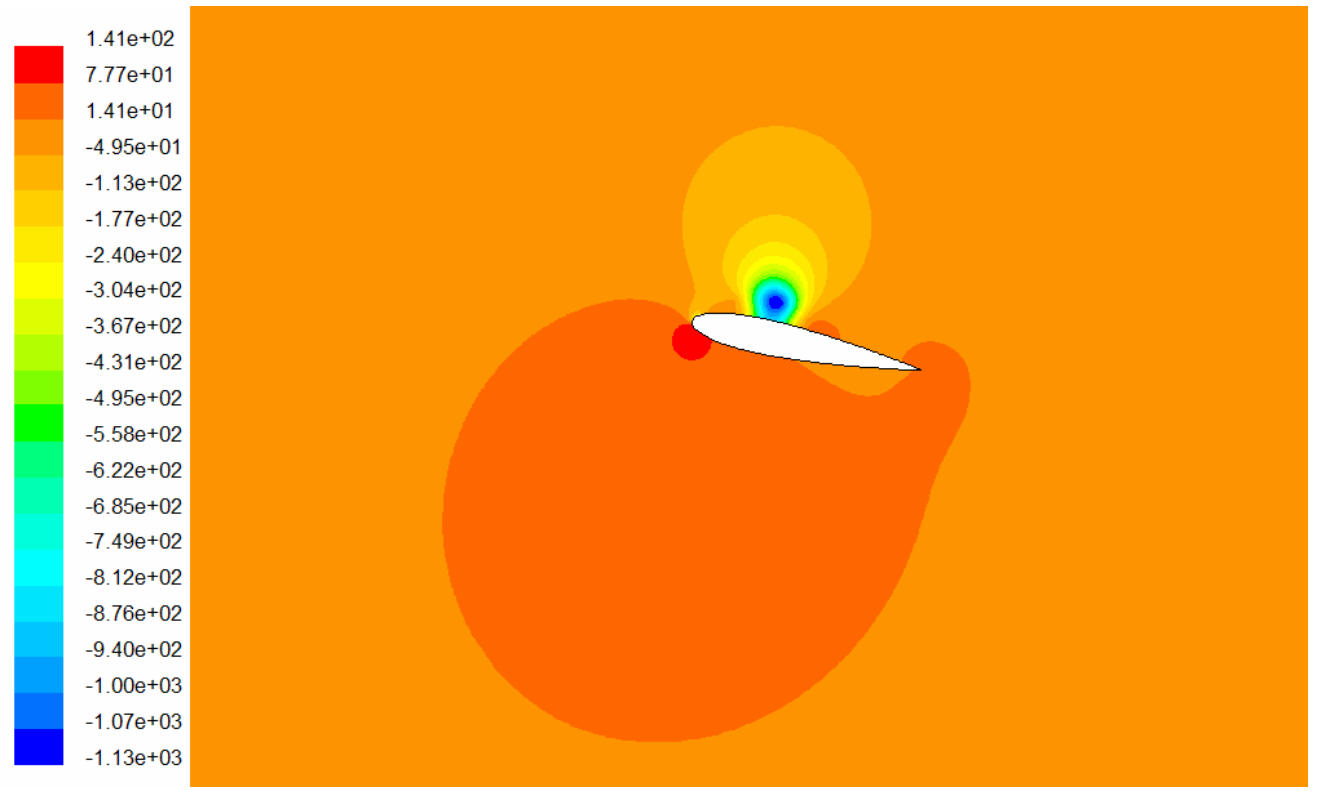

Figure 3-19: Contours of Static Pressure (Pa) for 2D NACA 0015 airfoil at $12^{\circ}$ angle of attack and $\operatorname{Re}=6 \times 10^{4}$

With these results, a plot was constructed to compare the lift coefficient versus the angle of attack using the different sources. These plots were very similar especially for the angle of attack, but the lift coefficient obtained from the CFD Fluent software were off from approximately $8^{\circ}$ angle of attack for very similar Reynolds numbers (Figure $3.20)$. 


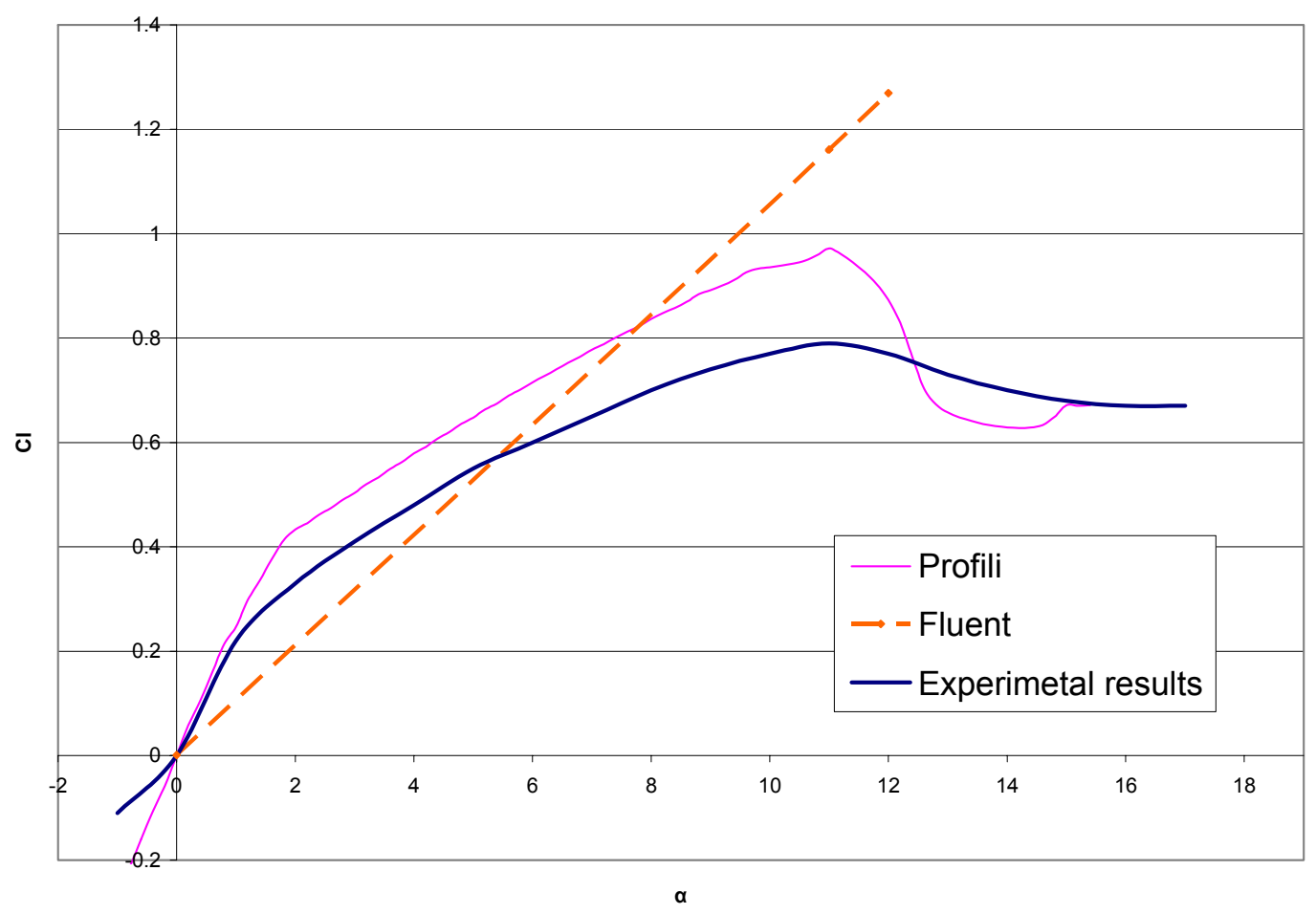

Figure 3-20: 2D comparison between computational (CFD and Profili) and experimental results (Miley, 1982) at $\mathrm{Re}=4.8 \times 10^{4}$

These angles of attack obtained in the present simulation matched with the experimental part. However, the lift coefficient was impossible to assure quantitatively because in the experiment, there were not any instrument to measure this parameter.

\subsubsection{Wing Modeling in 3D}

Once the calculated results in $2 \mathrm{D}$ were obtained, the simulation in $3 \mathrm{D}$ was very similar and ready to be conducted. Then, to assure the results in $2 \mathrm{D}$, the slope of the lift coefficient would have to decrease, but the angle of attack had to maintain at $12^{\circ}$. Therefore, a clean wing had to be simulated showing accordance with the previous 
results. As mentioned before, the steps explained before were very similar, but for this particular case the airfoil was extruded perpendicularly in the $\mathrm{z}$ direction in order to build the wing in three dimensions. Such extrusion was extended 8 inches initially, which was enough to include two delta flaps. With this configuration, the vortex core could be modeled. The goal of this procedure was to ensure that the vortex core from each delta flap would not cancel the adjacent one; otherwise, only the drag would increase and the results of adding the vertices to the wing would not be effective. That was also the reason for separating the holes in the bar by 1 inch in the real model.

\subsubsection{Boundary conditions and mesh design in 3D}

In order to define the boundary layer, the method explained for the simulation in 2D was copied. However, a brick shaped volume of $240 \times 250 \times 20$ inches was built to define the flow domain for 3D, see Figure 3-21. In this case, the upper volume was bigger by 10 inches as a result of the vortex generators modeling. It allowed a better analysis of the vortex phenomenon and the pressure contours on the wing. Then, the volume of the wing was subtracted from the volume of the brick, in order to have only the flow volume outside the wing. 


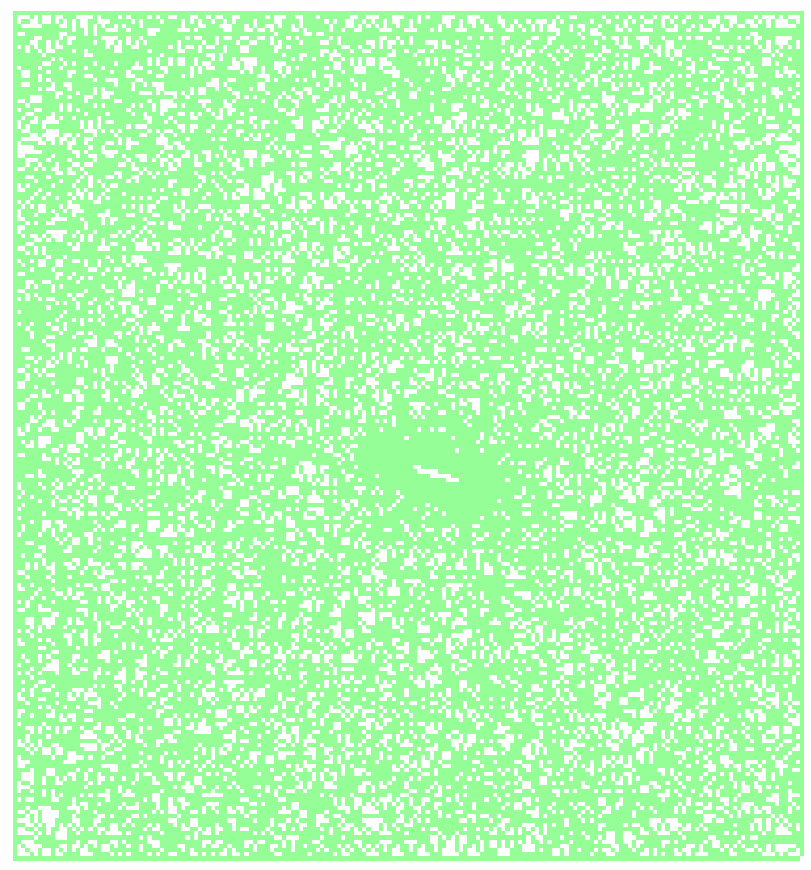

Figure 3-21: 3D Fluent boundary layer and mesh generation for airfoil NACA 0015 with vortex generators with up and downstream boundary location at 12.5 chord length distance from the airfoil

Next, the steps for meshing design in $3 \mathrm{D}$ would be different compared to the $2 \mathrm{D}$. In order to mesh the faces of the wing body, the option "Tri" was selected from the Elements options under Scheme that specifies only triangular mesh elements. Automatically, the "Pave" option was given as a first alternative that created a structural grid of mesh elements. This combination created a mesh consisting of irregular, triangular mesh elements.

In the same Windows pop up, the interval size of 0.05 under spacing was chosen to capture the boundary layer on the wing. The same procedure was applied to the walls 
of the brick in which they were meshed using the same characteristics for the wing-body with different interval size of 3 .

In order to mesh the volume, the option "Tet/Hybrid" was selected from the Elements options menu under Scheme and "TGrid" from the Type option menu. The interval size was maintained at the default size of 1 .

The "Tet/Hybrid" specified that the mesh was composed by tetrahedral elements. It could include hexahedral, pyramidal, and wedge elements when appropriate. The "TGrid" option basically defined tetrahedral mesh elements, but it could include hexahedral, pyramidal, and wedge when appropriate. The wing with no vortex generators had $1.9 \mathrm{e} 6$ grids.

Once the volume was meshed, the next step was to define the set of boundary conditions, such as the velocity inlet, pressure outlet, and walls described similar in the 2D simulation. The forward face of the brick to the wing was defined as the velocity inlet; the back face of the brick to the wing was defined as pressure outlet. The other faces of the brick (top, bottom, and sides) were defined as walls. The faces of the wing were also defined as walls, but with a different name to differentiate the body with the boundary layer. Finally, the file was ready to be exported from Gambit to Fluent.

\subsubsection{Computational process}

In the 3D simulation, the file had to be read, the grid checked, and the dimensions scaled because CFD Fluent software uses the SI system by default in order to work with the units of the English system. Next, several conditions had to be set in order to have the same test conditions given in the experiment. Air was the fluid by default under the 
Define Materials option in the software. The file had to be defined as segregated, implicit, and steady under the Models Solver options.

For the boundary conditions, the velocity inlet was defined according to the three most representative velocities measured in the experiment for each corresponding case. For the pressure outlet, a value of zero was used. Inside of the solve options, to guarantee greater accuracy, the control solutions for the pressure used was the standard, and second order upwind scheme was used. The second-order discretization was chosen for the scheme of the governing equation flow, since it allowed obtaining more accurate results for triangular and tetrahedral grids. The convergence criteria of the continuity, $\mathrm{x}, \mathrm{y}$, and $\mathrm{z}$ velocity were reduced to 0.01 to save computer resources. Finally, the software had to be initialized to be ready to start the iterations in the different scenarios required.

\subsubsection{Computational 3D Results with Fluent Software:}

Using the same conditions, the simulation for a wing with 8 inches of span was made. The results obtained in these simulations were not satisfactory; because at low aspect ratios the results changed drastically (these results are presented in the result section). It demonstrated that very small aspect ratio had a strong influence in the results. 


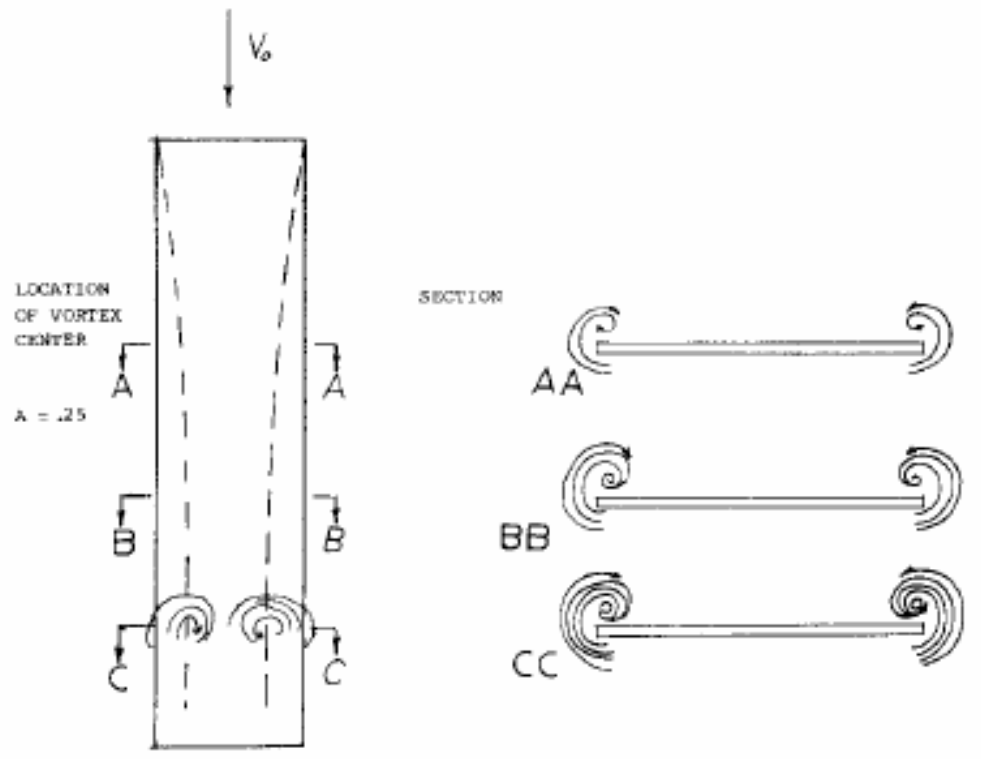

\section{Figure 3-22: Development and location of tip vortices on low aspect ratios wings (Hoerner, 1985)}

The basic lift curve slope was no longer used because the influence of the spanwise effects became more predominant. In addition, the lateral edges of the wing had a strong influence in the phenomenon known as tip vortex (Figure 3-21). It was a result of the trailing edge being exposed to a flow which had deflected by the leading edge.

Not only did the lift curve slope increase with the angle of attack up to the stall angle rather the remaining linear in conventional wing, but also the increase in slope was a secondary effect that took place over and above the wing circulation lift slope.

Figure 3-22 shows a comparison between the results with and without the delta flaps, with the same span (8 inches), to show how the lift coefficient and the angle of attack were different in the two cases. The continuous line represents the results for a 
regular wing, and the broken line corresponds to a wing in which two vortex generators were attached to the leading edge. The figure assumes the velocity value of $49.84 \mathrm{ft} / \mathrm{s}$ only, but the results for other velocities would be very similar.

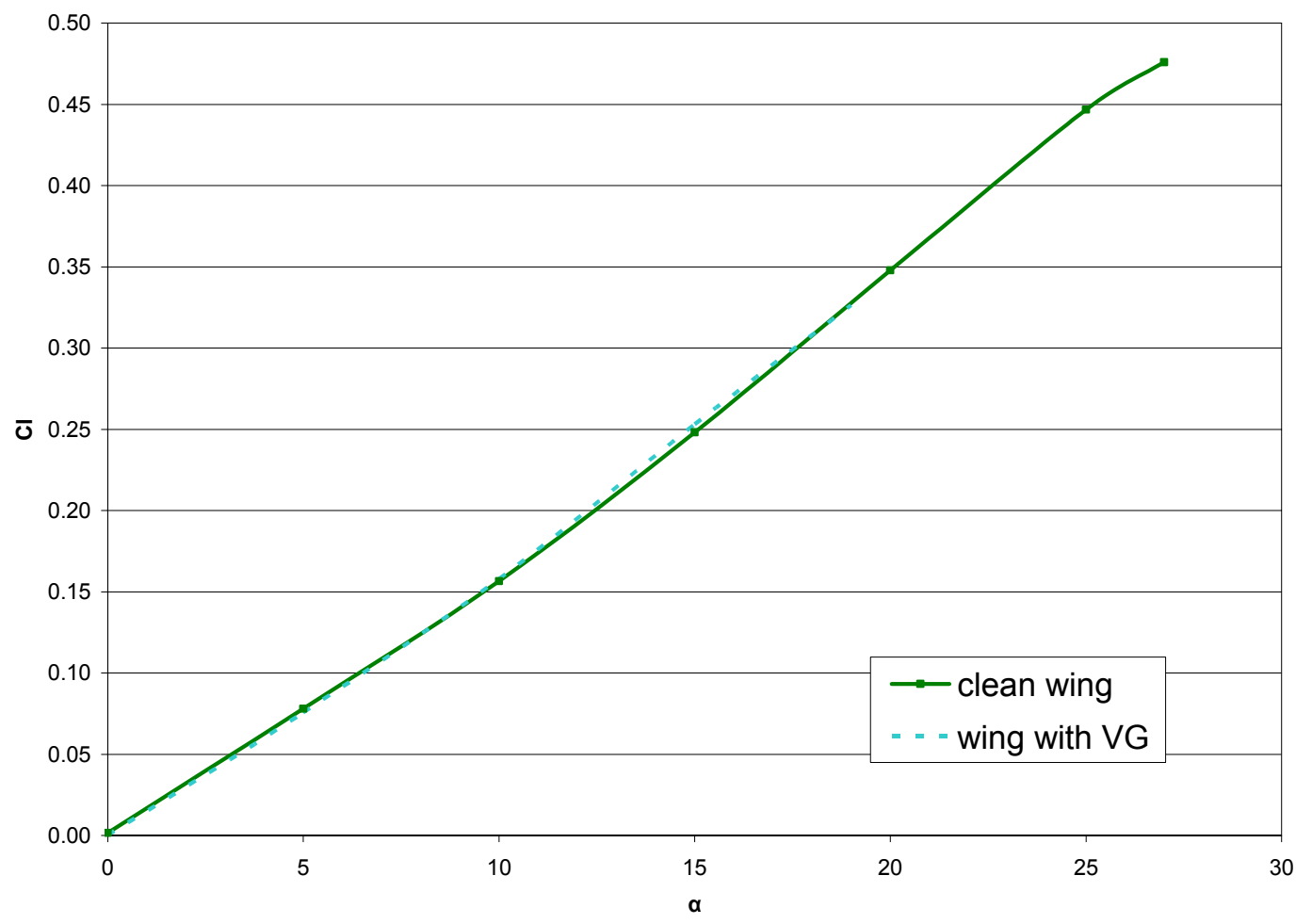

Figure 3-23: CFD Fluent results between a clean wing vs. a wing with 2 vortex generators attached with $A R=0.7$ at $R e=6 \times 10^{4}$

Therefore, in the modeling procedure mentioned above, instead of extruding 8 inches in the $\mathrm{z}$ direction, 16 inches were extruded. Hence, the wing modeled allowed to carry four horizontal triangular flat plates. Then, a new computational wing characteristic was constructed shown in Table 3-11. The core of the vortex generator was placed in the 
symmetry plane and half of the vortex generators were located on the end side of the wing.

Table 3-11: New wing dimensions for the CFD Fluent simulation

\begin{tabular}{|l|c|c|}
\cline { 2 - 3 } \multicolumn{1}{c|}{} & Value & Units \\
\hline Max. wing thickness & 1.425 & in \\
Wingspan (b) & 16 & in \\
Chord (c) & 9.5 & in \\
Base flat plate & 3 & in \\
Height flat plate & 2.6 & in \\
Vortex generator area & 3.9 & in ${ }^{2}$ \\
Wing area no flats & 152 & in $^{2}$ \\
Area wing (S) & 167.6 & in $^{2}$ \\
Computational domain & & \\
aspect ratio (AR) & 1.53 & \\
\hline
\end{tabular}

Then, the procedure followed was mostly the same as previously described, but the brick that defined the boundary layer also had to be increased to 30 inches in the $\mathrm{z}$ axis. Therefore, the new boundary layer had the dimensions 240x250x30 having 9 inches per side in the $\mathrm{z}$ direction to perform the new iteration process. In this latter case, the new mesh used was around 2.2e6 grids. The steps were the same as described before for the simulation in 3D. In here, a grid independence study was carried out using an unstructured tetrahedral mesh around the wing-body geometry. 
The results were consistent with the results found in the experiment, matching in $16^{\circ}$ angle of attack for the onset of stall. However, the quantitative lift coefficient data had not been compared since the experiment allowed only determining the angle of attack.

Figures 3-24, 3-25, 3-26, and 3-27 shows the velocity value at different localizations of the simulation. From these figures, the flow separation had already occurred on the section were no vortex generators was placed (Figure 3-27). At the apex of the vortex generator, the flow separation was controlled (Figure 3-24) and it grew as far as the apex was located (Figure 3-25 and 3-26).

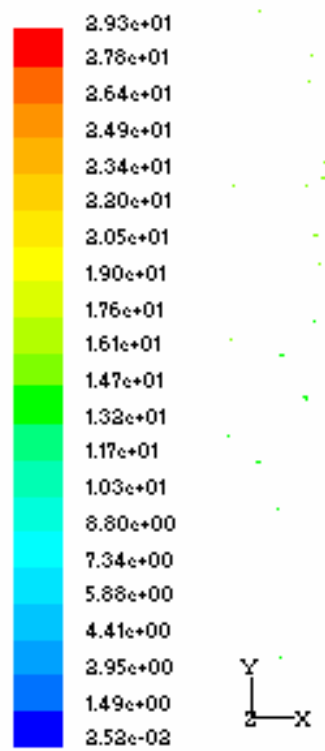

Figure 3-24: Velocity vectors colored by velocity magnitude $(\mathrm{m} / \mathrm{s})$ for 3D simulation with $4 \mathrm{VG}$ at $16^{\circ}$ angle of attack at the symmetry plane for $\operatorname{Re}=6 \times 10^{4}$ 


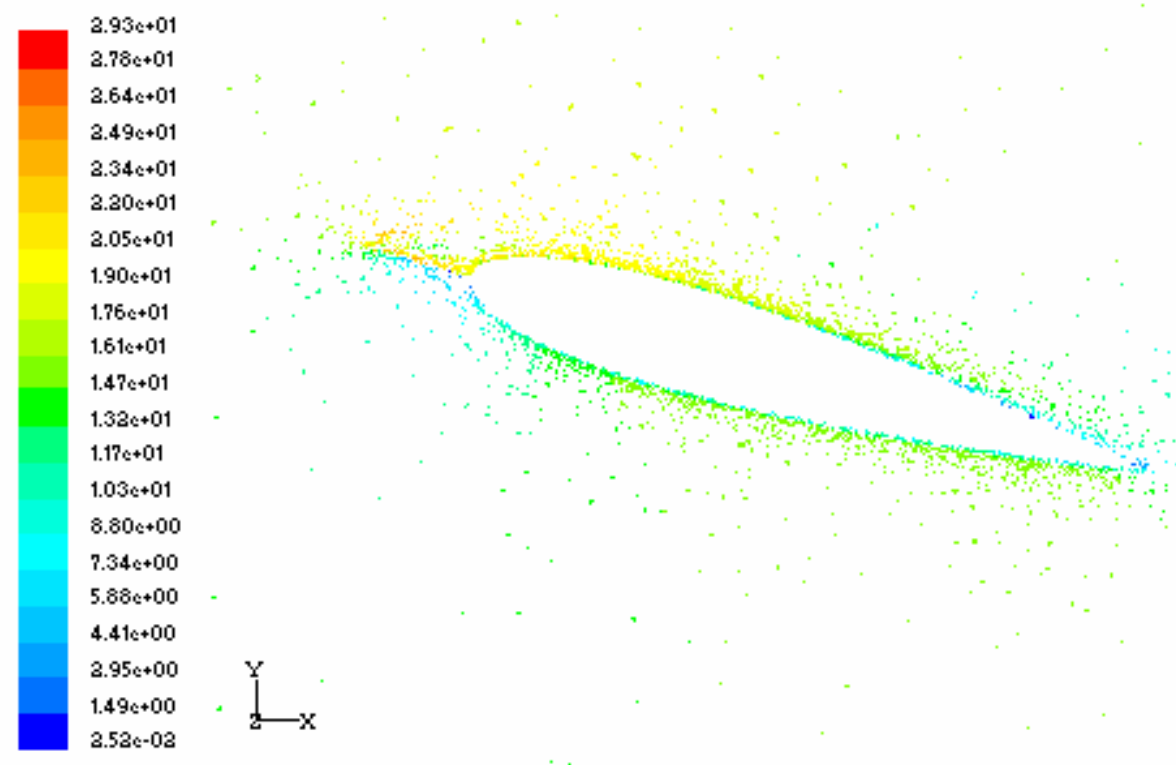

Figure 3-25: Velocity vectors colored by velocity magnitude (m/s) for 3D simulation with $4 \mathrm{VG}$ at $16^{\circ}$ angle of attack and at 0.75 inches off the symmetry plane for

$$
\operatorname{Re}=6 \times 10^{4}
$$

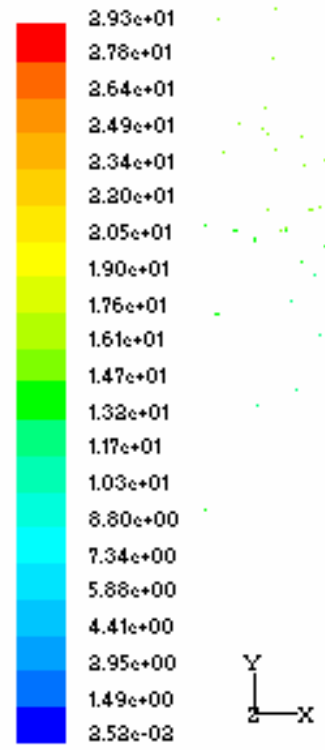

Figure 3-26: Velocity vectors colored by velocity magnitude (m/s) for 3D simulation with $4 \mathrm{VG}$ at $16^{\circ}$ angle of attack at 1.5 inches off the symmetry plane for $\operatorname{Re}=6 \times 10^{4}$ 


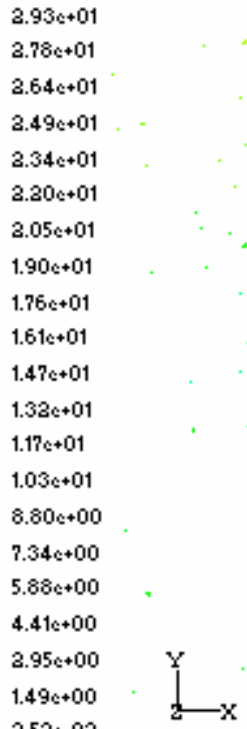

Figure 3-27: Velocity vectors colored by velocity magnitude $(\mathrm{m} / \mathrm{s})$ for 3D simulation with $4 \mathrm{VG}$ at $16^{\circ}$ angle of attack at 2 inches off the symmetry plane for $\operatorname{Re}=6 \times 10^{4}$

Figures 3-28, 3-29, 3-30, and 3-31 show the contours of pressure at different locations along the wing. The pressures behaved in an opposite way than the velocity around the wing. The highest pressure was on the lower surface along the wing at the stagnation point and below the vortex generator. Figure 3-28 shows the lowest pressure occurs at the vertices of vortex generator on the upper surface. Then, it was displaced backwards on the different planes of the airfoil shown in the next figures. Figures 3-29 and 3-30 show the vortices produced by the separated shear layer over the delta vortex generator and on the leading edge of the defined plane respectively. 


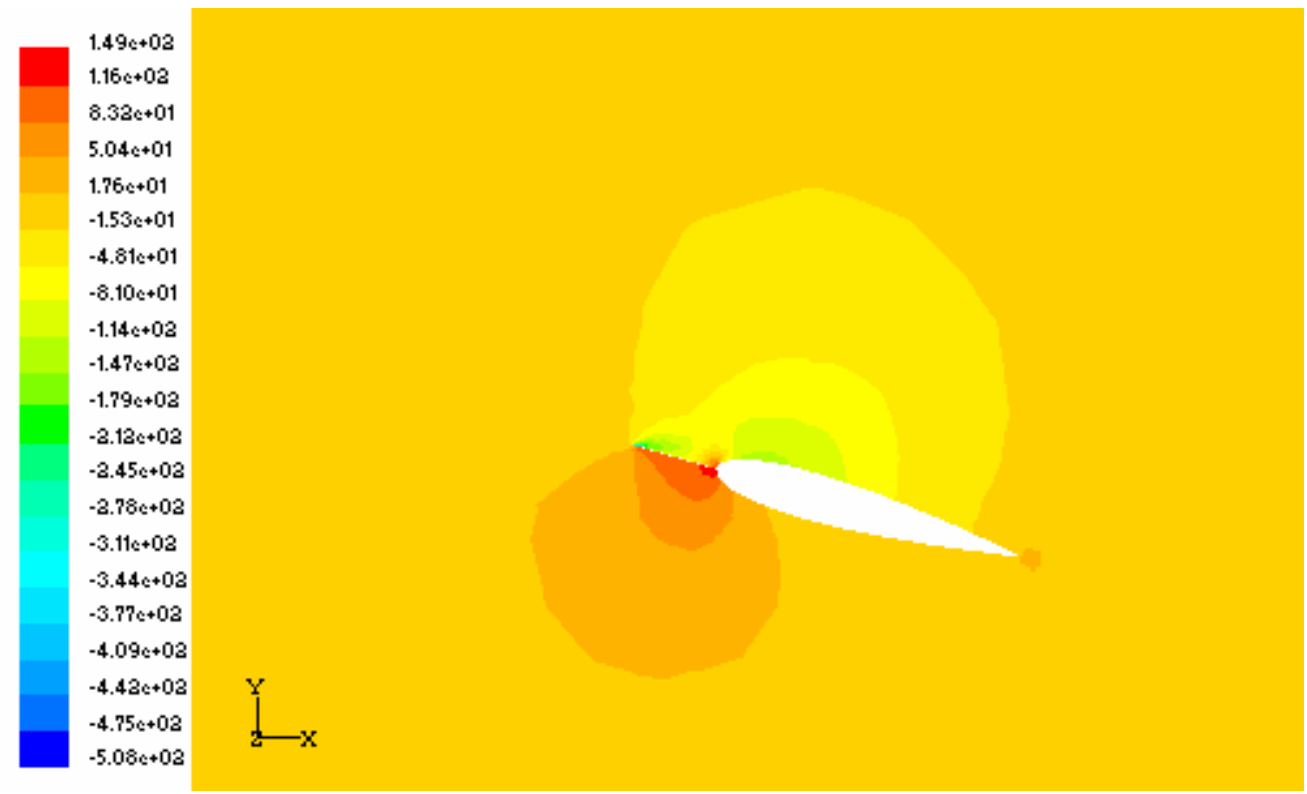

Figure 3-28: Contours of Static Pressure (Pa) for 3D simulation with 4 VG at $16^{\circ}$ angle of attack at the symmetry plane for $\mathrm{Re}=6 \times 10^{4}$

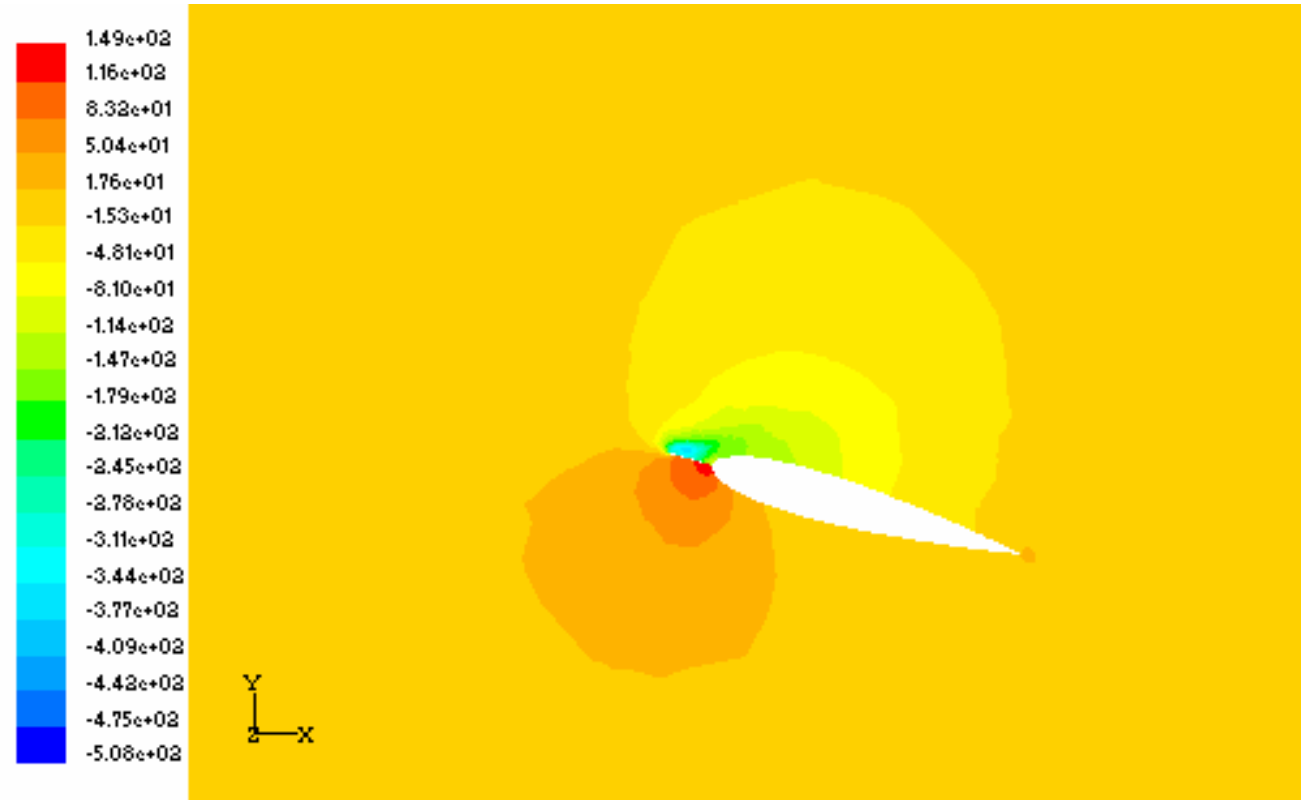

Figure 3-29:Contours of Static Pressure (Pa) for 3D simulation with 4 VG at $16^{\circ}$ angle of attack at 0.75 inches off the symmetry plane for $R e=6 \times 10^{4}$ 


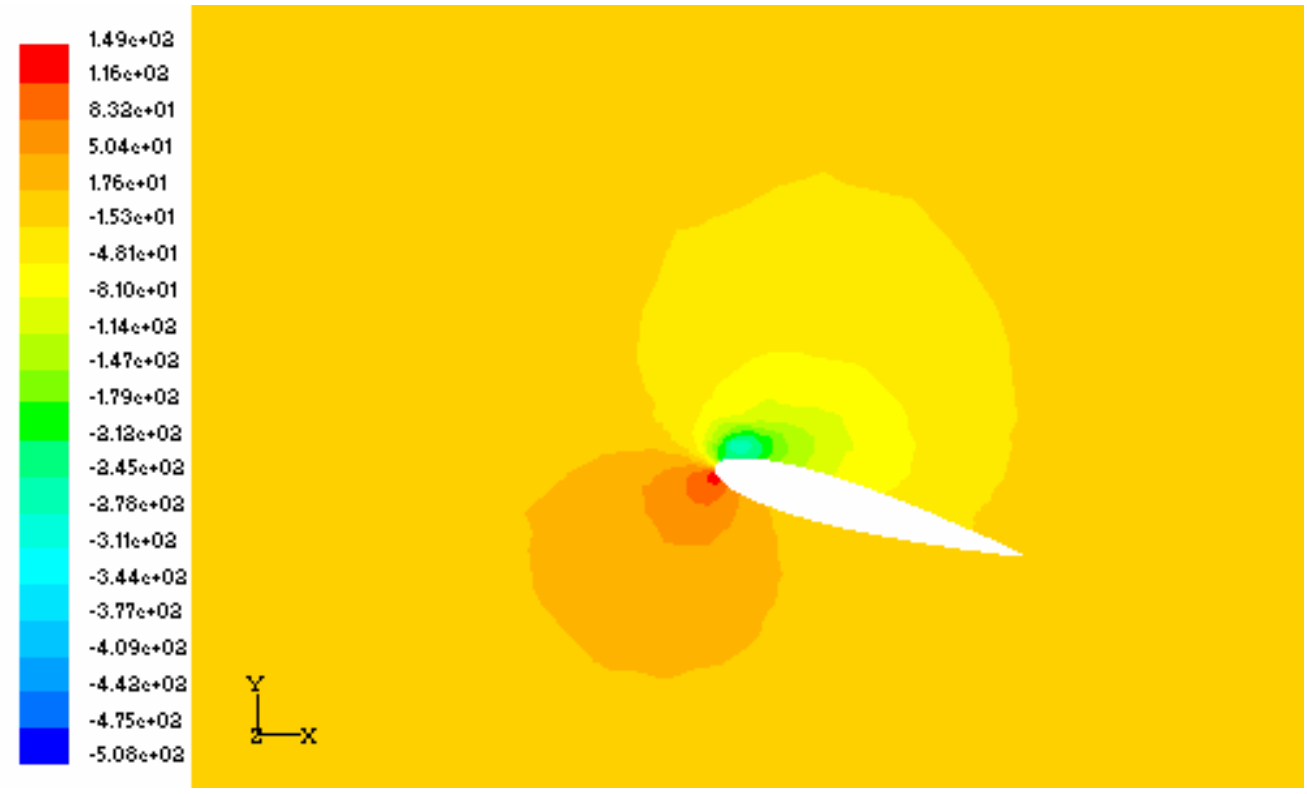

Figure 3-30: Contours of Static Pressure (Pa) for 3D simulation with 4 VG at $16^{\circ}$ angle of attack at 1.5 inches off the symmetry plane for $R e=6 \times 10^{4}$

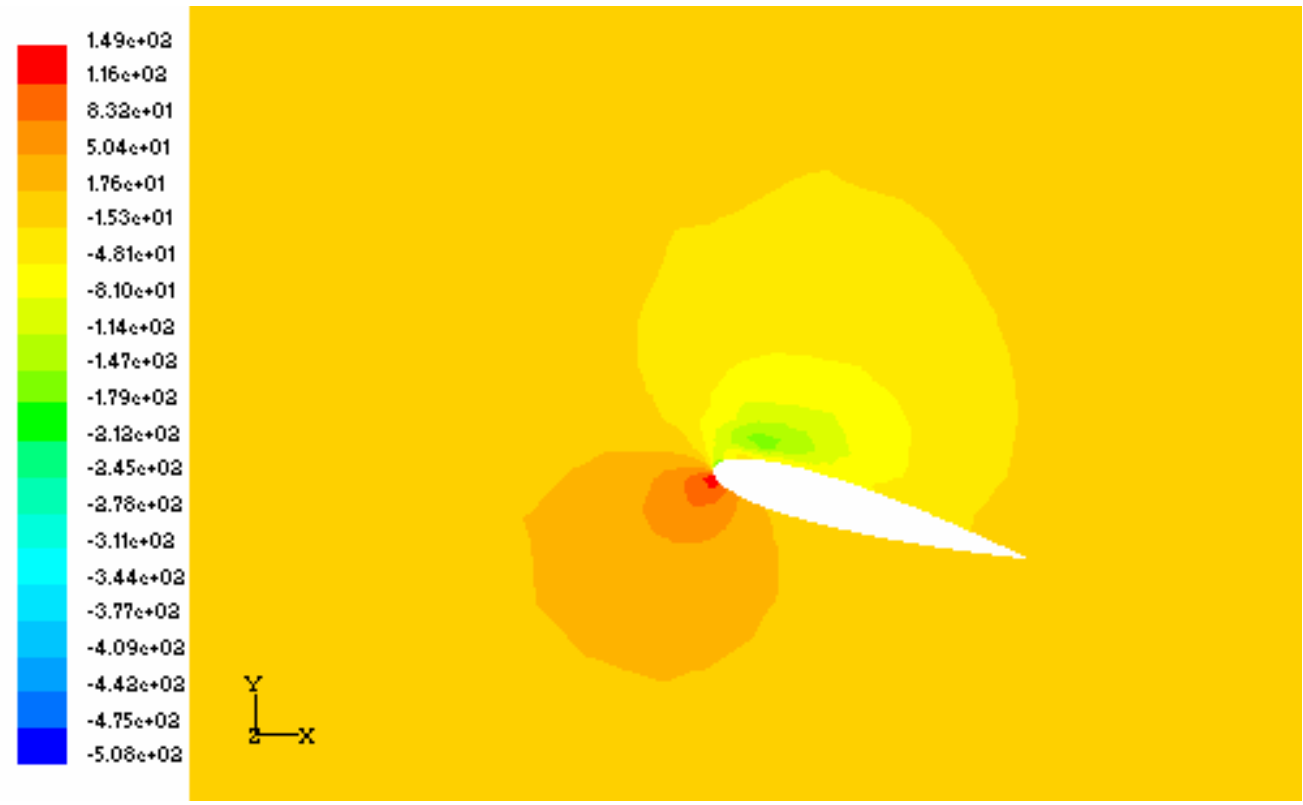

Figure 3-31: Contours of Static Pressure (Pa) for 3D simulation with 4 VG at $16^{\circ}$ angle of attack at 2 inches off the symmetry plane for $R e=6 \times 10^{4}$ 
Finally, using these results, a figure was built to show the lift coefficient versus the different angles of attack at the effective Reynolds number of $6 \times 10^{4}$ with vortex generators compared with a clean wing with the same span. Both simulations were performed at the same atmospheric conditions described before. From Figure 3-32, it is seen that the use of vortex generators assures the delaying of the flow separation energizing the boundary layer.

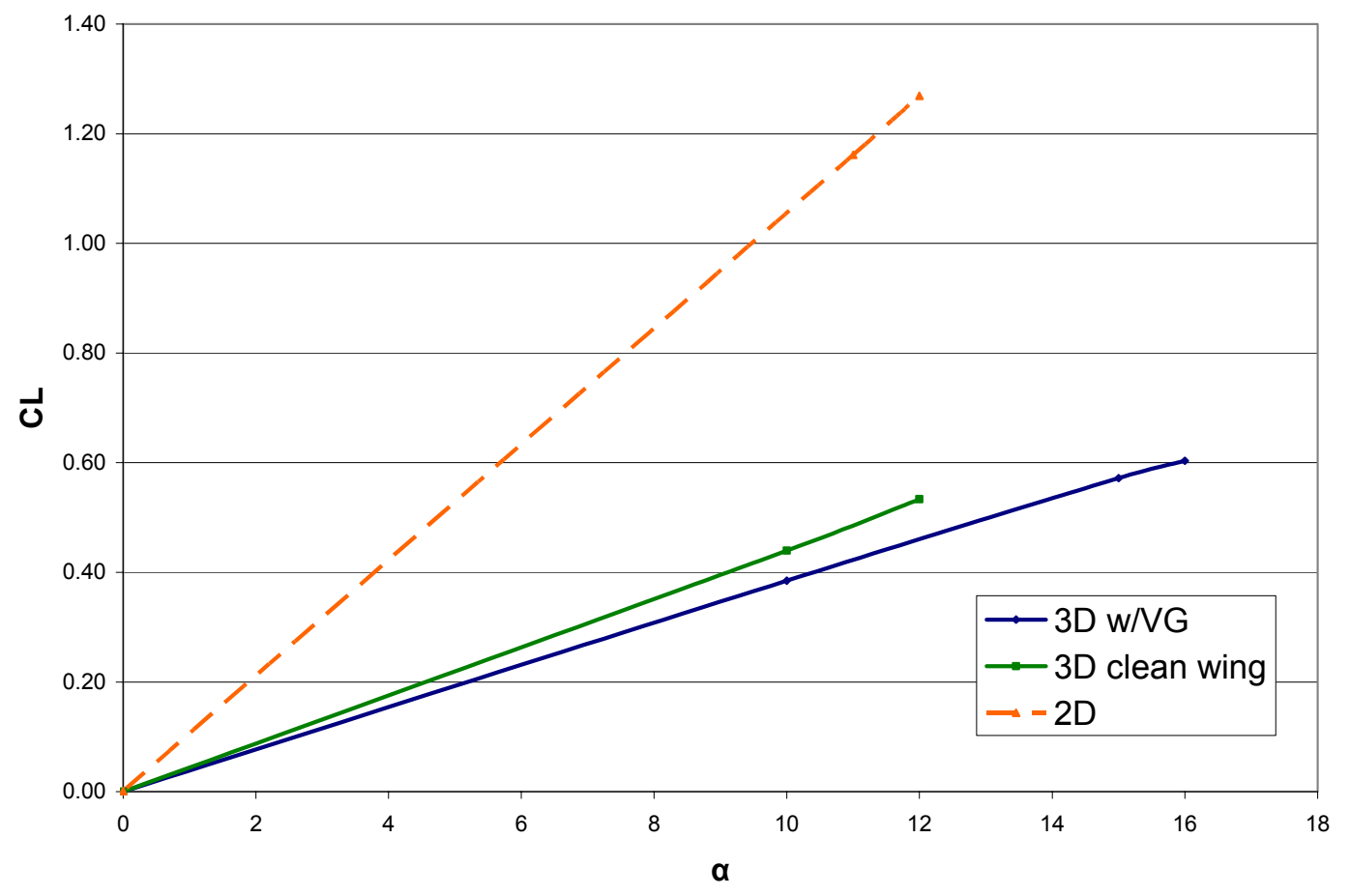

Figure 3-32: Comparison of the results obtained in the CFD simulation for a wing with $\mathrm{AR}=1.53$ at $\mathrm{Re}=6 \times 10^{4}$

Adding the vortex generators, the flow separation was delayed. However, the lift coefficient had a drag penalty. Although the increase of the lift coefficient and the angle of attack was showed at $16^{\circ}$ of angle of attack in the Figure $3-20$, at $12^{\circ}$, the lift 
coefficient decreased. In order to avoid this penalty, the solution to this problem may be achieved by using retractable vortex generators.

The most noticeable effect is that the low aspect ratio of the experimentally tested and computationally modeled wing with vortex generators has drastically reduced the resulting $\mathrm{C}_{\mathrm{L} \alpha}$ lift curve slopes. Reasons for this may be:

- The vortex generators are far too large relative to the chord, here at $25 \%$.

- The vortex generator values entrained ambient air into the surface, thereby reducing the vacuum and thus lift.

- Properly sized vortex generators should only affect the leading edge stall and not influence the main portion of the wing. 


\section{Chapter 4 SUMMARY AND CONCLUSIONS}

\subsection{Summary}

In order to delay stall during take off, landing, and in icy conditions, the leading edge of wing has to be modified. This investigation sought to determine if adding multiple horizontal triangular flat plates to the leading edge, each of them working as a vortex generator, would provide satisfactory stall delay. In general, the present vortex generators allow some increase in stall angle of attack as a result of turbulent vortices at their swept leading edges. The triangular flat plates vortex generators can be stowed in flight to be used only during take off and landing.

\subsection{Conclusions}

Neither experimental smoke studies, nor computational analysis indicated that the stall delay obtainable with vortex generators was as effective in delaying wing stall as the currently used Kruger flap. This may have been due to the large size of the present vortex generators.

Correlation between results obtained from the Profili software, from experiments and from the Fluent software, are difficult due to the low Reynolds numbers used in the smoke visualization study. Experimental inaccuracies in defining wing stall may explain the $2^{\circ}$ variation in measured stall angle of attack. The true value of wing stall angle lies within this range. No device was used to measure the pressure along the wing. Although tufts located in different positions along the wing were used to visualize the direction of 
the flow, such direction could be influenced by turbulence created by the vortex generators. Also, the surface of the wing was not perfectly smooth, so the roughness of the wing might have influenced the onset of wing stall. Moreover, the airfoil shape was not perfect, even in the spanwise direction, as a result of the sanding.

During the experiment some problems were encountered, such as those involved in the manometer reading. The dust present inside the tube may have affected the movement of the liquid (water). Moreover, apparatuses used such as the manometer, thermometers, rulers, etc. have uncertainties which were not considered in the analysis. Additionally, since the reference values taken from the experimental section were used in the computational method, they entailed starting with some small errors. The software used could not simulate exactly what happens with vortex generators as used in this experiment.

Vortex generators altered the stall characteristics at low speeds and the stall angle of attack of the wing. It was not possible to measure the increase in lift because the WVU wind tunnel balance was broken.

The CFD and experimental results were different because the boundary layer was defined differently. In the experiment, the test section was 44.5 inches wide and 32 inches of height testing a wing with 9.5 inches with solid walls at the top and the bottom. On other hand, the computational boundary layer was 250 inches wide and 30 inches of height. Therefore, the streamlines were under the influence of the size of the experimental boundary conditions.

The effect of the vortex generator size remains unknown since only one size was investigated. With vortex generators measuring $0.25 \%$ chord wing, the best results were 
found when spaced 2 inches apart. However, the optimum distance between each horizontal triangular flat plate should be investigated in the future as a function of their size.

Using the CFD Fluent software, the simulation performed in 2D showed results that were very similar to those found in the present experiments with respect the angle of attack.

According to CFD Fluent software, the flow separation was delayed from 12 deg to $16 \mathrm{deg}$ as a result of the presence of the vortex generators. The results regarding the angle of attack were comparable to the results found in the experiment conducted in the wind tunnel.

The CFD simulation showed that the velocity increased in between the vortices shed by the triangular vortex generators, because of the flowfield, performing roll up on the wing. This energized the boundary layer and prevented flow separation until an angle of attack of $16 \mathrm{deg}$. The separation bubble was found on the upper surface on the wing, located at different places. On the tip of the vortex generator the flow separation occurred very close to the leading edge, whereas in the absence of vortex generators, the separation occurred half way along the upper surface of the wing chord.

The use of vortex generators on the wing caused a drag penalty. This may be avoided when using retractable vortex generators to be used only when necessary (landing, taking off, and icing conditions).

It is important to consider the span size of the wing, because for very low aspect ratios, the vortex had a strong influence in the flow separation. Such separation could also be influenced by the vortex shed at the wing tip. 


\section{Chapter 5 RECOMENDATIONS}

The present investigation was carried out in order to determine the effect of horizontal leading edge delta flaps on the leading edge stall. However, it appears that the selected large vortex generator size overpowered the effect of the airfoil shape. Thus, the primary recommendation is to experiment with fewer and smaller vortex generators in future investigations.

The use of a hot wire anemometer is recommended to acquire data at the low Reynolds numbers used where pressure taps are unable to provide reliable data at such low Reynolds number. At higher Reynolds number, the use of multiple pressure taps would provide a better way to measure the static pressure distribution in the spanwise direction. Also, the drag could be measured via wake rake.

These devices called vortex generators might work better at delaying onset of stall if they were utilized on a thinner airfoil.

Since the computer resources were limited, only a computational domain aspect ratio of 1.5 was simulated in the CFD software. Additionally, the computer resources had limitations for the convergence criterion, which was of 0.01 and could be greater according to the requirements.

Higher Reynolds number values as occur in commercial aircraft should have been used, together with compressible flow as is possible with the CFD Fluent software, which allows changing this parameter from segregated to coupled in the solver mode to get more accurate results. Better computer resources would be required, however, in order to obtain such more accurate results. 


\section{References}

Abbot, I. H. \& Von Doenhoff, A. E. (1959). Theory of Wing Sections including a Summary of Airfoil Data. Dover Publications, Inc.

Anderson, J. D. Jr. (2000). Introduction to Flight. Fourth Edition. McGraw-Hill Book Company, Inc.

Anderson, J. D. Jr. (2001). Fundamentals of Aerodynamics. McGraw-Hill Book Company, Inc.

Bender, E. E. Anderson, B. H. \& Yagle, P. J. (1999). Vortex generators modeling for Navier-Stokes Codes. NASA/CR-2001-211144, 2001.

Bertin, J. J. (2002). Aerodynamics for Engineers. Fourth Edition. Prentice-Hall, Inc.

Bond, R. E. (2001). [Preliminary Results using vortex generators mounted on the leading edge of a wing]. Unpublished raw data.

Bragg, M. B. \& Gregorek, G. M. (1987). Experimental Study of Airfoil Performance with Vortex Generators. Journal of Aircraft, 5, pp.305-309.

DiCarlo, D. J., Brown, P. W., \& Hallissy, J. B. (1992). Flight Test Operations Using an F-106. Research Airplane Modified with a Wing Leading-Edge Vortex Flap (Report AIAA 92-4094). Hilton Head Island, SC: NASA Langley Research Center.

Fluent Inc Products. (2004). Gambit Tutorial Guide [Computer Software and Manual]. Retrieved from http://www.fluentusers.com/gambit2230/doc/doc_f.htm

Fluent Inc Products. (2004). Fluent Tutorial Guide [Computer Software and Manual]. Retrieved from http://www.fluentusers.com/fluent61/doc/doc_f.htm 
Gursul, I. (2004). Recent developments in delta wing aerodynamics. The Aeronautical Journal, 108, pp. 437-451.

Hasegawa, H., Yoshikawa, M. \& Matsuuchi, K. (2005). Effect of Vortex Generator Jets with different Aspect Ratios on Boundary Layer Control. Nihon Kikai Gakkaishi Transactions of the Japan Society of Mechanical Engineers, 71, pp. 496-503.

Hoerner, S. F. \& Borst, H. V. (1985). Fluid-Dynamic Lift: Practical Information on Aerodynamic and Hydrodynamic Lift. Hoerner Fluid Dynamics: New Jersey

Jirasek, A. (2004). A Vortex Generator Model and its Application to Flow Control. AIAA Journal, 22, pp.465-478.

Kerho, M., Hutcherson, S., Blackwelder, R. F., \& Liebeck, R. H. (1993). Vortex Generators Used to Control Laminar Separation Bubbles. Journal of Aircraft, 30, pp.315319.

Kim, S. (2004). Meshing and CFD Accuracy. Symposium conducted at the 2004 CFD Summit.

Littell, H. S. \& Eaton, J. K. (1991). Unsteady Flowfield Behind a Vortex Generator Rapidly Pitched to Angle of Attack. AIAA Journal, 4, pp.577-584

Loth, J. L., Morris, G. J., \& Bond, R. E. (n.d.). Wing Stall Prevention with Retractable Horizontal Vortex Generator and Flexible Trailing Edge. Provisional Patent Application.

Mathur, R. (2004). Meshing Complex geometry in Gambit. Symposium conducted at the 2004 CFD Summit.

Miley, S. J. (1982). A Catalog of Low Reynolds Number Airfoil Data for Wind Turbine Applications. College Station, Texas. 
Morris, G. J. (2003). [Pressure Distribution Measurement on an Airfoil]. Unpublished raw data.

Ol, M. V. \& Gharib, M. (2003). Leading-Edge Vortex Structure of Nonslender Delta Wings at Low Reynolds Number. AIAA Journal, 41, pp.16-25.

Pagan, D. \& Solignac, J. L. (1986). Experimental Study of the Breakdown of a Vortex Generated by a Delta Wing. La Recherche Aerospatiale, 3, pp.29-51.

Pope, A. (1951). Basic wing and airfoil theory. McGraw-Hill Book Company, Inc. First Edition.

Pope, A. \& Harper, J. J. (1966). Low-Speed Wind Tunnel Testing. John Wiley \& Sons, Inc.

Pope, A. (1947). Wind-Tunnel Testing. John Wiley \& Sons, Inc. Chapman \& Hall, Limited New York-London.

Scheidegger, T. (2004). Gambit 2.2 Tips \& Tricks. Symposium conducted at the 2004 CFD Summit.

Schlichting, H. \& Gersen, K. (2003). Boundary Layer Theory. Springer-Verlag Berlin Heidelberg New York.

Shapiro, A. H. (1961). Shape and Flow: The fluid dynamics of drag. Anchor Books, Doubleday \& Company, Inc., Garden City, New York.

Solignac, J.-L., Pagan, D., \& Molton, P. (1989). Experimental Study of Incompressible Flow on the Upper Surface of a Delta Wing. La Recherche Aerospatiale, 6, pp.47-65.

Duranto, S. (2005). Profili software (Version 2.18b) [Computer software]. Italy. 
Szumowski, A. \& Wojciechowski, J. (2005). Use of Vortex Generators to Control Internal Supersonic Flow Separation. AIAA Journal, 43, pp.216-218.

Toogood, Roger. (2004). Pro|Engineer Wildfire and multimedia CD. Schroff Development Corporation Publications.

Volino, R. J. (2003). Separation Control on Low-Pressure Turbine Airfoils Using Synthetic Vortex Generator Jets. Journal of Turbomachinery, 125, pp.765-777.

Wang, F. Y. \& Zaman, K. B. M. (2002). Aerodynamics of a Jet in Vortex Wake of a Wing. AIAA Journal, 40, pp.401-407.

Watts, P. \& Fish, F. E. (2002). Scalloped Wing Leading Edge. U.S. Patent No. 6431498 B1. Downingtown, PA: U.S. Patent and Trademark Office.

Wendt, B. J. (2004). Parametric Study of Vortices Shed from Airfoil Vortex Generators. AIAA Journal, 42, pp.2185-2195.

Wetzel, T. G. \& Simpson, R. L. (1998). Effects of Fin and Jet Vortex Generators on Crossflow. Journal of Aircraft, 35, pp.370-379.

Zaman, K. B. M. Q. \& Foss, J. K. (1996). The effect of vortex generators on a jet in cross-flow. Physics Fluids, 9, pp.106-114. 


\section{Appendix A Tables}

Table A-1: Coordinates used for the construction of the airfoil with 9.5 inches of chord

\begin{tabular}{|c|c|c|c|}
\hline $\mathrm{x}$ (upper) & y (upper) & $\mathrm{x}$ (lower) & $\mathrm{y}$ (lower) \\
\hline 0.0000 & 0.0000 & 0.0000 & 0.0000 \\
\hline 0.1188 & 0.2252 & 0.1188 & -0.2252 \\
\hline 0.2375 & 0.3107 & 0.2375 & -0.3107 \\
\hline 0.4750 & 0.4218 & 0.4750 & -0.4218 \\
\hline 0.7125 & 0.4988 & 0.7125 & -0.4988 \\
\hline 0.9500 & 0.5558 & 0.9500 & -0.5558 \\
\hline 1.4250 & 0.6346 & 1.4250 & -0.6346 \\
\hline 1.9000 & 0.6812 & 1.9000 & -0.6812 \\
\hline 2.3750 & 0.7059 & 2.3750 & -0.7059 \\
\hline 2.8500 & 0.7125 & 2.8500 & -0.7125 \\
\hline 3.8000 & 0.6888 & 3.8000 & -0.6888 \\
\hline 4.7500 & 0.6289 & 4.7500 & -0.6289 \\
\hline 5.7000 & 0.5415 & 5.7000 & -0.5415 \\
\hline 6.6500 & 0.4351 & 6.6500 & -0.4351 \\
\hline 7.6000 & 0.3116 & 7.6000 & -0.3116 \\
\hline 8.5500 & 0.1720 & 8.5500 & -0.1720 \\
\hline 9.0250 & 0.0960 & 9.0250 & -0.0960 \\
\hline 9.5000 & 0.0000 & 9.5000 & 0.0000 \\
\hline
\end{tabular}


Table A-2: 2D Experimental results for the NACA 0015 airfoil at different Reynolds

numbers (Miley, 1982)

\begin{tabular}{|c|c|c|c|c|c|c|}
\hline $\mathrm{Re}$ & \multicolumn{2}{|c|}{$4.3 \times 10^{4}$} & \multicolumn{2}{|c|}{$8.4 \times 10^{4}$} & \multicolumn{2}{|c|}{$1.7 \times 10^{5}$} \\
\hline$\alpha$ & $\mathrm{C}_{1}$ & $\mathrm{C}_{\mathrm{d}}$ & $\mathrm{C}_{1}$ & $\mathrm{C}_{\mathrm{d}}$ & $\mathrm{C}_{1}$ & $\mathrm{C}_{\mathrm{d}}$ \\
\hline-2.0 & - & - & - & - & - & - \\
\hline-1.0 & -0.11 & 0.0316 & -0.07 & 0.0216 & 0.1 & 0.011 \\
\hline 0.0 & 0.00 & 0.0290 & 0.00 & 0.0214 & 0 & 0.01 \\
\hline 1.0 & 0.22 & 0.0245 & 0.13 & 0.0179 & 0.08 & 0.0117 \\
\hline 2.0 & 0.33 & 0.0209 & 0.22 & 0.0167 & 0.19 & 0.0145 \\
\hline 3.0 & 0.41 & 0.0195 & 0.31 & 0.0175 & 0.28 & 0.0144 \\
\hline 4.0 & 0.48 & 0.0198 & 0.39 & 0.0184 & 0.37 & 0.0147 \\
\hline 5.0 & 0.55 & 0.0213 & 0.47 & 0.0193 & 0.46 & 0.0158 \\
\hline 6.0 & 0.60 & 0.0237 & 0.53 & 0.0205 & 0.53 & 0.0173 \\
\hline 7.0 & 0.65 & 0.0267 & 0.59 & 0.0223 & 0.6 & 0.0191 \\
\hline 8.0 & 0.70 & 0.0306 & 0.64 & 0.0250 & 0.66 & 0.0215 \\
\hline 9.0 & 0.74 & 0.0355 & 0.67 & 0.0291 & 0.71 & 0.0251 \\
\hline 10.0 & 0.77 & 0.0419 & 0.70 & 0.0356 & 0.74 & 0.0308 \\
\hline 11.0 & 0.79 & - & 0.72 & 0.0459 & 0.77 & 0.0399 \\
\hline 12.0 & 0.77 & - & 0.73 & 0.0629 & 0.78 & 0.0548 \\
\hline 13.0 & 0.73 & - & 0.73 & - & 0.78 & - \\
\hline 14.0 & 0.70 & - & 0.73 & - & 0.78 & - \\
\hline 15.0 & 0.68 & - & 0.72 & - & 0.76 & - \\
\hline 16.0 & 0.67 & - & 0.71 & - & 0.74 & - \\
\hline 17.0 & 0.67 & - & 0.70 & - & 0.71 & - \\
\hline 18.0 & - & - & - & - & 0.69 & - \\
\hline
\end{tabular}


Table A-3: Computational Profili results for airfoil NACA 0015 with $\operatorname{Re}=1.2 \times 10^{4}$

\begin{tabular}{|c|c|c|c|c|}
\hline$\alpha$ & $\mathrm{C}_{1}$ & $C_{d}$ & $\mathrm{C}_{\mathrm{l}} / \mathrm{C}_{\mathrm{d}}$ & $\mathrm{C}_{\mathrm{m}}$ \\
\hline 0 & 0 & 0.0445 & 0 & 0 \\
\hline 1 & -0.0195 & 0.0451 & -0.4324 & 0.012 \\
\hline 2 & -0.0209 & 0.0469 & -0.4456 & 0.0206 \\
\hline 3 & -0.0039 & 0.0501 & -0.0778 & 0.0252 \\
\hline 4 & 0.0525 & 0.0559 & 0.9392 & 0.0209 \\
\hline 5 & 0.2174 & 0.0671 & 3.2399 & -0.0013 \\
\hline 6 & 0.3092 & 0.0767 & 4.0313 & -0.0079 \\
\hline 7 & 0.396 & 0.0877 & 4.5154 & -0.0119 \\
\hline 8 & 0.4435 & 0.0992 & 4.4708 & -0.0114 \\
\hline 9 & 0.4557 & 0.1111 & 4.1017 & -0.0102 \\
\hline 10 & 0.4905 & 0.1248 & 3.9303 & -0.011 \\
\hline 11 & 0.4972 & 0.1382 & 3.5977 & -0.0125 \\
\hline 12 & 0.5051 & 0.153 & 3.3013 & -0.0168 \\
\hline 13 & 0.491 & 0.1726 & 2.8447 & -0.0317 \\
\hline 14 & 0.5034 & 0.1801 & 2.7951 & -0.0331 \\
\hline 15 & 0.5439 & 0.1954 & 2.7835 & -0.0372 \\
\hline 16 & 0.5994 & 0.2191 & 2.7357 & -0.0426 \\
\hline 17 & 0.6268 & 0.2297 & 2.7288 & -0.0459 \\
\hline 18 & 0.6669 & 0.2487 & 2.6815 & -0.0502 \\
\hline
\end{tabular}


Table A-4: Computational Profili results for airfoil NACA 0015 with $\operatorname{Re}=4.8 \times 10^{4}$

\begin{tabular}{|c|c|c|c|c|}
\hline$\alpha$ & $\mathrm{C}_{l}$ & $\mathrm{C}_{d}$ & $\mathrm{C}_{l} / \mathrm{C}_{\mathrm{d}}$ & $\mathrm{C}_{\mathrm{m}}$ \\
\hline-2 & -0.4335 & 0.0241 & -17.9876 & 0.0376 \\
-1 & -0.2467 & 0.026 & -9.4885 & 0.0247 \\
0 & 0 & 0.027 & 0 & 0 \\
1 & 0.2469 & 0.026 & 9.4962 & -0.0246 \\
2 & 0.4334 & 0.0241 & 17.9834 & -0.0375 \\
3 & 0.5035 & 0.0239 & 21.0669 & -0.0301 \\
4 & 0.5789 & 0.0244 & 23.7254 & -0.0229 \\
5 & 0.6477 & 0.0256 & 25.3008 & -0.015 \\
6 & 0.7152 & 0.0273 & 26.1978 & -0.0068 \\
7 & 0.7778 & 0.03 & 25.9267 & 0.0013 \\
8 & 0.8364 & 0.0335 & 24.9672 & 0.0095 \\
9 & 0.8918 & 0.0386 & 23.1036 & 0.017 \\
10 & 0.9353 & 0.0449 & 20.8307 & 0.0245 \\
11 & 0.9716 & 0.0531 & 18.2976 & 0.0309 \\
12 & 0.8733 & 0.0692 & 12.6199 & 0.0381 \\
13 & 0.6575 & 0.1223 & 5.3761 & 0.0093 \\
15 & 0.6289 & 0.147 & 4.2782 & -0.0015 \\
\hline & 0.6713 & 0.1575 & 4.2622 & -0.0012 \\
\hline 14 & & & & \\
\hline & & & & \\
\hline
\end{tabular}


Table A-5: Computational Profili results for airfoil NACA 0015 with $\mathrm{Re}=7.4 \times 10^{4}$

\begin{tabular}{|c|c|c|c|c|}
\hline$\alpha$ & $\mathrm{Cl}$ & $\mathrm{Cd}$ & $\mathrm{Cl} / \mathrm{Cd}$ & $\mathrm{Cm}$ \\
\hline-2 & -0.3238 & 0.0192 & -16.8646 & 0.0136 \\
\hline-1 & -0.1634 & 0.0193 & -8.4663 & 0.0061 \\
\hline 0 & 0 & 0.0193 & 0 & 0 \\
\hline 1 & 0.1635 & 0.0192 & 8.5156 & -0.006 \\
\hline 2 & 0.3238 & 0.0192 & 16.8646 & -0.0135 \\
\hline 3 & 0.4802 & 0.0193 & 24.8808 & -0.0217 \\
\hline 4 & 0.5902 & 0.0196 & 30.1122 & -0.0226 \\
\hline 5 & 0.6632 & 0.0205 & 32.3512 & -0.0163 \\
\hline 6 & 0.7307 & 0.022 & 33.2136 & -0.0089 \\
\hline 7 & 0.7931 & 0.0241 & 32.9087 & -0.0008 \\
\hline 8 & 0.8515 & 0.027 & 31.537 & 0.0074 \\
\hline 9 & 0.9094 & 0.0305 & 29.8164 & 0.0153 \\
\hline 10 & 0.9653 & 0.035 & 27.58 & 0.0224 \\
\hline 11 & 1.0125 & 0.0407 & 24.8771 & 0.0293 \\
\hline 12 & 1.0264 & 0.0473 & 21.6998 & 0.038 \\
\hline 13 & 1.0181 & 0.0575 & 17.7061 & 0.0431 \\
\hline 14 & 0.8985 & 0.0831 & 10.8123 & 0.0344 \\
\hline 15 & 0.6735 & 0.1496 & 4.502 & -0.0025 \\
\hline 16 & 0.6622 & 0.1723 & 3.8433 & -0.0134 \\
\hline 17 & 0.6687 & 0.1915 & 3.4919 & -0.0225 \\
\hline 18 & 0.7089 & 0.2108 & 3.3629 & -0.0256 \\
\hline
\end{tabular}


Table A-6: 2D CFD Fluent results for the NACA 0015 airfoil at $\operatorname{Re}=4.8 \times 10^{4}$

\begin{tabular}{|c|c|}
\hline $\begin{array}{c}\alpha \\
{[\mathrm{deg}]}\end{array}$ & $\begin{array}{c}\text { Lift } \\
{[\mathrm{N}]}\end{array}$ \\
\hline 0 & 0.031 \\
5 & - \\
11 & 39.656 \\
12 & 43.337 \\
\hline
\end{tabular}

Table A-7: 2D calculated results for the NACA 0015 airfoil at $\operatorname{Re}=4.8 \times 10^{4}$

\begin{tabular}{|c|c|}
\hline$\alpha$ & $\mathrm{C}_{1}$ \\
{$[\mathrm{deg}]$} & \\
\hline 0 & $9.1 \mathrm{E}-04$ \\
5 & - \\
11 & 1.161 \\
12 & 1.2691 \\
\hline
\end{tabular}


Table A-8: 3D CFD Fluent results for a wing with $A R=0.76$ for the NACA 0015 airfoil

\begin{tabular}{|c|c|c|c|}
\hline$\alpha$ & \multicolumn{3}{|c|}{ NACA0015 } \\
\hline [deg] & Lift $[\mathrm{N}]$ & Lift $[\mathrm{N}]$ & $\operatorname{Lift}[\mathrm{N}]$ \\
\hline 0 & $2.1 \mathrm{E}-03$ & 0.022 & 0.04 \\
\hline 5 & 7.4E-02 & 1.08 & 2.64 \\
\hline 10 & $1.5 \mathrm{E}-01$ & 2.17 & 5.37 \\
\hline 15 & 2.4E-01 & 3.44 & 8.38 \\
\hline 20 & $3.3 \mathrm{E}-01$ & 4.83 & 11.75 \\
\hline 25 & 4.3E-01 & 6.2 & 15.12 \\
\hline 27 & - & 6.60 & - \\
\hline 28 & - & - & 16.73 \\
\hline $\mathrm{V}[\mathrm{m} / \mathrm{s}]$ & 4.062 & 15.2 & 23.655 \\
\hline $\mathrm{q}_{\infty}$ & 10.11 & 141.51 & 342.73 \\
\hline
\end{tabular}


Table A-9: 3D calculated results for a wing with $A R=0.76$ for the NACA 0015 airfoil

\begin{tabular}{|c|c|c|c|}
\hline \multirow{2}{*}{$\begin{array}{c}\alpha \\
{[\mathrm{deg}]}\end{array}$} & \multicolumn{3}{|c|}{ NACA0015 } \\
\cline { 2 - 4 } & $\mathrm{C}_{\mathrm{L} 1}$ & $\mathrm{C}_{\mathrm{L} 2}$ & $\mathrm{C}_{\mathrm{L} 3}$ \\
\hline 0 & $4.23 \mathrm{E}-03$ & $3.14 \mathrm{E}-03$ & $2.61 \mathrm{E}-03$ \\
5 & $1.48 \mathrm{E}-01$ & $1.56 \mathrm{E}-01$ & $1.57 \mathrm{E}-01$ \\
10 & $3.08 \mathrm{E}-01$ & $3.13 \mathrm{E}-01$ & $3.19 \mathrm{E}-01$ \\
15 & $4.78 \mathrm{E}-01$ & $4.96 \mathrm{E}-01$ & $4.99 \mathrm{E}-01$ \\
20 & $6.72 \mathrm{E}-01$ & $6.96 \mathrm{E}-01$ & $6.99 \mathrm{E}-01$ \\
25 & $8.62 \mathrm{E}-01$ & $8.93 \mathrm{E}-01$ & $8.99 \mathrm{E}-01$ \\
27 & - & $9.52 \mathrm{E}-01$ & - \\
28 & - & - & $9.95 \mathrm{E}-01$ \\
\hline $\mathrm{V}[\mathrm{ft} / \mathrm{s}]$ & 13.314 & 49.834 & 77.538 \\
\hline $\operatorname{Re}$ & $1.2 \times 10^{4}$ & $4.8 \times 10^{4}$ & $7.4 \times 10^{4}$ \\
\hline
\end{tabular}

Table A-10: 3D CFD Fluent results for a wing with $A R=0.76$ for the NACA 0015 airfoil with two vortex generators attached

\begin{tabular}{|c|c|c|c|}
\hline \multirow{2}{*}{$\begin{array}{c}|| 3 \\
{[\mathrm{deg}]}\end{array}$} & \multicolumn{3}{|c|}{ NACA0015 $\mathrm{w} / 2 \mathrm{VG}$} \\
\cline { 2 - 4 } & Lift $[\mathrm{N}]$ & Lift $[\mathrm{N}]$ & Lift $[\mathrm{N}]$ \\
\hline 0 & 0.0004 & 0.0027 & 0.0129 \\
5 & 0.0745 & 1.0746 & 2.6009 \\
10 & 0.1544 & 2.2471 & 5.4954 \\
15 & 0.2466 & 3.5999 & 8.8016 \\
19 & 0.3173 & 4.6444 & 11.3614 \\
\hline $\mathrm{V}[\mathrm{m} / \mathrm{s}]$ & 4.062 & 15.2 & 23.655 \\
\hline $\mathrm{q}_{\infty}$ & 10.106 & 141.512 & 342.73 \\
\hline
\end{tabular}


Table A-11: 3D calculated results for a wing with $A R=0.76$ for the NACA 0015 airfoil with two vortex generators attached

\begin{tabular}{|c|c|c|c|}
\hline \multirow{2}{*}{$\begin{array}{c}\alpha \\
{[\mathrm{deg}]}\end{array}$} & \multicolumn{3}{|c|}{ NACA0015 w/2 VG } \\
\cline { 2 - 4 } & $\mathrm{C}_{\mathrm{L} 1}$ & $\mathrm{C}_{\mathrm{L} 2}$ & $\mathrm{C}_{\mathrm{L} 3}$ \\
\hline 0 & $7.35 \mathrm{E}-04$ & $3.67 \mathrm{E}-04$ & $7.31 \mathrm{E}-04$ \\
5 & $1.43 \mathrm{E}-01$ & $1.47 \mathrm{E}-01$ & $1.47 \mathrm{E}-01$ \\
10 & $2.96 \mathrm{E}-01$ & $3.08 \mathrm{E}-01$ & $3.11 \mathrm{E}-01$ \\
15 & $4.73 \mathrm{E}-01$ & $4.94 \mathrm{E}-01$ & $4.98 \mathrm{E}-01$ \\
19 & $6.09 \mathrm{E}-01$ & $6.37 \mathrm{E}-01$ & $6.43 \mathrm{E}-01$ \\
\hline $\mathrm{V}[\mathrm{ft} / \mathrm{s}]$ & 13.314 & 49.834 & 77.538 \\
\hline $\operatorname{Re}$ & $1.2 \times 10^{4}$ & $4.8 \times 10^{4}$ & $7.4 \times 10^{4}$ \\
\hline
\end{tabular}

Table A-12: 3D CFD Fluent results for a wing with $A R=1.53$ for the NACA 0015 airfoil

\begin{tabular}{|c|c|c|}
\hline \multirow{2}{*}{$\alpha$} & \multicolumn{2}{|c|}{ NACA 0015 } \\
\cline { 2 - 3 }$[\mathrm{deg}]$ & $\begin{array}{c}\text { Lift [N] clean } \\
\text { wing }\end{array}$ & $\begin{array}{c}\text { Lift [N] } \\
\text { w/ 4 VG }\end{array}$ \\
\hline 0 & 0 & 0 \\
10 & 5.87 & 5.88 \\
12 & 7.11 & - \\
15 & - & 8.75 \\
16 & - & 9.24 \\
\hline $\mathrm{V}[\mathrm{m} / \mathrm{s}]$ & 15.2 & 15.2 \\
\hline $\mathrm{q}_{\infty}$ & 141.512 & 141.512 \\
\hline
\end{tabular}


Table A-13: 3D calculated results for a wing with $A R=1.53$ for the NACA 0015 airfoil

\begin{tabular}{|c|c|c|}
\hline \multirow{2}{*}{$\alpha$} & \multicolumn{2}{|c|}{ NACA0015 } \\
\cline { 2 - 3 }$[\mathrm{deg}]$ & $\mathrm{C}_{\mathrm{L}}$ & $\mathrm{C}_{\mathrm{L}}$ \\
clean wing & w/ 4 VG \\
\hline 0 & 0 & 0 \\
10 & $4.23 \mathrm{E}-01$ & $3.85 \mathrm{E}-01$ \\
12 & $5.13 \mathrm{E}-01$ & - \\
15 & - & $5.72 \mathrm{E}-01$ \\
16 & - & $6.04 \mathrm{E}-01$ \\
\hline $\mathrm{V}[\mathrm{m} / \mathrm{s}]$ & 15.2 & 15.2 \\
\hline
\end{tabular}

